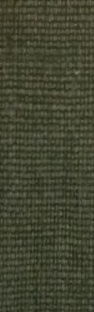



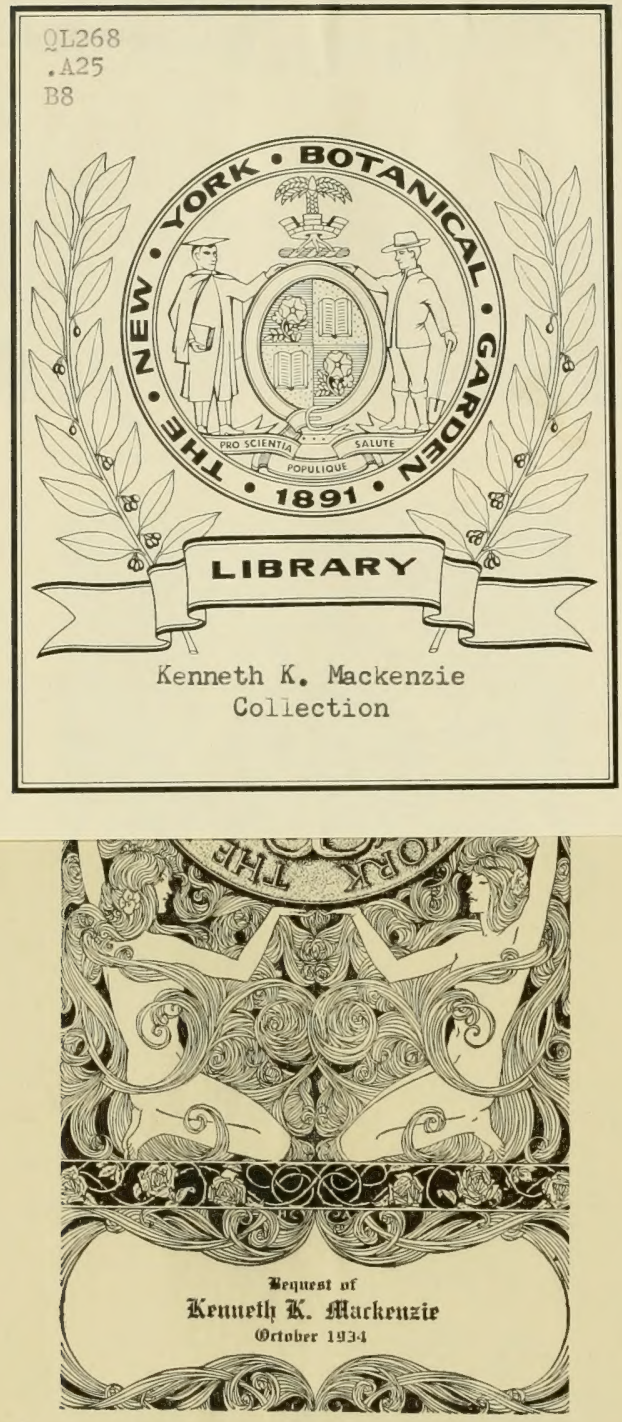



\section{MÉM OIRES \\ DE}

L'ACADÉMIE IMPÉRIALE DES SCIENCES DE ST.-PÉTERSBOURG, VII ${ }^{\mathrm{S}}$ SÉRIE, Tone XVIII, No 2.

\section{DIE GATTUNG \\ ACANTHOLIMON BOISS. \\ voN}

A. Hunge.

Mit 2 Tafeln

Lu le 18 mai 1871 .

ST.-PÉTERSB0URG, 1872.

Commissionnaires de l'Académie Impériale des sciences:

MM. Eggers et Cie, H. Schmitzdorff, à Migas adesma, Lelpzigs

J. Issakof et H. Schmitzdorff, M. N. Kymmel; M. A. E. Kechribardshi; M. Léopold Voss. Prix: 95 Kop. $=1$ Thal. 2 Ngr. 
Imprimé par oxdre de l'Académie Impériale des sciences 


\section{Einleitung:}

Es sind bald 250 Jahre her, dass Prosper Alpinus ${ }^{1}$ ) in seinen plantis exoticis (1627) p. 57 im 26. Capitel unter dem Titel: de Echino, seu de alia Tragacantha, eine Pflanze, die ihm ein Freund von der Insel Creta eingesandt, recht gut beschrieb, und in einer, zwar rohen, aber doch den Habitus kenntlich wiedergebenden Abbildung darstellte. Er bemerkt dazu: “Mirabilis natura, quae Echinum animal herbaceum produxisse visa est!» und characterisirt hierdurch nicht blos diese erst bekannt gewordene Art, sondern sämmtliche Arten der Gattung Acantholimon. Wie treffend der Vergleich mit einem Igel ist, wird jeder Reisende im Orient, der ein offenes Auge für dessen dornenreiche Pflanzenwelt hat, zugeben müssen, denn nur im Morgenlande in weiterem Sinne ist diese Gattung zu Hause.

Erklärlich ist es, wie die am weitesten nach Westen versprengte Art nicht nur zuerst bekannt wurde, sondern auch für lange Zeit die einzige und auch nur unvollkommen bekannte blieb. Von älteren Schriftstellern erwähnt ihrer nur Morison $\left.{ }^{1}\right)(1680)$ in seiner Historia plantarum oxoniensis, aber offenbar ohne eigene Anschauung, denn er giebt nur eine verballhornte Copie des Textes des Prosper Alpinus, und eine zwar sauberere, aber widernatürlich veränderte Nachbildung der Figur, der er, weil Alpinus sagt, dass die Blumen kleinen Hyacynthenblüthen ähnlich sind, lauter hexamere Blumen giebt; ja an einem Zweige sehen wir ein paar Organe, die wohl kleine Hülsen vorstellen sollen, weil die Pflanze ja eine "alia Tragacantha» ist.

Erst Tournefort fand (1700) die Pflanze auf dem Ida in Creta wieder und stellte sie zu seiner Gattung Limonium, entdeckte aber auf seiner Weiterreise durch Kleinasien und Armenien bis Tiflis noch 4 Arten der Gattung, die er in seinem trefflichen Corollarium

\footnotetext{
1) Da mir hier am Orte die Werke des Alpinus und pflichtet fühle, da er mir mit gewohnter Freundlichkeit Morison nicht zu Gebote stehen, so wandte ich mich an und Genauigkeit nicht nur die betreffenden Stellen in meinen hochverehrten Freund, den Herrn Akademiker vollständigen Excerpten, sondern auch eine getreue Copie Maximowits $\mathrm{ch}$, dem ich zu besonderem Dank mich ver- der Morison'schen Abbildung mittheilte. 
inst. rei herb., das uns zuerst die Reichthümer der orientalischen Flora erschloss, in damaliger Weise durch kurze, aber bezeichnende Phrasen unterschied.

Wenige Jahre darauf (1727) durchreiste Buxbaum dieselben Gegenden, drang jedoch weiter nach N.O. vor und fand cinter Hansem (d. ist Gandsha oder das heutige Elisabethpol) et Schamachiam» eine weitere Art, die er in seiner zweiten Centuria plantarum min. cogn. p. 18 kurz beschrieb und auf Tafel 10 - besser als andere Pflanzen - darstellte.

Auffallen muss es daher, wenn Linné, Tournefort, wie es scheint, absichtlich ignorirend, selbst in den letzten Ausgaben seiner Species plantarum nur eine Art dieser Gattung aufführt, sie der Gattung Statice beizählend, unter welchem Namen er die von Tournefort mit feinem Tact getrennten Gattungen Statice und Limonium vereinigt. Er nannte diese Art Statice Echinus, entnimmt also den Namen dem Pr. Alpinus, richtet aber seine Diagnose, ganz dessen Beschreibung und Abbildung zuwider, nach der Buxbaum'schen Abbildung zu, ohne, wie es scheint, weder die eine, noch die andere Pflanze gesehen zu haben; unterscheidet aber später als Varietät die Alpinische Art. Ein Blick auf die beiden Abbildungen reicht hin, um das Unstatthafte dieses Verfahrens zu erkennen. Linné legte da. durch den Grund zu einer bis in die neueste Zeit sich mehrenden Verwirrung der Synonymie dieser Pflanzen. Alles, was an Arten dieser Gattung ferner entdeckt wurde, zog man zu St. Echinus L., oder liess es unbeachtet in Herbarien liegen.

Hablizl, der mit S. G. Gmelin die transcaucasischen Gegenden bereiste und in den Jahren 1773 u. 74 im nördlichen Persien botanisirte, entdeckte zwei neue Arten, wie aus dem Herbar der Kaiserl. Academie der Wissenschaften, welche Originalexemplare enthält, hervorgeht, A. Hohenackeri und A. roseum, unterschied sie aber nicht, sondern bezeichnet sie mit dem Namen St. Echinus in seiner physicalischen Beschreibung der Krym, und weist diesen die Krym irrthümlich als Vaterland an, wo Niemand sonst eine Spur von Acantholimon gefunden hat.

Smith führt in dem Prodromus fl. graecae die von Sibthorp gegen den Schluss des vorigen Jahrhunderts auf dem Bithynischen Olymp gesammelte Pflanze des Alpinus einfach als St. Echinus L. auf. Eine neue Art, die Labillar dière im Libanon (1787) entdeckte, und eine andere, die Olivier und Brugière (1796-97) aus dem südwestlichen Persien zurückbrachten, blieben lange Zeit unbeachtet in Herbarien liegen.

Noch im Jahre 1797 führt Willdenow in seiner Ausgabe der Species plantarum nur eine Art auf, St. Echinus L. mit der Linnéischen Diagnose für die Art selbst, der ein nicht hingehöriges Synonym Tournefort's beigefügt wird, und mit einer variet. $\beta$. Bald darauf aber beschreibt er im 3. (nicht im 2., wie M. v. Bieberstein citirt) Bande der Schriften der Gesellschaft naturforschender Freunde Berlins (1801) p. 420 eine neue Art unter dem Namen St. acerosa, die er von Sestini aus Galatien erhielt, die sich von St. Echinus L., also von der Buxbaum'schen Pflanze, durch den einfachen nie getheilten Schaft unterscheidet. 
Im Beginn dieses Jahrhunderts wurden durch Marschall von Bieberstein und Steven der Caucasus und die Gegenden jenseits desselben botanisch näher bekannt, und in seiner Flora taurica-caucasica (1808) führt Bieberstein zwei hierher gehörige Pflanzen auf. Von diesen-war eine bereits von Hablizl entdeckt (A. Hohenackeri), die andere aber neu, dagegen blieb ihm, wie es scheint, die Buxbaum'sche Pflanze unbekannt. Von seinen beiden Arten identificirte er die erstere irriger Weise mit St. Echinus L. var. $\beta$. und behält für sie den Namen St. Echinus bei. Die andere hält er für die ächte St. Echinus L., führt sie aber, ganz im Widerspruch mit der Willdenow'schen Diagnose, als St. acerosa auf. Bei Wiedergabe und Vermehrung dieser Irrthümer erhalten wir dann im 6. Bande der Ausgabe des Systema vegetabilium von Römer und Schultes (1829) zunächst eine fragliche Bereicherung der Kenntniss von unserer Gattung aus dem Nachlasse Willdenow's; nämlich 1) Śt. ulicina W., d. h. Labillardière's libanotische Pflanze, die ihm Desfontaines mitgetheilt, der wieder eine nicht hingehörige Tournefort'sche Phrase beigegeben ist, dazu ungenau (caespitem statt capitulum) und unvollständig (es fehlen die sehr bezeichnenden Worte, durch welche Tournefort zwei Arten von Limonium von einander unterscheidet: "calyce purpureo» und "calyce albo»); und 2) St. juniperina W. von Pallas aus Persien, vielleicht also eine der Hablizl'schen Arten, erhalten. Boissier bringt diese Art zu A. Hohenackeri, sie könnte aber auch das mit jener vermengt gesammelte A. roseum sein, wofür die fast sitzenden Blumen, die Boissier veranlassen, sie als var. $\beta$. subsessile zu unterscheiden, sprechen.

Noch fünf Jahre später führt Sprengel in seiner leichtfertigen Compilation, die er als Editio XVI. des Systema vegetabilium herausgab, nur 3 hierher gehörige Arten in einer Weise auf, aus der deutlich hervorgeht, dass er keine derselben kannte, denn er zieht St. Echinus Sm. zu St. acerosa W., weist der St. Echinus L. ausser Griechenland und Kleinasien auch den Caucasus und sogar Aegypten als Vaterland zu, so wie der St. ulicina Kleinasien!

C. A. Meyer beobachtete auf seiner caucasischen Reise im Talyschgebirge nur eine Art, St. Hohenackeri, die er als St. Echinus MB. in seiner Enumeratio (1831) aufführt, ohne die Synonymie dieser Art zurecht zu stellen.

Erst Aucher-Eloy's (1830-37) grossartige Entdeckungen in der orientalischen Pflanzenwelt richteten die Aufmerksamkeit einiger Botaniker wieder auf diese Gattung und machten eine übersichtliche Zusammenstellung und Sichtung des darin bisher bekannt gewordenen Materials nothwendig. Eine solche versuchte zuerst Spach, dem in dem reichen Herbar des Pariser Musée d'histoire naturelle nicht nur eine der reichsten Sammlungen Aucher-Eloy's, sondern auch Tournefort's Originale, so wie Labillardière's und Olivier's Sammlungen zu Gebote standen. Er veröffentlicht seine Untersuchungen vorläufig in den Annales des sciences naturelles $\left(2^{\circ}\right.$ Série, Botanique, tome $\mathrm{XX}$ ) und dann im 1. Bande der trefflichen Illustrationes pl. orient. (1842-43). Zum ersten Mal werden hier die 140 Jahre lang unbeachtet gebliebenen Tournefort'schen Arten ans Licht gezogen, jedoch mit 
nicht ganz genügender Berücksichtigung der Phrasen des Corollarium, vielleicht weil in den Etiquetten nicht die gehörige Ordnung erhalten war ${ }^{1}$ ); es wird die Synonymie der als St. Echinus und St. acerosa von verschiedenen Autoren bisher verwechselten Arten, wenn auch nicht ganz vollständig, geordnet; die Arten Olivier's und Labillardière's, wobei jedoch die Willdenow'sche Benennung der letzteren übersehen wird, und die meisten Aucher'schen Arten, so,wie eine von Kotschy (1836) gesammelte und unter dem Namen St. Echinus vertheilte Art, characterisirt, davon 7 Arten ausführlich beschrieben und mit detaillirten Analysen trefflich abgebildet. So finden wir denn hier plötzlich 21 Arten, zwar noch der Gattung Statice beigezählt, aber als besondere Untergattung Armeriastrum vereinigt; der Character dieses Subgenus ist sehr ausführlich und genau auseinandergesetzt, und die Ansicht ausgesprochen, dass diese Gruppe mit demselben Rechte als besondere Gattung zu betrachten sei wie Armeria. Der einzige Vorwurf, der diese treffliche Arbeit trifft, seine Entschuldigung aber theils in dem mangelhaften Material, theils in den ungewöhnlichen Schwierigkeiten, die diese Gattung dem Systematiker entgegenstellt, findet, ist, dass zu viele Formen als besondere Arten unterschieden werden. Mindestens 5 von den 21 aufgestellten Arten müssen gestrichen werden, als nur auf locale Varietäten oder kleine Abweichụngen einzelner zur Verfügung gestandener Exemplare begründet.

In einer im folgenden Jahre in den Annales des sc. nat. (III ${ }^{\text {me }}$ série, bot. t. 2 p. 323 -332) erschienenen Erstlingsarbeit weist Hr. Fr. Girard die Unzulässigkeit einiger jener Trennungen nach, fügt zwei neue Arten, eine von Aucher, die Spach unbekannt geblieben war, und eine vom Baron Hügel in Caschmir entdeckte Art (mit falschem Synonym.) hin$\mathrm{zu}$, belastet aber, indem er willkürlich die älteren Spach'schen Benennungen ändert, die Synonymie mit unberechtigten neuen Namen und berücksichtigt die Trennung des Subgenus Armeriastrum gar nicht.

In dieser Zeit fing durch die Reisen von Boissier und Pinard in Kleinasien, besonders aber von Kotschy in Syrien, Kurdistan, Assyrien, Süd-Persien das Material rasch an zu wachsen, so dass Boissier (1846) im 7. Heft seiner trefflichen Diagn. pl. or. das Spach'sche Subgenus als selbstständige Gattung unter dem Namen Acantholimon anerkennend, schon 26 Arten aufführen konnte, ausser der nicht in seinen pflanzengeographischen Bezirk fallenden Art aus Caschmir.

Aber schon zwei Jahre später, als Boissier für den 12. Band des Prodromus (1848) die Familie der Plumbegineen monographisch bearbeitete, finden wir jene Zahl auf 42 Arten erhöht. Den stärksten Zuwachs, 9 Arten, lieferten die Sammlungen Griffith's aus dem südöstlichen Theil des Verbreitungsbezirks unserer Gattung; dazu eine centralasiatische Art von Al. Lehmann, eine nordpersische von Kotschy, zwei kleinasiatische und eine syrische. Doch auch diese trefflich durchgearbeite Aufzählung lässt noch Unsicherheiten

1) In seiner vorzüglichen aRelation d'un voyage du Le- $\mid$ durch die leider unterlassene Erwähnung der Fundorte vant» erwähnt Tournefort nur an einer Stelle den Fund der übrigen Arten wäre es leicht geworden die Synonymie eines Acanthalimon (Limonium creticum juniperifolio); seiner Phrasen vollkommen zurecht zu stellen. 
zurück, einzelne bis dahin schon entdeckte in Herbarien angegebene $\Lambda$ rten blieben dem Vf. unbekannt, und gerade in Bezug auf die ältest bekannten Arten bleiben theils die alten Irrthümer stehen, theils kommen, freilich durch, dem Verfasser nicht zur Last fallende, Verwechselungen, nene hinzu.

Allein schon während diese Arbeit erschien und bald darauf mehrten sich die Entdeckungen auf ihrem Gebiete. Noê (1846) bereiste S.-W,-Persien (1 Art); Buhse N.-W.und Mittel-Persien ( 4 Arten); Stocks drang (1850-51) nach Beludshistan vor (2 Arten); Huet de Pavillon (1853) entdecle in Armenien 2; Balansa in Cappadocien (1854) 3 ; Calvert, der um Erzerum sammelte, eine neue Art. Diese 13 Arten wurden von Boissier theils in dem vierten Heft der zweiten Reihe seiner Diagnosen (1859), theils in Boissier's u. Buhse's Aufzählumg transcaucasi : ch-persischer Pflanzen (1860) ausführlich beschrieben. Eine der Buhse'schen Arten war schon weit früher (1830) von Szovits im russischen Armenien entdeckt, und lag unbeschrieben in den Sammlungen des Petersburger botanischen Gartens; nach Buhse fand sie (1850) Kowalevsky - alle drei auf demselben Fundorte wieder. Sic wurde ron Stscheglejew sehr ausführlich unter dem ziemlich ummotivirten Namen St. Karelini (Bull, soc. mosc. 1851) beschrieben.

Im äussersten N.-0. des Verbreitungsbezirkes hatte schon früher (1841) Schrenk, dann aber (1857) Semenow und zehn Jahre später (1867) Osten-Sacken eine Art der Gattung beobachtet, die von Trautvetter, damn von Herder, endlich von Ruprecht für eine Form von $\Lambda$. Hohenackeri gehalten wurde, aber, wie schon aus pflanzengeographischem Grunde zu vermuthen war, als eigene Art unterschieden werden muss. Ausser dieser Art entdeckte aber Sacken auch noch eine neue ausgezeichnete Art, die Ruprecht als A. latifolium in dem Sertum tianschanicum beschrieb, cin Name, der leider, weil schon verwendet, geändert werden muss.

Mir war es beschieden, weite Strecken cines bis dahin fast ganz unbekannten Gebiets im Herzen des Verbreitungsbezirkes rer Gattung botanisch kemen zu lernen (1858-59) und eine reiche Ausbeute von 23 Arten heimzubringen, von deuen 17 bis dahin unbekannt geblieben waren. Die letzten Reisen Kotschy's in Kleinasien und Syrien bereicherten die Sammlungen um weitere zwei Arten; zwei Reisen Hausknecht's in den Jahren von 1865 -69 nach Syrien, in den cataonischen Taurus, Kurdistan, Asstrien und S.-W.-Persien gewährte die reiche Nachlese von noch 6 nenen Arten.

Durch die Güte der Herren Maximowitsch und Regel, die mir das gesammte Material der beiden grossen offentlichen Herbarien Petersburgs zusandten, meines Freundes Boissier, des Monographen der Gattung, der mir aus scinem für dic orientalische Flora reichsten Herbar sehr viele Arten als Geschenk, und alle unica zur Ansicht mittheilte, so wie meines Freundes Fenzl, der mir einige seltene Arten des Wiener Museums anvertraute, bin ich in den Stand gesetzt, mit Ausnahme von 3 nur im Kew'schen Herbar befindlichen, nicht nur sümmtliche oben angeführte Arten fast durchweg in zahlreichen Originalexemplaren genau zu untersuchen, sondern auch mehrere scit lingerer Zeit in Herba- 
rien aufbewahrte, nicht beschriebene kemnen zu lernen; so mamentlich eine ron Szovits (1829) in West-Persien, cine von Wiedemann (1840) in Klcinasien und eine von Bode in Nord-Persien gesammelte. So wurde die Zahl der im Prodromus erwähnten Arten verdoppelt.

Oben erwähnte ich bereits, dass die Gattung Acantholimon dem Systematiker ungewöhnliche Schwierigheiten entgegenstellt. Diese liewen einestheils in der grossen Einfachheit und Gleichförmigkeit des Baues und der daraus entspringenden Armutlı an characteristischen Merkmalen, die meist auf ein mehr oder weniger hinausgehen; dann aber in der Variabilität sogar wichtiger Organe; endich in dem Umstande, dass der fast immer articulirte Blüthenstand in ller getrockneten Pflanze answerordentlich leicht in seine Glieder zerfällt, so dass seine Beschaffenheit nicht erkannt werden kann.

Sämmtliche Arten sind kleine Halbsträucher, die meisten vor dem Blühen igelförmig gestaltet, indem die nadelförmigen Blïter in sjoralen dicht gedrüngt, anf kurzen gleich-

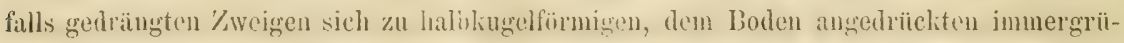
nen, hänfig graugrünen Kissen zusammenballen. Selten sind die Zweige etwas verlängert, die Blïtter weiter ron einander gerückt, so dass die Pflanze strauchartig wird; allein hinfig variirt ein und dieselbe Art in dieser Bezielıung je nach der Natur des Standortes.

Fast ohne Ausnahme sind die ersten im Frühjahr sich entwickelnden Blätter, dic schon im Herbst in der nackten Blattknospe häufig weit vorgerückt sind, kürzer, minder hart, zuweilen fast fleischig und dann rasch vertrocknend und brüchig. Sehr selten sind auch die spitteren Blïtter fast weich, kaum stachelspitzig. Diese sind stets linienförmig, oben flach und am Raude durch sehr feine harte Wimpern oder Zühnchen scharf. Bei weitem die Mehrzahl der Arten zeigt dieselbe Bildung auch an allen übrigen Blättern, nur dass die spaiteren Blïtter gewöhnlich lïnger, Iriirter, trockener und stechender sind. Selten sind alle Bhätter liur\% und verhliltnissmässig breit, lanzettlich, und zwar nur in einigen üstlichsten Arten. Eine geringere Auzahl, bisher nur in den dürrsten Gegenden Mittel-Persiens und in Afghanistan beobachtete Arten, scheiden sich von jenen scharf dadurch ab, dass die nachfolgenden, dic Sommerblättur, sich zu wahren harten Dornen gestalten, wenn gleich selten pfrimenfürmig; und meist oben abgeflacht, doch mit alogerundeten mul rollkommen glatten, nicht gewimpert scharfen Rändern. Auf diesen, für die einzelnen Arten nie schwankenden Untersehied hrugündete Spach mit Recht seine zwei Sectionen: acerosae und spinosae.

Bei den meisten Arten sind die Blätter und die übrigen krantigen Organe mit kleinen Gribehen versehen, aus denen Kalk in Form rundlicher Schuppen ausgeschieden wird; sie fehlen wenigen $\Lambda$ rten, variiren in Grösse und Dichtigkeit und becinflussen die Firbung der ganzen Pflanze. Diese ist bald rein grün, bald mecrgrün (glaue), bald fast kreideweiss; ver- 
hailtnissmässigg selten find die Blätter (und andere Organe) behatut, zuweilen mit kleinen Stacheln auf der: Oberfläche - nicht blos am Rande, bestrent, und dies giebt, wie es scheint, ein tgutes, nicht schwankendes Unterscheidungsmerkmal; dagegen variirt zuweilen die Behtarung des Schaftes, kaum aber die eigenartige Behaarung der einzelnen Glieder der Spindel.

Weit schwankender sind die Unterschiede, welche der Blïthenstand darbietet. Mit einigem Recht wird der gemeinschaftliche Blïthensticl in den Beschreibungen, wegen des verkürzten Stengels, als Schaft bezeichnet, und sonderbar erscheint es, wenn Sprengel seine 3 Arten in der Gattung Statice weit auseinanderwirft, indem er zweien einen beblätterten Stengel und gerade der St. ulicina einen Scapus zuschreibt. Die Länge dieses bald stielrunden, bald zusimmengedrückten, cinfachen oder verzweigten Schaftes ist, oft in derselben Art, nicht constant; je nach der Länge trägt er bald mehr, bald weniger schuppenförmige Blätter. Bei mehreren Arten ist er so verkürzt, dass die wenigen Blumen, die er trägt, fast in der Axel der Blätter zu sitzen scheinen, doch kommen Exemplare derselben Art mit dentlich verlängerten (A. Echinus), zuweilen mit recht langen Schaften $(\Lambda$. alatavicum) vor! Bei andern beträgt seine Länge einen halben Fuss oder sogar mehr. Nur bei sehr wenigen Arten verzweigt sich der Schaft an der Spitze vielfach in eine ausgebildete Trugdolde; meist ist diese unvollkommen antwickelt, und der Schaft träigt scheinbar bald nur eine, bald mehrere, bald wenige, bald vielblumige, dicht gedrïingte oder lockere verlängerte Aehren. Alle diese Verhältnisse sind nicht in jeder Art constant, sondern schwanken bei einigen in sehr bedentendem Grade? (A. alataricum, flexuosum), mod daher sind die ihnen entnommenen Charactere werthlos. Dazu kommt, wie oben erwälnt, der erschwerende Umstand, dass sowohl der Schaft, als vor Allem die Spindel gegliedert sind, und bei der getrockneten Pflanze bei weitem der meisten Arten bei der leisesten Berührung in ilıre Glieder zerfallen und darüler, ob der Blithestand einfach oder zusammengesetzt, und in welcher Weise zusammengesetzt sei, liein Urtheil zulassen. Manche Irrthümer rülıren daher, namentlich Trenumgen, wic $A$. ferox und Scorpius, brachyphyllum und subulatum etc.

In verhältnissmässig wenigen Arten besteht die Aehre oder das Köpfchen aus 2-3-, bis jhlumigen Aelnchen, jedes mit $t$ oder mehr Deckblitteru. Bei weitem in der Mehrzahl aber sind die $\Lambda$ ehren und Köpfehen aus einzehnen Blumen, stets nur mit drei Deckblättern, zusammengesetzt, deren jede demmach nach Aualogie als ein auf eine einzelne Blume reducirtes Aehrchen betrachtet wird, so sonderbar auch der Ausdruck spicula uniflora klingen mag. A uf diesen Unterschied begründet Boissier seine Eintheilung der Gattung in die Sectionen Armeriopsis und Glumaria einer-, und Staticopsis andererseits. Doch scheint dieser Character geringeren Werth zu haben, als der der verschiedenen Blattbildung, denn in den meisten Arten mit mchrblumigen Aehrchen sind cinzelne oberstïndige einblumig, in andern nur selten einzelne mehrblumig, so dass selbst Boissier zuweilen in der Feststelluug dieses Characters irrt, und z. B. A. tomentellum, A. fasciculare in der 
Abtheilung Staticopsis anffiblut, wilhrend sie streng genommen zu Glumaria gezogen werden müssten. Ueberdies giebt es Arten, die in allen Stiicken mit Arten der Abtheilung Glumaria übereinstimmen, aber nur oder fast nur einblumige Aehrchen zeigen. Fast immer weist dann die Melırahl der Decliblätter auf die richtige Stellung hin, wie bei dem zierlichen A. diapensioides, das freilich, obzwar sehr selten, auch zweiblumige Aehrchen zeigt; in andern Fillen aber, wie bei $\Lambda$. avenaceum, das sich in den meisten Characteren einigen Glumarien eng anschliesst, fehlt dieser Hinweis, und man wird zu küustlicher Gruppirung gezwuugen.

Die Gestalt und Consistenz der Deckblätter, so wie ihre verhältnissmässige Länge zu cinander und zur Blume ist zwar in cinigen Arten sehr characteristisch und nicht nur von den meisten Schriftstellern zur Diagnosticirung der Arten, sondern von Boissier sogar zur Tremung der Sectionen Armeriopsis mol Glumaria verwerthet; allein auch dies ist schwankend, häufig nur auf ein melı oder weniger beschränlit, und Arten wie A. bracteatum und latifolium, dic schönsten der Gattung, cinander zuntichst verwandt, werden durch dies eine Kennzeichen von einander gerissen. Der Mittehnerv der Deckblïtter geht häufig in cine Stachelspitze aus oder verlïngert sich unterhalb der Spitze des Decliblattes in eine feine aus dessen Rücken hervortretende Grame, und dies giebt in allgemeinen gute Kennzeichen; nicht selten liommen aber in einer und derselben Art, ja in einer und derselben Achre Schwankungen in dieser Ilinsicht vor; dem häutig verhalten sich die Deckblätter der unteren Aelırchen anders als die der oberen in demselben Blüthenstande.

Der Kelch giebt gute une wohl auch feste Charactere 1. in der Färbung: weisslich, oder glasartig durchscheinend, rosenroth oder dunkelviolett; 2. in der absoluten Grösse: von $2^{1 / 2} 2^{\prime \prime \prime}$ (polystachyum) bis zu $10^{\prime \prime \prime}$ (latifolium) - sehr constant; 3. im Verhältniss der Röhre zum Saum; 4. in der Behaarung der Kelchröhre; doch scheinen hier schon bedeutende Schwankungen vorzukommen, wie namentlich in den sonst ganz übereinstimmenden Formen des $\Lambda$. bromifolium; 5 . in der Bildung des Saumes, der bald weit trichterförmig geöfnet, bald durch Faltung eng röhrig, dessen Rand bald gestutzt, bald stumpf oder spitzig fünf- selten zchnlappis ist; dessen Rippen bald bis zum Rande verlaufen, bald vor dem Rande verschwinden, bald frei, zuweilen fast gramnenfürmig, selten fast spatelförmig auslaufen. Die Beharunn dieser Rippen vom aussen, die häufig vorkommt, ist aber sehon nicht constant; eher die Färbung vom fast Schwarzen, durch Purpur und Rosenroth bis zum Furblosen. Nur in zwei von mir entdeckten Arten sind diese Fippen verdickt und an der Innenseite stark behaart; ein Kennzeichen, das um so wichtiger erscheint, als es in einer dieser Arten mit einem sonst in der Gattung nicht vorkommenden Blïthenstand zusammentrifft. Auch dic andere Art zeigt einen eigenthümlichen Blïthenstand, den wir fast ebenso wielerfinden in einer dritten Art, die sich durch eigenthümliche Bildung der Deckbläter anszeichnet; so dass liese 3 Arten, jede für sich, als monotypische Sectionen der Gattung betrachtet werden müssen. 
Hiermit ist aber dic Summe der unterscheidenden Charactere auch so ziemlich erschöpft; denn die sehr vergänglichen, meist schön rosenrothen Blumenkronen, fast das einzige parenchymatöse Organ an der ganzen Prlanze ${ }^{1}$ ), die nach dem Verblühen sich einrollt und zerfliessend zusammenlilebt, lässt sich an getrockneten Exemplaren kaum gehörig entfalten, und möchte auch zu gleichförmig sein, um scharfe Unterscheidungsmerkmale zu gewähren. Die verhältnissnässige Lünge der Sexualorgane, gleichfalls in Folge des Verhaltens der Blumenkrone nach dem Verblühen schwer zu ermitteln, scheint in dichogamischer Weise zu variiren. Die einfache, den einzelnen Samen eng umschliessende Frucht ist, so weit sie mir bekannt ist - denn nur höchst selten beobachtet man an den Pflanzen vollständig gereifte Früchte, wegeu des frülizeitigen Zerfallens der Fruchtstände - , überall dieselbe.

Auf die wesentlichsten Charactere: 1) Beschaffenheit der Blätter, 2) innere Behaarung des Kelchsaumes, 3) Einzahl oder. Mehrzahl der Blumen im Aehrchen sind weiter unten die Hauptgruppen der Gattung begründet, allein für die Begrenzung und Unterbringung der zahlreichen Arten sind die eben erwähnten schwankenden Verhältnisse in hohem Grade erschwerend, und diese schwierigkeiten werden nur wenig vermindert durch Berïcksichtigung der

\section{geographischen Vertheilung,}

indem die Arten meistentheils einen sehr engen Verbreitungsbezirk haben.

Die ganze Gattung Acantholimon ist auf einen wenig ausgedehnten Bezirk beschränkt. Sie findet sich nur zwischen dem 42 . und $95^{\circ}$ östl. L. und dem 43 . und $28^{\circ} \mathrm{n}$. Br. Auf dem ganzen Gebiet, das sich also vom ästlichen Griechenland bis zum westlichen Tibet und von Transcaucasien und dem Tian-schan bis nach Syrien, S.-Persien und Beludshistan erstreckt, schliesst sie die übrigen Gattungen der Staticeen fast gänzlich aus.

Lassen wir die 3 kleinen, fast sämmtlich monotypischen Gattungen Aegialitis, Limoniastrum und Bubania als ganz ausserhalb unseres Bezirks bei Seite, so findet sich die dem Character nach nächststehende Gattumg Goniolimon, deren sïmmtliche Arten auf salzhaltimem Boden der niederen Steppen gedeihen, nur im Norden in grösserer Lüngenausdehnung, in einer geringen Breite kaum den 52. Breitegrad erreichend, und steigt nur in einer Art in Kleinasien bis zum 40. Grad hinab, wo es die Gränze des Verbreitungsbezirkes von Acantholimon berührt.

Die dem Habitus nach, besonders den höchsten Formen der Gattung Acantholimon, näher stehenden Armerien, die ihr Maximum in den Ungebungen des westlichen Theiles des Mittelmeeres bis zu den Canaren (29 Arten von 51 ), besonders in der pyrenäischen Halbinsel (15 Arten) zeigen, sich aber von dort aus in den Norden Europas, Asiens und Amerikas ausbreiten, dann wieder isolirt in S.-Amerika auftreten (5 Arten), nähern sich

1) Bei der indisch-australischen monotypischen Gattung Aegialitis, die ich übrigens nicht gesehen habe, sind aucb die Kronenblätter lederartig.

Mémoires de 1'Acad. Imp. der sciences. VIImo Série. 
nur den iussersten Westen unseres bezirkes in einer griechischen und einer lileinasiatischen Form.

Die artenreichste und den weitesten Verbreitungsbezirk eimehmende Gattung der Staticeen, Statice, tritt nur in sehr wenigen Arten im geographischen Bezirke der Acantholimon auf; uur die kleine, in vielen Stïclien von den übrigen $A$ rten abweichende Abtheilung Psylliostachys fillt ganz in diesen Bezirk hinein; aber diese sowohl, wie die wenigen anderen Arten finden sich nie auf denselbon Standorten zusiummen mit $\Lambda$ cantholimon, denn während Statice niedere Standorte, die wenigstens in Friilujahr f'ucht sind, und den salzhaltigen Boden der Mecreskïste und der Salzsteppen suelıt - (allein die Küïten des Mittelmeeres zählen über 40 Arten, die nicderen Salzstejpen Mittelasions ibber 20; andere Verbreitungscentren sind die (anaren mit den Capverden (1+ Arten) und das Cap (12 Arten), während einzelne Arten über Arabien, Aegypten, Scinde, Cabul, die Molucken, China, Japan, N.-Holland, Brasilien, N.-Amerika und N.-Lurepa zerstrent sind), liebt Acantholimon ausschliesslich einen dürren, kalkhaltigen Felshoden nach süden gerichteter Gebirgsabhänge, kaum je in geringerer Itöhe als $3000^{\prime}$ über dem Neere und im Ifochgelirge bis zu $15-16000^{\prime}$ aufsteigend. Diese hohen somnigen Standorte in einem höchst trockenen Klima mit ganz regenlosem Sommer und sebr extremen Temperaturen bedingen d'n parenchymarmen starren Habitus dieser PHanzengruppe.

Am schürfsten ausgeprägt ist dieser: Habitus in den Arten, deren Sommerblätter in Dornen umgewandelt sind; sie nehmen den südöstlichsten, dürsten und heissesten Theil des Verbreitungsbezirkes ein, fon den Vimgrommen Cithuls begimend über Beludshistan und Afghanistan, besonders in S.- mud Mittel-P'ersicn in der Umgebung der grossen Salzwüste, und überschreiten nur in zwei Arten den $65^{\circ}$ nach Osten, immerhalb der N.-W.Gränze Persiens. Bei melıreren Arten dieser Gruppe treten zwei- mo melublumige Aehrchen auf; sie bilden den Uebergang zı den Formen mit constant mehrbhunigen Aehrchen und dabei gleichförmigen, scharfiandigen Blittern, welche im N.-O. des Verbreitungsbezirkes dominiren, sich vom 'Tian-schan und 'Tibet über den liolor'-dagh und tie Hochgebirge Cabuls, westlich bis nach Meschhed und Schahrud im Chorassan hinziehen, um dann, mit einem kleinen Sprunge ${ }^{1}$ ), in 4 einander nah verwanden, von den übrigen aber mehr abweichenden, theils durch den Glanz ihrer grossen Deckblitter, theils durch Grösse und schön rosenrothe fiurbung des Kelehes, schmuckvollsten Formen, im westlichen Persien, wenig westlich vom geographischen Centrum, wicher aufzutreten. Ihnen zunichst verwandt, nehmen die drei obon erwihnten, jede für sich eine monotypische Abtheilung bil-

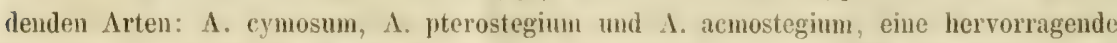
Stellung ein; sie liegen nur wenig östlich vom Centrum. Jie kleinblütligen Arten finden sich nur im äussersten S.-O., und dam wieder zahlreich gedrängt im S.-W. Persiens und in Kurdistan. Westlich vom $73^{\circ}$ kommen nur noch Arten mit eimblumigen Aehrehen und

1) Vielleicht schwindet dieser Sprung durch spaitere Eutdeckungen auf der noch fast ganz unbekannten Strecke zwischen Teheran und Schahrud. 
gleichartigen Blättern, also solche, die am wenigsten hervorragende Charactere darbieten, vor; und zwar werden auch diese je weiter westlich und nördlich immer schmuckioser, dem im westlichen Persien. in Assyrien. Kurdistan und Armenien tinden wir noch Arten mit schünfarbigem lielch und verlïngerten vielblumigen Achren; in der Mitte Ḱleinasiens zwar noch mit vielblumigen verlingerten Achren, aber schon mit farblosen Kelchen, und an den äussersten Gränzen der Gattung im Westen, Norden, ebenso wie im äussersten N.-O. die selnucklosesten Arten mit wenigen znsammengedrängten, fast sitzenden, weissen Kelchen.

Die kleine beiliegendo Karte mag diese eigenthümlichen pHtanzengeographischen Verhältnisse verdeutlichen. Die schwarz geschriebenen Namen bezeichnen die Arten mit gleichartigen Blittern und einblumigen Aehrchen; die blan geschriebenen geben die Arten mit mehrblumigen Achrchen und gleichartigen Blïtern an; in beiden Fällen sind die rothkelchigen Arten unter diesen roth unterstrichen; die roth geschriebenen sind dornige Arten und von diesen blau unterstrichen die mit mehrblumigen Aehrchen.

Auf einer zweiten Tafel habe ich den Versuch gewagt, die verwandtschaftlichen Beziehungen der Arten der (iattung Acantholimon unter einanter graphisch darzulegen, ohne jedoch Anspruch darauf zu machen, die Entstehung aus einander oder die Descendenz der Arten aus einer ursprünglichen oder mehreren untergegangenen formen unzweifelhaft nachgewiesen zu haben. So sehr es jetzt an der Tagesordnung ist, so ist doch einstweilen einen solchen Nachweis zı liefern, besonders ohme erschöpfende Detailkemntniss, en sehr gewagtes Unteruehmen, hei welchem der Phantasie und Willkür ein zu weiter Spielraum gewährt ist.

Schon die Entscheidung darüber, von welcher Form aus am wahrscheinlichsten die anderen Arten sich entwickelt haben, hat grosse Schwierigkeiten. Es müssen dabei sowoht morphologische als pflanzengeographisele Gründe wohl erwogen und mit einander in Uebereinstimmung gehracht werden. Morphologiseh genügt es nicht, die scheinbar am wenigsten entwickelte Form als Stammart aufzufassen: denn eine niedere Form kamn nicht nur, sondern ist wohl anch wirklich nicht selten ans einer höheren allmählig durch Ungunst der ¿̈usseren Verhältnisse zur niederen Stufe herabgesunken; wie dies wohl an den äussersten Gränzen des Verbreitungsbezirkes cines Formenkreises, wo die Bedingungen für die Exi'stenz seiner Glieder allmählig ganz schwinden, in der That statt hat. Dafür sprechen in unserem concreten Falle so einfache Arten, wie A. Echinus, alatavicum, lycopodioides, in welchen dabei dennoch der (haracter der Abtheilung, der sie angelı̈ren, sehr entschieden ausgesprochen ist. Vielmehr wird diejenige Art den Ausgangspunkt eimehmen, welche in Bezug auf die wesentlichen, dic Gruppen der Gattung bedingenden Charactere die indifferenteste ist. Ans einer solchen lassen sich die Uehergänge nach versehiedenen Richtungen am leichtesten ableiten. 
Keine Art entspricht diesen Bedingungen so sehr, als A. diapensioides. Sie ist von allen Arten die kleinste, hat die kürzesten, dichtest gedrängten Blätter, die ihr ein moosähnliches Ansehen verleihen; der scharfe Rand derselben ist so wenig entwickelt, dass sie, obgleich unzweifelhaft zu Spach's acerosac zählend, doch bisher zu den spinosae gestellt wurde. Der Blüthenstand ist meist auf eine einzige Blume reducirt, so dass Boissier sie seiner Abtheilung Staticopsis beizählt, während sie doch wegen der Mehrzahl der Deckblätter und wegen der, obwohl selten, auftretenden Zweizahl der Blumen im Aehrehen jedenfalls den Glumarien angehört. Sie scìwankt also, wenigstens bei flüchtiger Beobachtung, zwischen den drei Hauptgruppen der Gațtung.

In pflanzengeographischer Beziehung ist sie vor Allen geeignet als Stammart angesehen zu werden. Es wäre verfehlt, die Stammart im geographischen Centrum des Verbreitungsbezirkes zu suchen, wo wir nicht nur die am höchsten entwickelten, sondern auch die grösste Mannichfaltigkeit der Formen finden. Es sind vornehmlich die âusseren Verhältnisse, welche die Verbreitung und die allmählig höhere Entwickelung bedingen. Die Stammart kam möglicherweise in der Nähe der Gränzen des Verbreitungsbezirks entstanden sein, wenn die Bedingungen für ihre eigene Existenz sowhl, als für die ihrer etwaigen Descendenten nach einer oder der anderen Himmelsrichtung hin plötzlich schwinden, während sie in einer anderen auf weite Strecken hin sich immer günstiger gestalten. Für Acantholimon ist das der Fall. Sie können nicht auf den Nordabhange der Gebirgszüge bestehen, auf deren Südseite sie gedeihen, und wahrscheinlich in bedeutender Höhe zuerst entstanden. A. diapensioides ist zuerst in den Hochgebirgen nördlich von Cabul in einer Höhe von 12-14000' üb. d. M. entdeckt worden; im Tian-schan, höher im Norden, steigt sie tiefer bis zu $6000^{\prime}$ (?) hinab. Hre Descendenten konnten nur wenig uach Norden vordringen, wo wir nur noch eine Art, A. alatavicum, finden; auch nach Osten war die Verbreitung gehemmt, denn über Tibet und Kaschmir hinaus, wo A. lycopodioides die äusserste südöstliche Form ist, sind die Südabhänge des Himalaya wegen der starken Niederschläge ungünstig für die Gattung. I)agegen mehren sich die Bedingungen für ihr Gedeihen auf den nach Westen sich erstreckenden Gebirgszügen bis in das mittlere und westliche Persien, wo sich die am höchsten entwickelten, jedenfalls späteren Arten findelı.

Gesetzt nun, wir hätten in dem A. diapensioides mit einiger Wahrscheinlichkeit die noch bestehende Stammart der Gattung erkannt, so treten uns weitere Schwierigkeiten entgegen beim Forschen nach den Wegen, die wir von dieser Form zu den am höchsten entwickelten einzuschlagen haben. Die verwandtschaftlichen Bezielıungen der cinzelnen Arten zu einander sind so mannichfaltig und verwickelt, dass die Feststellung der Reihenfolge, in der die Arten aus einander hervorgingen, in hohem Grade zweifelhaft wird.

Wenigstens möglich, wemn nicht höchst wahrscheinlich, ist es, dass scheinbar einander sehr nah verwandte, hoch entwickelte Arten zu dieser hohen Entwickelung auf verschiedenem Wege gelangt sind. Es ist z. B. fraglich, ob das schöne A. splendidum sich 
aus dem unscheinbaren $A$. distachyum durch die Zwischenstufen von $A$. cabulicum und $A$. cephalotes entwickelt hat, um dann durch $\Lambda$. latifolium und $\Lambda$. bromifolium zu der Reihe der rothblühenden locker- und langährigen Arten mit Einzelblumen herabzusinken, oder ob es umgekehrt als gipfelnde Art aus dieser letzteren Reihe hervorgegangen ist. Oder, um cin anderes Beispiel zu wählen, sind A. cymosum und A. pterostegium, durch einen, sie rom allen übrigen Arten scharf unterscheidenden Character mit einander jedenfalls sehr nahe verwandt, aus einander entsprungen, oder aus einer gemeinsamen Stammform, oder sind sie Gipfelpunkte zweier verschiedenen Reihen? das erstere etwa der Reihe der dornigen Arten mit mehrblumigen Aehrchen, das letztere derjenigen Reihe, welche sich zu A. acmostegium erhebt? Dafür spräche der Habitus, denn A. cymosum hat im Aeussern mehr Aehnlichkeit yon A. schahrudicum als von A. pterostegium, und dieses steht wieder dem A. acmostegium weit näher, als dem A. cymosum.

Einigermassen leitend können hier die geographischen Beziehungen sein, dem es leuchtet ein, dass die an einander zu reihenden Arten nicht nur nach ihren Characteren, sondern zugleich auch geographisch benachbart sein müssen.

$\mathrm{Zu}$ alledem gesellt sich nun noch die Schwierigkeit, die bezeichneten complicirten Terhältnisse graphisch klar zu machen. In wie weit mir dies gelungen, überlasse ich einer nachsichtigen Beurtheilung. Durch die wenigen obigen Andeutungen wollte ich nur die Schwierigkeit, wenn nicht Unmöglichlieit der Herstellung einer befriedigenden Descendenztufel hervorheben, und meinen gewagten Versuch vor einen verdammenden Urtheil schützen. Wenn ich ihn dennoch gewagt, so geschah es nur, um nicht ganz hinter denen zurückzubleiben, die den Anforderungen der Neuzeit lechnung zu tragen wähnen, wenn sie - oft mit der grössten Unbefangenheit und sicherheit - Ahnentafeln construiren rom einfachen Plasmodium hinauf bis zum Menschen. 


\title{
Acantholimon Boiss.
}

\author{
diagn. pl. or. 7, p. 69.
}

Statices subgenus Armeriastrum Jaub. et Spach ann. sc. nat. XX. p. 248. et Illustr. pl. orient. 1, p. 161.

Statices species L. Willd. al.

Limonii spec. Tournef. Coroll. inst. rei herb. p. 25.

Calyx infundibularis vel tubulosus, limbo scarioso quinquenervi, truncato, quinquevel decemlobo. Petala quinque ima basi comata, longe unguiculata, tenera peracta anthesi confluenti-involuta. Filanenta 5-glabra libera. Ovarium lineari-oblongum. Styli 5-liberi glabri. Stigmata capitata. Utriculus membramaceus semen arete cingens, pentagonus vel oblongus laevis indehiscens. Embryo rectus utroque latere albumine cotyledonibus vix crassiore obtectus. Suffrutices erinacei in apricis rupestribus editioribus vel alpinis a Graecia usque ad Tibetum occidentalem vigentes, foliis acerosis vel spinosis, Horibus in rachi plerumque fragillima simplici vel ramosa, in spicula vel solitariis tribracteatis vel $2-5$ 4-pluri-bracteatis. Calycis basis truncata, minute foveolata, linbus expansus vel arete plicatus, hyalinus, albidus, roseus, vel atropurpureus. ('orolla rosea vel albida, aestivatione contorta.

\section{Conspectus sectionum.}

1. Nervi limbi calycini intus villosi incrassati. 2.

" " " glabri 3 .

2. Spiculae numerosae in cymam dichotomam confertae .......... Cymaria

n in capitula subtria in apice scapi dense confertae, bracteae exteriores membranace 0 -alatae. ................. Pterostcgia.

3. Folia homomorpha, omnia acerosa, margine scabra, plerumque omnia diu persistentia. 4 .

" heteromorpha, vernalia carnosula saepius margine scabra jam sub anthesi saepe diffracta, aestivalia spinescentia margine laevisșima. Tragacanthina.

4. Spiculae bi-pluriflorae, rarius abortu uniflorae, 4-pluribracteatae. 5.

" omnes uniflorae tribracteatae.................. Staticopsis.

5. Capitula e spiculis numerosis in apice scapi subterna, bracteae exteriores late hyalino-marginatae interior coriaceo-herbacen convoluta

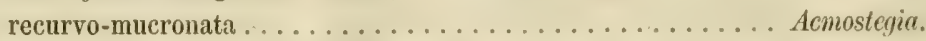

Spiculae in capitulum vel spicam simplicem vel compositam dispositae. 6.

6. Capitulum simplex, rachis brevissima, bracteae exteriores latissimae ex toto membranaceae . ..................... Armeriopsis.

Spica uni-pauciflora vel plerumque composita elongata vel interrupta, bracteae exteriores herbaceo-coriaceae hyalino-marginatae...... Glumaria. 


\section{Secrio I. Cymaria.}

Spiculae bi-triflorae in cyma pluries dichotoma confertac. Calyx crasse quinquenervius, nervis intus villosis, aristato excurrentibus. Folia aestivalia triquetra spinescentia margine laevia.

\section{A. cymosum. m.}

Species sectionis unica, diagnosi non egens, habitat in rupestribus dolomiticis prope schahrud, movinciae Chorassan occidentalis, Persiae transelbrusensis mediae borealis. (Bunge et Bienert!) v. v. sp.

Fruticults humilis glaucus, ramis subelongatis, crassis, foliorum vaginis tectis. Folia vernalia breviora recurva planiuscula margine, praesertim basin versus scabriuscula, seriora basi late vaginantia, vagina crasse multinervia ciliata, superne triquetra rigide spinosa margine fere omnino laevia, punctis calcareis dense conspersa, $1_{2}^{1}$-pollicaria vel parum longiora. Pedunculi folium parum superantes retrorsum hispiduli, firmi. Bracteae infimae amplexicaules longiuscule cuspidatae, cuspirle saepius recurvo. Rami cymae ancipites pube patenti densa brevissima tomentelli, primarii 3-4"' longi. Bracteae subflorales late et breviter cordatae herbaceo-coriaceate abrupte recurvo cuspidatae anguste hyalino-marginatae ciliolatae, utrinque villosae practer baseos faciem interiorem, dorso carinatae; interiores multo minores aristatac, intimate minutae hyalinae. Calyx nondum ommino evolutus $3 \frac{1}{2}{ }^{\prime \prime}$ longus infundibularis, tubo extus et limbo albido in nervis crassis extus et intus villoso. Corolla nondum evoluta videtur albida.

\section{Secrio II. Pterostegia.}

Spiculae bi-triflorae in capitula parvula in apice scapi sessilia subtema congestae. Calycis limbus muticus crasse quinquenervius, nervis dilatatis ante medium limbum abrupte desinentibus intus villosulis. Folia omnia margine scabriuscula.

2. A. pterostegium. m.

Species sectionis unica; liabitat in rupestribus prope T'scheschme-Ghilas ad orientem ab urbe Meschled, Persiac provinciate Chorassan orientalis, ubi sub finem Iulii mensis, perpauca specimina arida capitulis dilapsis collegi v. v. sp.

Suffruticulus erinaceus glancus punctis calcareis obsitus, ramosissimus ramis abbreviatis, horridus foliis confertis. Folia primaria carnosula pauca emarcida, breviora, recurva; caetera rigidissima patula recta $1-1 \frac{1}{2}$-pollicaria, supra plana nervosa, subtus obtuse carinata, margine obsolete scabra. Scapi brevissimi graciles, patulo muriculatohirti. Capitula parva subterna (?) in apice scapi, sessilia conferta. Bracteae exteriores medio late ovatae coriaceo-herbaceae rufenscentes pubescentes breviter mucronatae, late abrupte praeter apicem hyalino alatae orbiculari-cordatac margine slabrac, vix ultra $4^{\prime \prime \prime}$ longae et 5." paulo latiores: interiores hyalinae, basi plicato-uninerviae, nervo medio dorso breviter mucronulato. Calyeis $4^{\prime \prime \prime}$ longi tubus rufus extus undique dense hispidulus, limbus 
praeter nervos rufescentes crassos fere in medio limbo abrupte desinentes intus hispidos sordide albidus, obsolete quinquelobus, omnino muticus. Petala basi commata, apice denique involuta persistentia utriculum lineari-oblongum acuminatum tegunt.

\section{SeCtio III. Acmostegia.}

Armeriopsis sp. Boiss. I. infra cit.

Spiculae inferiores saepius bi-, caeterae uniflorae, confertae in capitula disticha 3-4sessilia in apice scapi. Bracteae exteriores late hyalino-marginatae, interior coriaceo-herbacea convoluta recurvo mucronata calycem arcte cingens et occultans, intima (in spiculis bifloris) minuta hyalina. Calycis nervi intus glabri, Folia margine seabra.

3. A. acmostegium. Boiss. et Buhse. Aufz. transcauc. pers. Pf. p. 182.

Species sectionis unica; habitat in lapidosis apricis ad pedem montium in Persiae provincia Chorassan occidentali, prope Rischm (Buhse), Dangan (Göbel!), Schahrud (Bge et Bienert!) v. v. sp.

Suffruticulus humilis dense pulvinato-erinacens, glaber, cretaceo-glaucus. Rami breves dense foliis horridi. Folia crassa rigida margine denticulato-scabra lincari-subtriquetra, infima breviora, caetera longiora, $1 / 2-1$-pollicem longa, linea latiora, punctis calcareis dense obsita. Scapi ebracteati saepius brevissimi vel subuulli, in planta vegetiori interdum pollicures vel longiores, tbracteati, glabri. Spicae $2-4$ in apice scapi sessiles capitatae breves confertae distiche compressae, magnitudine avellanae, e spiculis $5-8$, inferioribus sacpius bi-, caeteris unifloris. Bracteae inferiores amplae ovatae dorso coriacco-scariosae rufescentes, carinatae, attenuato-acuminatae, margine late albo-membranaceae; intermedia paulo longior angustior subrecurva dorso complicato-carinata, in acumen recurvum producta late membranaceo-marginata; tertia longior, 5 "' aequans oblongo-spathulata 'coriaccoherbacea amoene purpurascens, subpungenti recurvo-acuminati, couvoluta calycem arete vaginans; interna in spiculis bifloris multo minor membranacea. Calycis tubulosi glabri vel parcissime hispiduli tubus rubellus, limbus minutus scariosus profunde quinquelobus nervis excurrentibus aristulatus bracteae inclusus vel vix apicibus exsertus. Corolla ampla ammene rosea, $8^{\prime \prime \prime}$ longa. Variat vegetior scapis pollicaribus et longioribus, spiculis tunc semper, saltem inferioribus bifloris, bracteis littioribus (prope Damgan), et humilior capitulis subsessilibus, spiculis tunc fere semper mifloris.

\section{Sectio IV. Armeriopsis Boiss.}

Boiss. diagn. ser. 1. n. 7. p. 70. DC. prodr. 12. p. 622.

Spiculae 2-5-florae in capitulum simplex in rachi brevissima confertae, bracteae exteriores latissimae splendentes $\mathrm{ex}$ toto scarioso-membranaceae. Limbi calycini nervi intus glabri. Folia acerosa margine scabra.

- Habitant in Persia boreali-occidentali et in Cabulistano. 
Clavis diagnostica specierum.

1. Bracteae interiores e medio dorso longe aristatae, calyces laete rose0purpurei, spiculae dense globoso-capitatae. 2.

ex apice breviter mucronatae, calyces albidi, spiculae distichae in capitulo oblongo compresso. 3.

2. Scapus folio triplo longior, spiculae $3-5$-florae, calycis tubus glaber. . A. splendidum. " folia aequans, spiculae 2-3-florae, calycis tubus pilosulus..... A. bracteatum. 3. Scapus foliis subcoriaceo-gramineis vix pollicaribus $4-5$-plo longior... A. cephalotes. " folia rigide acerosissima $1-2$-pollicaria subaequans......... A. cabulicum

4. A. splendidum. im.

A. caespitosum, ramis subelongatis, scapis folia triplo superantibus glabris tri-quadribracteatis, capitulis splendentibus magnis globosis, spiculis numerosis confertissimis 3 -5-floris, bracteis interioribus e medio dorso aristatis, calycibus purpureis tubo glaberrimis in costis limbi extus parcissime hispidulis.

Habitat in Persia boreali in montosis inter Agh-kent et urbem Mianeh. (Bge et Bienert!) v. v. sp.

Omnium generis specierum pulcherrimae tria tantum collegimus specimina. Proxime affine $A$. bracteato, sed formis intermediis haud observatis, adinterim specie distinguendum. Multo majus. Rami subelongati, foliis vetustis elongatis refractis tecti. Folia hornotina primaria breviora latiora coriaceo-subherbacea tenuissime subulato-pungentia glaucescentia plana, margine scabra, caetera similia sed longiora et angustiora $2-2 \frac{1}{2}$-pollicaria, vix lineam lata. Scapi e quovis ramo solitarii semipedales vel parum longiores teretes glabri purpurascentes, squamis $3-4$ distantibus scariosis ovato-oblongis longe acuminato-cuspidatis margine albo membranaccis vestiti. Capitula magnitudine nucis juglandis caducissima et facillime in spiculas $8-12$ plerumque 5 -floras dilabentia. Bracteae exteriores suborbiculares, media parte oblonga convexa ccarinata coriaceo-membranacea purpurea apice in mucronulum brevem, rarius bipartitum excurrente, margine latissime splendide hyalino-membranaceac tenuissimae glabrae, 5-6"' longae totidemque latae. Bractea in spicula sequens late obovata, prater nervum angustum purpureum paulo supra medium dorsum bracteae in aristam gracillimam apicem bracteae tamen vix attingentem solutum, tenuissime hyalino-membranacea, $5^{\prime \prime \prime}$ longa et superne fere totidem lata. Bracteae sequentes in spicula 5 -flora saepius usque ad 7 sensim minores angustiores, intima vix $3^{\prime \prime \prime}$ longa, $1 / 2$ lata, attamen omnes e dorso breviter aristulatae, arista decolore. Calyx semipollicaris, tubus glaber purpureus, limbus tenuis pallide roseus inter nervos abbreviatos obsolete 5-lobus, muticus, nervi purpurei pilis paucis adpressis extus adspersi. Corolla pulchre rosea $8^{\prime \prime \prime}$ parum longior. 
5. A. bracteatum Boiss.! II. cc. n. 1.

A. caespitosum, brevirameum; scapis folio brevioribus vel subaequantibus asperulis subunibracteatis, capitulis splendentibus globosis, spiculis $7-9$ trifloris, bracteis interioribus e medio dorso aristatis, calycibus purpureis tubo undique hispidulis in costis limbi glabratis.

Syn. Statice bracteata Girard. in Ann. sc. nat. 1844. p. 330.

Hab. in Persiae boreali-occidentalis provincia Adserbidshan, per districtum Choi (Szovits!) et prope Seid-chodshi (A ucher Eloy lib. d'or. n. 5242!). Vidi insuper specimen minutum in herb. Boissieriano, a $\mathrm{D}^{\text {no }}$ Calvert prope Erserum (?) collectum et a Tschichatschewio communicatum. v. s. sp.

Praecedente multo minus. Folia multo breviora vix unquam sesquipollicaria, caetera discrimina diagnosis indicat. Calyx structura et magnitudine fere idem sed intensius purpureus et ad tubum ad costas et inter costas hispidus.

6. A. cephalotes Boiss.! in DC. prodr. 1. c. n. 2 Catal. Griff. distr. n. 4161.

A. caespitosum, brevirameum; scapis folia 4-5-plo superantibus remote tribracteatis, capitulis ovato-oblongis e spiculis $5-7$ distichis $2-5$-floris, bracteis interioribus obcordatis e sinu aristatis, calycibus albis tubo inter costas dense piloso.

Habitat in Afghanistano (Griffith n. 1580) v. s. sp. in hb. h. bot. Petrop.

Glaucescens; folia calcareo-punctata patentissima, trinervia, 8-10"' longa. Scapi gracillimi fore semipedales. Capitula fere pollicaria, angusta. Bracteae exteriores ovatae medio coriaceo-membranaceae, late marginatae.

7. A. cabulicum Boiss. in DC. prodr. 1. c. p. 623. n. 3 Cat. Griff. n. 4162.

A. dense caespitosum, brevirameum; scapis folia clongata subaequantibus unibracteatis (?), capitulis oblongis e spiculis $5-7$ distichis trifloris subpedicellatis, bracteis interioribus obovatis ex apice mucronatis muticisve, calycibus sordide albis inter costas parce puberulis.

Habitat in Afghanistano (Griffith n. 1581), non vidi.

Planta sub hoc nomine ab horto Kewensi horto bot. Petropolitano communicata ad speciem sequentem spectat.

Sectro V. Glumaria. Boiss.

Boiss. in DC. prodr. l. c. p. 623.

Spiculae 2-3-florae sessiles, vel approximatae vel remotae in spicam brevem vel clongatam, intersuptam dispositae. Bracteae cxteriores glumaceae, coriaceo-membranaceae angustius hyalino-marginatae. Folia margine scabra. Limbi calycini nervi intus glabri.

Habitant in jugo Tianschan et Himalaio occidentali, in Afghanistano et Persia orientali, tum vero rariores in Persia austro-occidentali. Species habitu inter se valde diversae. 
Clavis specierum diagnostica.

1. Bracteae intimae e dorso aristatae, calycis limbus albidus. 2.

» $\quad$ ex apice mucronatae vel omnino muticae. 3.

2. Scapi folio subbreviores, folia elongata acerosa linearia, spiculae subbinae approximatae, calycis limbus aristulatus.......... distachyum.

». multo longiores, folia breviter lanceolata, spiculae $5-7$ laxe spicatae, calycis limbus muticus.............. tataricum.

3. Scapi vix folia excedentes vel subnulli. 4 .

» elongati folia longe superantes, spicae elongatae laxae. 6.

4. Folia brevia late lanceolata, spiculae 3 vel plures $2-3$-florae rarius superiores uniflorae. 5 .

" minutissima triquetra submutica, spicae sessiles 1-rarisssime bispiculatae, spiculis 1-rarissime 2 -floris $4-5$-bracteatae.... A. diapensioides.

5. Calycis limbus albus subtruncatus muticus .............. lycopodioides.

" " atropurpureus nervis late excurrentibus obtuse quinquelobus......................... Ruprechti.

6. Calycis limbus albus, scapi gracillimi remotissime $4-5$-spiculati, bracteae interiores muticae............... scirpoides.

》 $\quad$ purpurascens vel roseus. 7.

7. Glauca, spicae multispiculatae simplices, scapi firmi validi, calyces $5^{1 / 2}-10$ lineas longi. 8.

Virens, spicae basi ramo uno-alterove auctae; scapi tenues, bracteae interiores longe recte mucronatae, calyces $3 \frac{1}{2}$ linea longi glaberrimi................................ffithianum.

8. Spiculae in spicam oblongam confertae, calyces $10^{\prime \prime \prime}$ longi........ Aatifolium.

„ laxissime spicatae remotae, calyces $5 \frac{1}{2}-6^{\prime \prime \prime}$ longi. 9.

9. Spicae rachis valde anfractuosa, bracteae intimae multo breviores intermedia rigide coriacea arcte convoluta recurvo-cuspidata calycem glaberrimum 5 -aristatum includens............ restiaceum.

n rachis recta, bracteae subaequales interiores subplicatae brevissime mucronatae calycis tubum pubescentem superantes limbo mutico exserto..................... bromifolium.

8. A. distachyum. Boiss. 1. c.! n. 4. Catal. distr. Griff. n. 4163.

A. dense erinaceo-caespitosum, brevirameum; foliis elongatis linearibus acerosis, scapis folio brevioribus glabris apice spiculas subbinas approximatas bi-trifloras gerentibus, bracteis exterioribus basi coriaceis late albo-marginatis, intermediis dorso puberulis, intimis hyalino scariosis spathulato-obovatis e dorso aristatis, calycis tubo inter costas hirtello, limbo albido nervis pallidis excurrentibus aristulato. 
Hab. in Afghanistano (Griffith! n. 1582). v. s. sp. sub nomine A. cabulici in herb. h. b. petrop.

Glaucum, calcareo-punctatum. Folia $12-15^{\prime \prime \prime}$ longa. Spiculae vix $5^{\prime \prime \prime}$ longae. Calyx vix $4^{\prime \prime \prime}$ excedens, tubo pilis patentibus parcis hirtulo. $\Lambda$ ffine videtur A. cabulico sed jam calycibus aristulatis nec muticis facile distinctum.

9. A. tataricum. Boiss. 1. c.! n. 5. Rel. Lehm. n. 1074.

A. confertissime caespitosum, brevirameum; foliis breviter lato-lanceolatis planis, scapo subglanduloso-hispidulo folia pluries superante, spiculis 2 -floris $5-7$ sessilibus alternis remotiusculis in spicam laxam dispositis, bracteis interioribus e dorso aristatis, calycis tubo inter costas adpresse puberulo, limbo albo nervis atropurpureis ad marginem usque productis mutico.

Hab. in regione alpina montium Karatau prope Samarkand (Lehmann!) v. s. sp.

Glaucescens, rami inferne foliis confertissimis reverso-imbricatis tecti; folia hornotina patentia 5-6 raro $9^{\prime \prime \prime}$ longa, basi linea vix latiora, plana acerosissima, coriacea. Scapi 3-4-pollicares basi 2-4-bracteati. Spica 2-pollicaris constans e spiculis 5-7, quarum inferiores interdum magis l'cmotae, superiores vero approximatae. Calyx $5^{\prime \prime \prime}$ longus.

10. A. Ruprechti m. A. latifolium Ruprecht et Ost. Sack. Sert. tiansch. p. 69.! non Boiss.

A. conferte pulvinato-caespitosum, brevirameum, foliis breviter lato-lanceolatis planis, scapo folia vix superante hispidulo-scabro, spiculis $5-6$ inferioribus bi- superioribus unifloris in spicam densam confertis, bracteis interioribus hyalinis brevissime mucronulatis, calycis tubo inter costas pubescente, limbo atropurpureo nervis longius late excurrentibus 5-lobo inter lobos truncato.

Hab. in jugo Tian-schan, in declivitate meridionali jugi Dshaman-Daban versus vallem fluvii Arpa, in solo arido lapidoso $10000^{\prime}$ s. m. (Osten-Sacken!) v. s. sp. comm. ab amic. beato Ruprecht.

Subglaucescens. Folia lato-lanceolata plana $4-8^{\prime \prime \prime}$ longa, crasse coriacea breviter acutato-pungentia, margine dense longiuscule hispido-scabra, calcareo-punctata. Spica compressa densa $1 / 2-1$-pollicaris. Bractea exterior dorso late herba-minute puberula margine hyalino scariosa, breviter acuminata, interiores, in spiculis bi-floris ternae parum longiores, praeter nervum purpureum in mucronulum brevissimum productum hyalinae. Calyx $4^{\prime \prime \prime}$ longus basi virens, abhine atropurpureus, limbus plicatus. Corolla pulchre rosea $6^{\prime \prime \prime}$ longa.

11. A.lycopodioides Boiss.! 1.c. p.632.n. 42. A.tibeticum Hook. fil. etThoms.! pl. Ind. or. exs. Statice lycopodioides Girard ann. sc. nat. ser. III. vol. 2.p. 330. excl. syn. Willd.

A. densissime caespitosum, brevirameum; foliis confertissimis breviter lanceolatis coriaceis pungentibus, scapis brevissimis hispidulis, spiculis $3-8$ confertim fasci- 
culatis $2-3$-floris, bracteis interioribus praeter nervum in mucronem productum hyalinis, calycis tubo dense hispido, limbo ampliato albo glaberrimo nervis atris ante marginem evanidis subtruncato.

Hab. in regno Caschmir prope Pir-Paniohl (Hügel! exs. n. 950 in hb. Mus. vind.!) et in Tibeto, prope Iscardu (Hügel! exs. n. .074 ibid.) in Tibeto occidentali (Thomson!), v. s. sp. specimina sterilia Hügeliana in hb. Mus. vindob, ab amic. Fenzl. ad videndum communicata, et plurima florida in hb. petrop. Ac. imp. et hort. bot. et in proprio ab horto Kewensi communicata.

Specimina Hügeliana omnino cum Thomsonianis congruunt. Caepites densi omnino ut in A. tatarico. Folia $3-4^{\prime \prime \prime}$ longa, saepe vero etiam semipollicaria, basi linea paulo angustiora. Scapi vel subnulli vel folia vix aequantes. Bracteae exteriores fuscae coriaceae, margine pallide fuscescente hyalino cinctae cuspidatae, intermediae paulo longiores praeter basin et nervum in mucronem productum hyalinae ovatae, intimae ternae vel quaternae paulo breviores sensim teneriores ex apice aristato productae, flos alter interdum longiuscule pedicellatus. Calycis tubus purpurascens cum limbo vix $4^{\prime \prime \prime}$ excedens.

12. A. diapensoides. Boiss.! 1. c. p. 624. n. 8. Catal. distr. Griff. n. 4177. Herder in bull. mosq. 1868. 1. p. 394 !

A. densissime caespitosum, ramis brevibus confertis columnaribus ob folia persistentia confertissima, foliis minutis squarrosis margine praesertim basi ciliato-scabris acutis, spiculis $1-2$-floris solitariis rarissime binis in centro rosulae sessilibus, bracteis $4-5$ ovatis membranaceis mucronatis rufescentibus, tubo calycis parce patule piloso, limbo rubello brevissime quinquelobo mutico.

Hab, in Afghanistani alpe Kuh-i-Baba alt. 14-15000' s. m. (Griffith! n. 1588); in jugi Tian-schan valle fluvii Sauka alt. $6000^{\prime}$ s. m. (Semenow!) v. s. sp. in hb. Boiss. et $\mathrm{h}$. bot. petr.

Species distinctissima habitu Aretiae vel Saxifragae bryoidis vel caesiae, evidenter affinis A. Ruprechtii et lycopodioidi, et quamvis semel tantum spiculam bifloram viderim, saepissime unifloram, tamen ob bracteas quaternas vel saepius quinas etiam in spicula uniflora ad Glumarias spectans. Folia minutissima $1 / 2-1 \frac{1}{1} 2^{\prime \prime \prime}$ tantum longa, crassiuscula submutica, certissime saltem basi ciliato-scabra nec glabra. Bractea extima orato-triangularis rigidula membranaceo-marginata, superiores duplo longiores tubum calycis aequantes, truncatae, praeter costam brevissime mucronato-excurrentem omnino membranaceae, tenerae, rufescentes. Spiculae rarissime binae tune superior brevissime stipitata. Calyx vix $3^{\prime \prime \prime}$ longus. Planta tianschanica parum differt ab augana, foliis paulo longioribus, minus crassis, subpungentibus; floris vero bractearumque structura omnino eadem. 
13. A. Griffithianum Boiss. 1. c. p. 623. n. 6. Catal. distr. G riff. n. 4158.

«A. dumosum, ramis foliis vetustis horridis, annotinis breviter rosulatis, foliis vires"centibus mediocribus tenuibus subtriquetris acerosissimis, scapis virgatis tenuibus alongissimis ramulo uno alterove saepe auctis superne spiculas plures $2-3$-floras "parvas sessiles alternatim et distanter in spicam laxam dispositas gerentibus, abractea inferiori dimidio breviori coriacea fusca ovato-triangulari mucronata inaterioribus oblongis praeter nervum medium virescentem in mucronem longiuscualum excurrentem fusco-membranaceis carinatis calycem aequantibus, tubo calycis "glaberrimo, limbo brevi pallide rubello obsolete lobato-eroso.

"Hab. in Afghanistano (Griffith n. 156. in hb. Hook.).

"Folia tenuia $9-10$ "' longa. Scapi fere pedales superne tantum spiculiferi. Calyces ( $33^{1 / 2}$ lineas fere longi,» Boiss. 1. c. Non vidi.

\section{A. scirpinum $\mathrm{m}$.}

A. dense erinaceo-caespitosum, glaucescens; foliis lineari-lanceolatis acerosis margine tenuissime scabris, scapis gracillimis folio multoties longioribus remotissime $4-5$ spiculatis, interdum ramo uno alterove auctis, bracteis glaberrimis lucidis muticis vel brevissime mucronulatis, calycis tubo parce hispidulo, limbo ampliato albo nervis glabris purpureis vix prominulis submutico.

Habitat in provincia Chorassan in montosis ad occidentem ab urbe Meschhed in aridis lapidosis supra pagum Dshegar (Bge. et Bienert!) v. v. sp.

Rosulae paulo elongatae, foliis vetustis dense reverso imbricatis, junioribus patentibus, semipollicaribus, omnino evolutis vix ultra $9^{\prime \prime \prime}$ longis, basi $3 / 4^{\prime \prime \prime}$ latis rigidis, margine crassiusculo tenuissime scabris, subcanaliculatis, breviter pungenti-cuspidatis, glaberrimis. Scapi 5-6-pollices alti, firmi nec fragiles, gracillimi, glaberrimi, teretes, basi remote subbibracteati, plerumque mono-, raro di-tristachyi, spiculis plerumque 4 longe remotis intervallo $1-1 \frac{1}{2}$-pollicari, summa praecedenti approximata, interdum loco spiculae infimae vel duarum inferiorum rami spiculas $3-2$ gerentes serius evolutas. Spiculae sessiles bi- uniflorae, 3-5 bracteatae. Bractea extima late ovata maxima parte coriaceo-herbacea, anguste membranaceo-marginata, breviter cuspidata; interiores fere duplo longiores calycis tubum superantes, obovato-oblongac subcoriaceae a medio modicae carinatae obtusae, omnino muticae vel in mucronulum brevissimum innocuum terminatae. Calyx 4 lineas vix excedens, limbus tubo multo brevior, at ampliato-infundibularis.

\section{A. restiaceum $\mathrm{m}$.}

A. caespitosum, brevirameum; foliis densissime confertis vetustis reversis rigidissimis valde glaucis basi margine scabris, scapis firmis folia superantibus, spica simplici elongata anfractuosa laxa fragillima, spiculis bifloris distantibus patulis, bractea 
inferiore rigida ovata longe aristata, media duplo longiore arctissime convoluta coriacea margine membranacea patentim cuspidata calycem omnino includente, intimis dimidio brevioribus lanceolatis acuminatis, calycis glabri limbo brevissimo arcte plicato quinquelobo aristato purpurascente.

Hab. in Persia maxime orientali inter Meschhed et Turbet Scheich-i-Dshami, prope Abdulabad (Bge. et Bienert!) v. v. sp.

Quatuor caespites tantum collegimus speciei singularis, fere omnino tunc mucedine Corruptos. Spicae forma quodammodo ad sequentem speciem appropinquat, floribus vero, praesertim bracteae intermediae structura $A$. acmostegium. Rami breves crassi omnino obsessi foliis reversis elongatis $1 \frac{1}{2}-2$-pollicaribus rigidissimis pungentibus omnino squamis calcareis tectis. Folia juniora in rosula pauca, breviora, basi linea parum latiora, supra praeter apicem plana, subtus convexa, vix al medium usque margine scabra superne laevia, patentissima. Scapi sine spica $2 \frac{1}{2}-3$-pollicares sat validi, teretes, glabri. Spicae articuli semipollicares vel paulo longiores recti glabri. Spiculae $8^{\prime \prime \prime}$ longae. Bractea inferior cum arista $4^{\prime \prime \prime}$ longa; intermedia $8^{\prime \prime \prime}$ longa fusca obovato-oblonga, sed aretissime convoluta, modice compressa, dorso praeter basin carinata; intimae margine membranaceae medio fuscae. Flores in spicula heterochroni. Calyx semipollicaris purpurascenti-fuscus, limbi lobi lanceolati. Corolla e bractea intermedia prominens.

\section{A. bromifolium. Boiss. in litt.!}

A. dense caespitosum, brevirameum; foliis confertis planis margine albo-cartilagineo scabris lineari-lanceolatis, scapis folia pluries superantibus firmis teretibus pluribracteatis, spiculis $1-2$-floris $12-20$ in spica elongata recta distantibus; bractea exteriore coriaceo-herbacea hyalino-marginata pungente, interioribus subaequilongis subplicatis brevissime mucronulatis calycis tubum pubescentem superantibus, limbo calycino purpureo exserto infundibulari quinquefido mutico.

Habitat in Kurdistania persica et in Persia australi-occidentali, in selistosis montis Dala-chani, in monte Geminan inter Sinah et Kermanschah, et in monte Otesch-ga inter Awiheng et Silnna 7-9000' s. m. (Hausknecht! pl. exs. n. $832^{3}$ et $832^{\circ}$ !) v. s. sp. communicatum ab amicissimo Boissier et in hb. Acad. petrop.

Suffruticulus brevirameus, ramis crassiusculis reliquiis foliorum diffractor'un fuscescentibus patentissimis dense tectus. Folia juniora glauca, ad summum sesquipollicaria $3_{4}^{\prime \prime \prime \prime}$ lata, subcoriacea, minus rigida, enervia, calcareo-punctata, apice brumneo-acerosa. Scapi cum inflorescentia $1 / 2-1$ pedales vel longiores, firmi teretes, a basi bracteis amplexicaulibus superne late membranaceo-marginatis longe abrupte vel sensim aristato-acuminatis vestiti. Spiculae sessiles alternae in rachi glabra, in mediis articulis intus parcissime puberula, firma nec dilabente, uni- biflorae interdum cum rudimento tertii floris, inter se longitudine bractearum, vel totius spiculae vel logins distantes 5-7-bracteatae. Bractea exterior basi ecarinata apice recta, $4-4^{1}{ }_{2}^{\prime \prime \prime}$ longa, interiores oblongae rigidae rufescentes, 
carinato-subplicatac, ad carinam superne parce pilosae, margine anguste hyalino membranaceae. Calyx $5 \frac{1}{2}$ "' Iongus, tubo parce laxe puberulo sensim in limbum dilatato ipso breviorem infundibularem quinquefidum, lobis ovatis obtusiusculis, interjectis lacinulis erosoinacqualibus. Nervi limbi extus basi densius puberuli ad apices usque producti purpurei. Corolla rosea longe exserta.

Descriptio haec facta ad specimina in monte Geminan sub fo $^{\circ} 832^{\mathrm{b}}$ collecta. Ab his non differt, nisi foliis longioribus paulo latioribus, sicut scapi, pube brevi patula sat densa tennissime velutinis, planta ibidem collecta sub $\mathfrak{j}^{\circ} 832^{3}$. Magis vero differt di $832^{\mathrm{b}}$ e monte Dalechani Kurdistaniae, foliis latioribus brevioribus, scapo foliisque glabris, bractea spicularum extima breviore, caeteris paulo longioribus, intermediis latius marginatis, praesertim vero calycis tubo dense adpresse minute puberulo. Denique in speciminibus e monte Oteschga folia paulo laxiora omnino evoluta usque ad 3 pollices longa, uti scapus pubescentia; bracteae latius membranaceo-marginatae, calyx ut in binis prioribus. Habitus ommium omnino idem.

17. A. latifolium Boiss.! diagn. ser. 2. n. 4. p. 61.

A. dense caespitosum, brevirameum; foliis confertis planis margine albo-cartilagineo scabris late linearibus, scapo folia pluries superante, spiculis bi- trifloris $5-12$ in spicam ovato-oblongam approximatis, bractea exteriore ovato-triangulari acuta late albo marginata, interioribus paulo longioribus amplis obovatis latissime scariosis ex apice breviter mucronatis, calycis glaberrimi tubo in limbum purpureum obtuse et breviter lobatum muticum ampliato.

Hab. in Persia occidentali Mesopotamiae finitima prope Mendeli (Noë!) et in monte Awroman (Hauskneclit! pl. exs. n. 831) v. s. sp. in hb. am. Boissier.

Pulcherrima species omnino media inter A. splendidum et bromifolium. Folia omnino evoluta vetustiora interdum usque ad $2 \frac{1}{2}$ pollices longa, molliora quam in aliis speciebus. Calyces in genere maximi $10^{\prime \prime \prime}$ longi. Scapus cum spica 2-3-pollicari interdum 10-pollicaris.

\section{Secrio VI. Staticopsis.}

Spiculae omnes uniflorae tribracteatae. Nervi calycini intus glabri. Folia homomorpha acerosa margine scabra, plerumque omnia persistentia raro vernalia carnosula mox diffracta. Species numerosae lujus sectionis aptissime dividuntur in series 4 sat naturales, secundum calycis magnitudinem et colorem et inflorescentiae naturam, formis intermediis tamen junctas, sequenti modo:

1. Calyces majusculi vel magni $4 \frac{1}{2}{ }^{\prime \prime \prime}$ longi vel majores. 2 .

"parvi $3^{\prime \prime}$, ad summum $4^{\prime \prime \prime}$ longi............... Microcalycina.

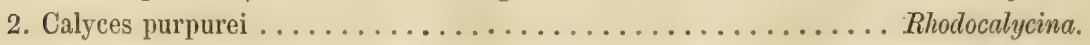

1 albi. 3 .

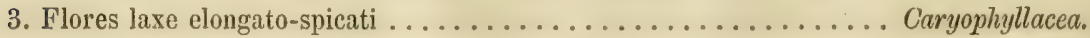

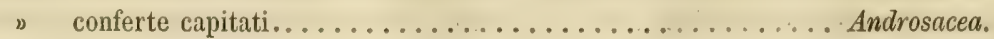


Series 1. Rhodocalycina.

Spicae plerumque laxae elongatae. Calyces purpurei $4 \frac{1}{2}-8^{\prime \prime \prime}$ longi. Habitant praesertim in Persia occidentali, Kurdistania et Armenia; formae intermediae A. avenaceum, A. scirpoidi habitu plurimisque characteribus affine, in Persia orientali crescens ad Glumarias accedit; $\mathrm{A}$. assyriacum affine $\mathrm{A}$. bromifolio; $\mathrm{A}$. Calverti a caeteris inflorescentia discrepans melius forsan, obstante solummodo calycis colore, A. glumaceo. collocandum.

Claris specierum diagnostica.

1. Spicae laxae elongatae. 2.

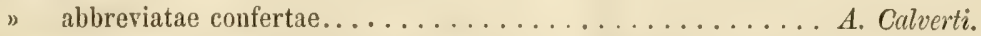

2. Spicae ramosae, bracteae fuscae muticae intimae obtusae, scapi graciles longissimi glaberrimi .................. avenaceum.

s simplices. 3 .

3. Scapi et rachis velutini vel scabri, vel saltem articuli spicae intus scabro ciliolati, vel bracteae pubescentes. 4 .

" " $\quad$ et bracteae glaberrimi. 7 .

4. glaucescentia vel glauca, rachis recta, bractea exterior caeteris multo brevior. 5 .

viridia, rachis anfractuosa, bracteae pubescentes. 6 .

5. Scapus dense muriculato-scaber, bracteae interiores apice carinae hispidulae acuminatae, calyx $7 \frac{1}{2}$ lineas longus........... venustum.

b scabriusculus, bracteae interiores fere omnino hyalinae glaberrimae obtusae vel bilobae, calyx $5^{\prime \prime \prime}$ longus............ senganense.

6. Bractea exterior interioribus longior calycis tubum superans, scapi glabri, folia linearia elongata................. Olivieri.

" exterior interioribus paulo brevior, scapi velutino-pubescen-

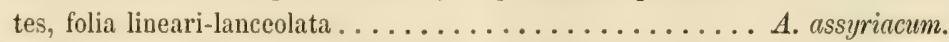

7. Dumosum, folia in rosula elongata carnosula mox diffracta basibus revolutis, bractea cxterior herbaceo-coriacea........... laxiflorum. dense caespitosum, folia in rosulis confertissima anni praeteriti reverso-imbricata. 8.

8. Bractea exterior interioribus dimidio brevior ............. petraeum. » $"$ interiores aequans, vel fere superans......... atropatanum.

18. A. avenaceum $\mathrm{m}$.

A. densissime caepitosum, brevirameum; foliis confertis plano-subtriquetris rigidis margine scabris, scapis gracilibus elongatis teretibus glaberrimis ramosis, spicis inferioribus pedunculatis $1-5$ serotinis $3-5$-spiculatis, spiculis superioribus praecocibus sessilibus solitariis omnibus inter se remotis, bractea exteriore ovata 
coriaceo-herbacea acuta, interioribus multo longioribus fusco-membranaceis obtusis calycis tubum superantibus, calycis tubo hirsuto, limbi subtruncati infundibularis nervis concoloribus extus glabris vix mucronato-prominulis.

Hab. in aridis lapidosis montium ad occidentem urbis Meschhed ad pagos Dshegar Gulistan etc. provinciae Chorasan orientalis (Bge. et Bienert!) v. v. sp.

Habitus fere A. tenuiflori; proxima affinitas cum A. scirpoide. Caespites hemisphaerici, densissime horridi; folia vetustiora patentissima vel reversa, juniora patula glaucescentia, $7-10^{\prime \prime \prime}$ longa, basi ${ }^{3 / 2} / 4$ lata, supra planiuscula subtus convexa parce calcareo-punctata, margine denique fere laevigata. Scapi cum inflorescentia saepe pedales vel parum breviores, gracillimi, sed sat firmi, nec fragiles, fere semper pleiostachyi a basi bracteati, bracteis late membranaceo-marginatis longe cuspidatis, scapum arcte amplectentibus pollicem vel sesquipollicem ab invicem remotis. Spiculae semper uniflorae tribracteatae. Bractea exterior lateribus membranacea fusca, versus apicem nervo fusco haud excurrente carinata, nec mucronata, nec aristata, vix ultra $2^{\prime \prime \prime}$ longa; interiores $4^{\prime \prime \prime}$ longae praeter carinam virentem fusco-membranaceae, convolutae omnes glaberrimae. Calyx $4^{1} /_{2}^{\prime \prime \prime}$ longus sensim in limbum purpurascentem brevissime quinquelobum simulque eroso-denticulatum ampliatus; nervi limbi fere semper ad warginem tantum producti, rarius brevissime mucronato-prominuli.

19. A. venustum Boiss.! diagn. s. 1. 7. p. 80. DC. prodr. 1. c. p. 631 . 1. 39. - Statice venusta Fenzl. pl. Kotsch.! St. dianthifolia Jaub. et Sp. illustr. 1. p. 162, et Ann. sc. nat. 1. c. p. 253. ex p. excl. synon. - Limonium orientale humilius caryophylli folio angustiore non aculeato, flore spicato suave rubente. Tournef. Coroll. p. 25.

A. laxe caespitosum, glaucescens, impresso-punctatum, calcareo-squamatum; ramis inferne denudatis, foliis vix acerosis, scapis dense muriculato-scabris, spicae simplicis laxe 8-9-florae subunilateralis rachi subrecta, bracteis interioribus acuminatis apice ad carinam parce hirsutis exteriorem superantibus, calycis $\left(7^{1} /^{\prime \prime \prime}\right.$ longi) tubo sparse piloso, limbo subtruncato mutico.

Hab. in Asia minore (Tournefort) in Tauro cilicico (Kotschy! pl. taur. n. 414) ad plumbi fodinas territorii Güllek; nec non in monte Deve teppe et Pasch Olug alt. $7000^{\prime}$ s. m. in alpibus Bulgardagh Tauri cilicici (Kotschy n. 297! et 247!); in Natoliae (Tschichatschew! in hb. Fisch. nunc. h. b. petrop.) monte Ildysdagh (Wiedemann! hb. h. b. petr.); in monte Elmalu Phrygiae (Bourgeau pl. exs. 295! sub nom. A. laxiflori); in Tauri cataonici monte Berytdagh (Hausknecht!) v. s. sp.

Synonymon Tournefortii supra allatum vix dubie hue spectat, ob folia molliora, spicam (nec capitulum) et calycis colorem, nec plantam in Asia minore ulteriore et Armenia, ut videtur, frequentem, Tournefortium effugisse crediderim. Binis sequentibus affine, sed di- 
versum glancedine, poris in foliis majusculis crebrioribus, foliis latioribus brevioribus ad summum 15 "' longis. Scapi folio duplo longiores. Spicae saepe subarcuato-recurvae; rachis articuli breviores, ad summum tres lineas longi, floribus exinde subimbricatis, saepe unilateralibus. Bractea exterior $3^{\prime \prime \prime}$ longa, glabra, latius coriaceo-herbacea, angustius hyalinomarginata, inter marginem hyalinum et partem coriaceam fulvo-picta. Bractea intima fere $5^{\prime \prime \prime}$ longa, intermediam paulo superans, calycis tubo brevior, utraque valde carinatae et nisi versus apicem carinae parce hirsutae, caeterum glabrae acuminatae et nervo excurrente breviter aristulato-pungens. Calycis tubus limbum aequans, intense purpureus, nervis in basi limbi intensius coloratis, pubescentibus, ante marginem evanescentibus. Folia jam amni praeteriti plerumque detrita, basibus adhuc persistentibus subrevolutis, vetustiora omnino evanida, ideoque rami inferne denudati, saepe elongati. - Planta cataonica paululum differt foliis brevioribus laxioribus, pube scapi molliore, bracteis interioribus ad carinam fere a basi crebrius pubescentibus. Plantam Bourgeaui vix distinctam credo, quamvis calyces pallidiores, et flores serius in rachi, caeterum recta, distichi.

20. A. assyriacum Boiss.! diagn. s. 1. 7. p. 81. DC. prodr. 1. c. p. 632, n. 41.

A. dense caespitosum, viride, minutissime impresso-punctatum vix calcareo-squamulatum, brevirameum, foliis lineari-lanceolatis acerosis, scapis dense breviter patulopubescentibus, spicae simplicis laxae rachi subflexuosa pubescente, bracteis pubescentibus interioribus exteriorem superantibus acuminatis aristulatis, calycis ( $8^{\prime \prime \prime}$ longi) tubo undique prostrato-piloso limbum quinquelobum muticum superante.

Hab. in Assyria inter Mardin et Diarbeckir (Kotschy pl, assyr. n. 313 !) v. s. sp. in hb. amic. Boissier.

Valde affine praecedenti, sed vix glaucescens pallide virens; rami abbreviati foliis vetustis griseo-fuscis reversis obtecti; rosulae hornotinae subelongatae. Folia supra ad medium plana, costato-nervosa, superne canaliculata, pungenti-acuminata, margine dense ciliato-scabra, inferiora breviora, pleraque pollicaria interdum usque ad $14^{\prime \prime \prime}$ longa, basi parum membranaceo-dilatata, linea vix latiora. Scapi folium parum superantes pauci-articulati fragiles; articuli pollice breviores. Spicae laxae pluriflorae, articuli sub anthesi $3-5$ "' longi. Bractea exterior ovato-lanceolata, medio coriaceo-herbacea viridis, latiuscule hyalinomarginata, nervo longe excurrente aristato-acuminata $4^{\prime \prime \prime}$ parum excedens; interiores 5 $5^{1} / 2$ ' longae, intima mediam superante, oblongo-lanceolatae, praeter costam basi latiorem fere omnino hyalino-scariosa. Calycis tubus sensim ampliatus in limbum purpurascentem plicatum, nervis concoloribus extus adpresse pubescentibus ad apices loborum usque productis, nec prominulis. Petala intense rosea ampla limbum calycinum ejus longitudine supereminent.

21. A. Olivieri Boiss.! 1. c. p. 80. Prodr. 1. c. p. 631. n. 40. Statice Olivieri Jaub. et Spach. ill. p. 163 et 168 . tab. 93 ! Ann, sc. nat. 1. c.! 
A. laxe caespitosum, viride, vix impresse punctatum; ramis inferne longe denudatis, foliis linearibus elongatis, scapis glabratis, spicae simplicis laxae subflexuosae articulis vix puberulis, bracteis interioribus pubescentibus exteriore glabrata brevioribus obtusiusculis vel breviter mucronatis, calycis $\left(7^{1} / 2\right.$ "' longi) tubo prostratopiloso limbum obsolete 5-lobum muticum superante.

Hab. in Persia media occidentali inter Kermanschah et Hamadan (Olivier et Bruguière), in Persia (Auch. Eloy. hb. d'or. n. 2512!) v. s. sp. in hb. am. Boissier.

Proxime affine praecedenti et vix specie distinguendum; sed laxius, rami inferne denudati, folia angustiora et longiora saepe bipollicaria, minus conspicue costata, fere graminea, nec rigide acerosa. Articuli spicae longiores; bractea exterior latius membranaceomarginata interdum calycis tubum superans. Calycis limbus magis patens, latior. Caetera discrimina diagnosis indicat. - Lubentius $A$. assyriacum pro varietate A. Olivieri haberem.

22. A. laxiflorum Boiss. herb.; Kotschy pl. syr. exs. n. 128.

A. dumosum, purpurascenti-glaucum, crebre impresse punctatum et calcareo-squamatum; ramis elongatis basi denudatis, foliis carnosulis enerviis subito in spinulam tenerrimam fuscam contractis mox diffractis basibus extus trinerviis revolutis persistentibus, scapo rachique glaberrimis, spica simplici laxissima subrecta, bracteis interioribus exteriorem superantibus glaberrimis acuminato-cuspidatis, calycis (subsemipollicaris) tubo patulo piloso limbum pallide rubentem nervis atropurpureis vix ad marginem productis muticum obsolete 5-lobum superante.

Habitat in monte Amano Syriae borealis (Kotschy!) v. s. sp. in hb. Boiss.

Affine $\Lambda$. venusto, magis differt ab $A$. petraeo, signis in diagnosi indicatis. Rosulae paucifoliae elongatae. Folia exsiccata fragilia, triquetro-subplana versus apicem canaliculata, margine dense ciliolato-scabra, vix unquam pollice longiora, lineam lata. Scapi sine spica folium aequantes. Spicae articuli infimi $8^{\prime \prime \prime}$ longi, etiam superiores 4-lineares. Bractea exterior ovata medio late et crasse coriaceo-herbacea purpurascenti-atroviridis subito in marginem hyalinum latiusculum dilatata, apice nervo excurrente breviter aristulata vix $4^{\prime \prime \prime}$ longa; interiores medio coriaceo-scariosae fuscae, margine praesertim superne late hyalinae, oblongo-lanceolatae, nervo longius excurrente acuminato-cuspidatae, intima paulo longior calycis tubum aequans. Calycis limbus patentim ampliatus.

23. A. petraeum Boiss. herb.! et Kotschy it. cil. kurdicum 1859. pl, exs. n. 379!

A. densisssime caespitosum, glaucum, impresse punctatum calcareo-squamatum; ramis abbreviatis foliis retustis reverso imbricatis dense obsessis, foliis lanceolatis plurinerviis pungenti-acerosis, scapo rachique fragillima flexuosa glaberrimis, spica simplici laxissima, bracteis glaberrimis exteriore brevi scariosa, intermedia multo longiore obtusiuscula praeter costam excurrentem hyalina, intima hanc excedente basi viridi rigidiore calycis tubum superante submutica, calycis $\left(6^{\prime \prime \prime}\right.$ longi) tubo 
parce puberulo subito in limbum pallide roseum obsolete quinquelobum nervis puberulis purpureis ad marginem productis muticum ampliato.

Habitat in Kurdistaniae provincia Musch, in districtu Warto, ad pedem meridionalem montis Bimgüll, in rupestribus trachyticis supra Goschkar, 6800' s. m. (Kotschy!), in finitimis Persiae occidentalis vel in Kurdistano persico prope Pir-omar-gudrun (Hausknecht pl. exs. n. 832 !) v. s. sp.

Folia vetusta brunnea, hornotina dense rosulata, patula, praeter apicem plana, margine scabra, $6-8^{\prime \prime \prime}$ longa, raro pollicaria, basi linea parum angustiora. Scapi sine spica folia parum superantes, articulo infimo circiter $10^{\prime \prime \prime}$ longo persistente, squamis omnino fere scariosis ovatis aristato-acuminatis pallidis. Articuli spicae inferiores semipollicares, summi $3-4^{\prime \prime \prime}$ longi. Bractea exterior ovata vix ultra $2 \frac{1}{2}{ }_{2}^{\prime \prime \prime}$ longa, breviter et molliter aristulata, intermedia oblonga $4^{\prime \prime \prime}$ longa, intima vix aristulata costa latiore basi late viridi rigidior. Calycis tubus $3 \frac{1}{2}$ longus, limbus valde expanșus.

\section{A. atropatanum $\mathrm{m}$.}

A. dense caespitosum, valde glaucum, tenuiter impresso-punctatum, calcareo-squamulosum; ramis brevissimis confertis foliis vetustis patulis reversisve dense obsessis, folis hornotinis rigide acerosis lanceolato-linearibus pungentibus, scapo rachique anfractuosa glaberrimis, spica simplici laxișsima disticha 3-8-spiculata, bracteis subaequalibus glaberrimis scariosis late hyalino-marginatis, intima obtusa calycis tubum vix superante, calycis $\left(6 \frac{1}{2} /\right.$ longi) tubo dense patulo piloso limbum roseum expansum obiter quinquelobum nervis atropurpureis ante marginem evanidis muticum aequante.

Habitat in montosis aridis Persiae borealis transelbrusensis inter Turkmentschai et Tikmedescht (Bge. et Bienert!) v. v. sp.

Affine A. petraeo, sed magis glaucum, et bractearum proportione et consistentia diversum. Rosulae numerosae, folia conformia versus apicem canaliculato-triquetra, margine ciliato scabra, semipollicaria vel vetustiora usque ad $10^{\prime \prime \prime}$ longa, basi parum dilatata $3 / 4$ "' lata membranacea. Scapi e quavis rosula solitarii cum spica florida $2-3$-pollicares, parte sterili pollicem parum excedente, plerumque unibracteati, bractea fere omnino scariosa ad medium late hyalino-marginata, abhinc longe aristato-acuminata pungens, patula. Spicae articuli inferiores $4^{\prime \prime \prime}$, summi vix $2^{\prime \prime \prime}$ excedentes. Bractea exterior scariosa medio subcoriacea aequaliter late marginata, ovato-lanceolata, dorso basi rotundata, apice costa brevissime excurrente acuta $3 \frac{1}{2}-4^{\prime \prime \prime}$ longa; intermedia vix brevior obtusiuscula, praeter carinam acutam breviter excurrentem hyalina; intima paulo longior vix mucronulata $4^{\prime \prime \prime}$ longa. Corolla intense rosea, parte exserta limbo calycino brevior.

25. A. senganense m.

A. dense caespitosum, glaucum, minute impresso-punctatum, parce calcareo-squamosum; ramis brevissimis foliis vetustis dense tectis, scapis scabriusculis, rachi sub- 
recta intus scabra, spica simplici laxissima 3 -6-flora subunilaterali, bracteis glaberrimis omnino hyalinis obtusis bilobisve interioribus multo longioribus, calycis ( $5^{\prime \prime \prime}$ longi) tubo prostrato-hispido sensim in limbum truncatum nervis pallidis extus glabris ad marginem productis muticum dilatato.

Habitat in montosis aridis Persiae borealis transelbrusensis inter Chorum-derreh, Sultanieh et Sengan (Bge. et Bienert!) v. v. sp.

Valde affine praecedenti, sed praeter characteres indicatos differt, foliis angustioribus, bractea exteriore multo latiore et breviore basi fere auriculato-hyalino-dilatata. Totius seriei gracillima species, folia vetusta reversa, hornotina in rosulis conferta e basi latiuscule hyalino-marginata ciliata anguste linearia, margine scaberrima, apice longe aceroso-pungentia, planiuscula, apicem versus costa subtus prominente trigona, supra anguste canaliculata, ad summum $8-9^{\prime \prime \prime}$ longa, infima rosulae breviora, supra basin vix ${ }^{1 / 2}$ ' lata. Scapi multo graciliores quam in pracedente, sine spica vix unquam bipollicares plerumque breviores, bracteis $2-3$ fere omnino membranaceis, basi late hyalinis praediti. Spicae $1-2-$ pollicaris articuli inferiores $5^{\prime \prime \prime}$ longi, ad basin spicularum intus parce scabri. Bractea exterior pallide straminea late subauriculato-hyalino-membranacea $2^{1} / 2^{\prime \prime \prime}$ Ionga, costa pallida. Bractea intermedia longior praeter nervum apice brevissime excurrentem viridem omnino scariosa pallide straninea apice obtusa hyalino-marginata; intima similis sed paulo longior $3 \frac{1}{2} 2^{\prime \prime \prime}$ longa, calycis tubum subsuperans, et costa pallida. Calycis limbus minus patens. Corolla rosea parte exserta limbum calycinum aequans.

26. A. Calverti Boiss.! diagn. ser. 2. n. 4. p. 65.

A. caespitosum, viride, minutissime impresso-punctatum, vix calcareo-squamosum; ramis parum elongatis basibus foliorum revolutis tectis, foliis anguste longe linearibus tenue brevissime mucronatis molliusculis, scapis folia superantibus pubescentibus $1-2$ stachyis, spicis ovatis dense distichis $5-7$ spiculatis, bracteis herbaceo-glumaceis basi puberulis subaequilongis, calycis (5 $\frac{1}{2}$ "' longi) tubo puberulo sensim in limbum roseum nervis nigris ad marginem usque productis muticum obsolete lobatum ampliato.

Hab in Armeniae monte Tesch-dagh prope Erserum (Calvert! pl. exs. n. 517) vidi s. sp. unicum specimen in hb am. Boissier.

Vix dubitarem huc spectare synonymon Tournefortii Ćoroll. 25.: "Limonium orientale "caryophylli folio acutissimo, floribus velut in capitulum congestis acaulon et calyce pur"purascente»; ideoque etiam Statice Tourncfortii Spach 1. c. tab 90. Cel. Spach conjunxit duas plirases Tournefortianas, discrimen e calycis colore depromtum negligens et omittens; alia nempe phrasis, "calyce albo" vix dubie ad A. glumaceum, A. Calverti proximum. spectat; phrasis vero a Spachio A. glumaceo attributa, ut jam supra monui, certissime A. venustum indicat. Icon. Spachiana, 1. c. tab. 90., sat bene convenit etiam foliis inferioribus laxe recurvis cum nostra planta, praeter scapos abbreviatos quod vero variare solet, et in 
specimine Tournefortiano forsan a statu jurenili pendet. In descriptione calyx dicitur riolaceo-hyalinus. Cum vero mihi occasio defuit inspiciendi specimen Tournefortianum, rem dijudicare non audeo et nomen Boissierianum servo. - Scapus gracilis sub spica unibracteatus. Folia sesquipollicaria. Bracteae medio virides margine fuscescenti-membranaceae. Melius forsan collocaretur inter Androsacea, nam flores quidem A. venusti, caetera vero omnia A. glumacei!

\section{Series 2. Caryophyllacea.}

Spicae elongatae laxae. Calyces albi vel hyalini, $4^{1} / 2$ "' longi vel longiores.

Hąbitant in Asia minore, Armenia, Syria et in regionibus transcaucasicis; orientaliores plagas fugiunt. A. tenuiflorum, A. lepturoidi proxime aftine inter Caryophyllacea et Microcalycina intermedium huc ductum ob calyces ultra 4 lineas longos.

Clavis specierum diagnostica.

1. Scapi di- pleiostachyi, rachis glaberrima. 2.

") semper monostachyi, rachis articuli intus scabro-pubescentes. 3 .

2. rami brevissimi, rachis subrecta firma, spicae $3-5$, bractea exterior interioribus acerosis brevior, calyx $4 \frac{1}{2}-5^{\prime \prime \prime}$ longus .... A. tenuiflorum.

» elongati, rachis flexuosa fragillima, spicae geminatae, bractea exterior interiores obtusas aristulatas calycisque $6^{\prime \prime \prime}$ longi tu-

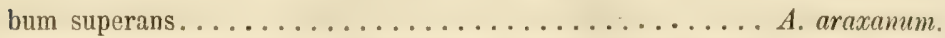

3. folia tota superficie scabra, bracteae pubescentes, rachis undique scabra $A$. carymplyllaceum. " praeter marginem glabra. 4 .

4. atro-viride, dumosum, rachis valde flexuosa........... Listoniae. pallide virentia vel glaucescentia vel glauca. 5 .

5. Spicae laxae anfractuosae distichae articuli bracteas exteriores aequantes vel superantes. 6 .

" imbricatae subrectae articuli bracteis exterioribus breviores. 7 .

6. glaucescens, rami elongati, scapi folia superantes, spicae 15-20spiculatae, bracteae exteriores dorso virentes, interiores anguste membranaceo-marginatae acuminatae, petalorum pars exserta limbo calycis brevior ............... acerosum.

purpurascenti-glaucum, rami abbreviati, scapi folio breviores, spicae 7-12-spiculatae, bractea exterior purpurascenti-glanca, interiores late membranace -marginatae obtusae cuspidatae, petalorum pars exserta limbo calycino longior........... Pinardi.

7. Limbus calycis nervis pallidis concolor, valde glaucum, scapi abbreviati, muriculato-asperi, folia plana lanceolata......... Kotschyi. calycinus byalino-pellucidus, nervi nigri vel atropurpurei. 8 . 
8. Dumosum, ramis rosulisque elongatis, folia elongata rigida lineari-

triquetra, bracteae subaequales, spicae $4-7$-spiculatae..... A. libanoticum. Caespitosa, rami abbreviati folia plana. 9.

9. Folia valde glauca, calycis $6^{\prime \prime \prime}$ longi limbus omnino truncatus.....A. armenum. folia virenti-subglaucescentia, calycis $5^{\prime \prime \prime}$ longi limbus 5-lobus. 10.

10. Scapi unibracteati folio breviores, bractea exterior late hyalino-marginata, ferrugineo-picta, interiores longiores, fol. $1-1 \frac{1}{2}$-pollic. A. Balansae.

" pluribracteati folio longiores, bractea exterior anguste marginata purpurascens interiores aequilongae, folia $7-9^{\prime \prime \prime}$ longa. . A. Hausknechti.

27. A. tenuiflorum Boiss. diagn. s. 1. 7. p. 78. DC. prodr. 1. c. p. 630. n. 33. excl. syn. M. a Bieb. St. acerosa Hohenack. Enum. Elisab. in Bull. mosq. 1833. p. 227. Enum. talysch. in Bull. mosq. 1838. p. 262. Led. fl. ross. III. p. 470 . ex p. non Willd nec M. a Bieb. Statice Echinus L. Codex. n. 2194. ex p. Limonium spicatum foliis aculeatis Buxb. cent. 2. p. 18. tab. 10.

A. glaucum, minute punctatum, calcareo-lepidotum, brevirameum; foliis angustissime linearibus acerosissimis vetustis dense reverso-imbricatis praeter marginem glabris, scapis gracillimis glaberrimis folio multoties longioribus di-pentastachyis, spicis laxissimis rachi glaberrima rectis remote $3-12$ spiculatis, bractea exteriore interioribus acerosis breviore, intima calycis tubum aequante, calycis $\left(4^{1} / 2-5^{\prime \prime \prime} 1\right.$.) tubo sparse patulo hirsuto limbum albidum obsolete 5-lobum nervis fuscis glabris ante marginem evanidis muticum superante.

Hab. in Transcaucasiae montosis apricis, inter Gandsha et Schemacha (Buxbaum) in montibus calcareis prope pagum Chanachlaer districtus Airum (Kolenati pl. exs. n. 1736!), in collibus apricis lapidosis prope coloniam Helenendorf (Hohenacker!) et in tractu Suwant (Holenacker!) v. s. sp.

Species habitu et characteribus valde constans, diu confusa cum A. lepturoide, i e. Stat. acerosa M. a Bieb. nec Willd, a Buxbaumio detecta et a Linnaeo sub nomine Statices Echini cum Echino Alpini mixta. E radice lignosa simplici multicipiti, caespites brevissimi pauci; rami novelli steriles annotini subelongati, rosulae floridae confertae foliis vetustis densissime revers 0 -imbricatis, junioribus squarroso-patentissimis margine scaberrimis, subtriquetris, plerumque $8-10^{\prime \prime \prime}$ longis, raro pollicaribus, $1 / 3^{\prime \prime \prime}$ latis, rarius usque ad $1 / 2$ '" latis. Scapi teretes sine inflorescentia $3-5$-pollicares, minus fragiles, squanis $5-7$ ab invicem remotis angustis arcte amplectentibus latiuscule albo-marginatis, pungenti cuspidatis vestiti. Inflorescentia ipsa saepe plus quam semipedalis constaus e spica terminali praecoirere elongata recta nec flexuosa $5-12$ spiculata, spiculis inter se plus quam tota earum longitudine remotis, et spicis $1-3$ lougius pedunculatis serius floridis paucius-spiculatis. Bractea exterior ovato-lanceolata aceroso-acuminata medio coriacea, margine albo-membranacea patula circiter $2 \%_{2}^{\prime \prime \prime}$ longa; interiores praeter costam fuscam aceroso-productam fere omnino 
membranaceae, media exteriorem, intima mediam superans. Calycis limbus parum expansus, diu plicatus. Petala pallide rubicunda, parte exserta fere limbo calycis longiora.

28. A. araxamum $\mathrm{m}$.

A. glaucescens, impresse punctatum et dense calcareo-squamulatum; ramis elongatis, foliis elongato-lineari-triquetris longe pungenti-acerosis vetustis reversis praeter marginem glabris, scapis crassiusculis teretibus glaberrimis folium parum superantibus mono-, saepius distachyis, spicis fragillimis subbinis altera breviore $2-3$-altera longiore 7-10-spiculata, rachi flexuosa glaberrima, spiculis longitudine bractearum $\mathrm{ab}$ invicem distantibus, bractea exteriore interiores et calycis tubum superante, interioribus obtusis eroso-denticulatis praeter nervum aristulato-excurrentem membranaceis, calycis ( $6^{\prime \prime \prime}$ longi) tubo patule piloso limbum album subtruncatum nervis purpureis ad marginem productis muticum superante.

Habitat in apricis siccis ad Araxem, et in districtu Choi provinciae atropatanae Persiae boreali-occidentalis (Szovits!) v. s. sp.

Rami crassi subelongati, folia patentissima, vetustiora reversa, basi dilatata anguste membranaceo-marginata quinquenervia, inferiora breviora paulo latiora plana fere lineam lata, superiora bipollicaria vel longiora triquetra angusta, margine scaberrima. Scapi e rosula saepius bini atropurpurei, bracteati, bracteae longe acuminatae, praeter costam purpurascentem fere 'omnino membranaceae 5 "' longae. Spicae coaetaneae. Bractea exterior ovato-lanceolata acuminata pungens, medio coriaceo-herbacea $4-4^{1} / 2_{2}^{\prime \prime \prime}$ longa, margine late alђo-membranacea, glaberrima. Bracteae interiores oblongae vix $4^{\prime \prime \prime}$ longae, costa purpurascente, ex apice in aristam longiusculam excurrente. Calycis tubus $3^{1} / 2$ '" longus, limbus $2^{1} / 2^{\prime \prime \prime}$. Corolla $8^{\prime \prime \prime}$ longa fere tribus lineis calycis limbum supereminens, petalis obovatis retusis.

I. ter A. acerosum et lepturoides medium, ab illo jam rachi laevissima, ab hoc floribus magnis foliisque valde elongatis praeter alia facile distincta.

29. A. acerosum Boiss. Diagn. ser. 1. 7. p. 80. Statice acerosa Willd. neue Schr. d. Gesellsch. naturf. Fr. III. p. 420. Spach, ill. pl. or. tab. 94. non M. a Bieb. Ledeb. al. - Acantholimon phrygium Boiss. diagn. 7.p. 79. DC. prodr. 1. c. n. 41. Limonium orientale frutescens Caryophylli folio in aculeum rigidissimum abeunte Tournef. Coroll. p. 25.

A. dumoso-erinaceum, glaucescens, grosse impresso-punctatum, calcareo-squamulatum; ramis elongatis, foliis longissimis acerosissimis plano-triquetris praeter marginem glabris, scapis monostachyis folio longioribus, spica laxa elongata multispiculata, rachi flexuosa scabra, bractea exteriore dorso virente triangulari acuminata breviore interioribus anguste membranaceo-marginatis calycis tubum superantibus acuminatis crasse compresse costatis, calycis $\left(6^{1} / 2-7^{\prime \prime \prime}\right.$ longi) tubo 
limbum rubrinervium subtruncatum muticum superante, petalorum parte exserta limbo calycino breviore.

Hab., ut videtur, frequens in Asia minore (Tournefort), in Galatia (Sestini!), in regione alpina montium Lydiae, Sipylo, Tmolo (Boissier!), inter Kiutaja et Argani Phrygiae (Mitchell); in Cariae monte Cadmo (Jaubert); prope Caesaream (Wiedemann!); prope Safranbol (idem!), in Tauri cataonici monte Baltun-dagh (Hausknecht!); in alpibus Bulgar-dagh Tauri cilicici, in monte Castelli Güllek et inferiore parte vallis Gusguta alt. $5000^{\prime}$ s. m. (Kotschy! pl. exs. sub nom. A. Piuardi Boiss. var. n. 99 et 267).

Vidi specimina a Willdenowio communicata sub nomine Staticis acerosae, quae omnino congruunt cum A. phrygio Boissieri. Specimen herb. Stephaniani nunc hort. bot. petrop. "ex dono Willdenowii» compositum e spicis 2 solutis St. acerosae, et e caespitibus foliorum A. lepturoidis. Diagnosin feci ad specimina Boissieriana in monte Sipylo collecta, a quibus specimina e Tmolo vix discrepant rosulis magis elongatis laxioribus, foliis minus glaucis, angustioribus longioribus fere tripollicaribus, spicis densioril)us minus flexuosis et bracteis interioribus eximie compressis. Planta Wiedemanni prope Caesaream lecta convenit cum planta tmolea foliis, sed (quia junior floribus vix expansis?) spica densior usque ad 20-flora, rachis adhuc recta, bracteae exteriores fere aequantes, calyces breviores. Longius distat planta Kotschyana e Tauro cilicico, magis glauca, rosulis densioribus, foliis multo brevioribus, nervis limbi calycini pallidioribus, praesertim vero bractea exteriore intimas omnino aequante, hisce rufescentibus nec viridibus; planta simul cun hac sub fin 99 edita spicis paucifloris differens videtur forma depauperata; has ut varietatem brachyphyllam distinguit amiciss. Boissier. Huic onnino congrua planta Hauslinechti. Transitum quasi faciunt ad A. Kotschyi. Omnes hae formae longius distant a planta Kurdistana quam nomine A. caryophyllacei designavit Boissier. Confer etiam Boiss. diagn. ser. 2, n. 4. p. 66. in adnot. ad A. caesareum.

30. A. Pinardi Boiss. diagn. 7. p. 79. DU. prodr. 1. c. n. 38. Statice caryophyllacea Boiss. in Pinard pl, exs. 1843.

A. caespitosum, purpurascenti-glaucum, impresse punctatum, calcareo-squamulatum; ramis abbreviatis, foliis lanceolato-linearibus longe aceroso-pungentibus praeter marginem glabris rigidissimis, scapo monostachyo folio breviori, spicae laxe $7-12$ spiculatae rachi subrecta scabriuscula, bractea exteriore purpurascenti-glauca, interioribus longioribus late membranaceo-marginatis obtusis cuspidatis, calycis ( $7^{\prime \prime \prime}$ longi) tubo limbum rubrinervium obsolete 5-lobum mucronulatum hyalinum superante, petalorum parte exserta limbum calycinum superante.

Habitat in Asiae minoris provincia Caria interiore (Pinard!) v. s. sp.

Praecedenti nimis affinis, mihi tantum e paucis speciminibus nota. 
31. A. Listonáae Boiss. in DC. prodr. 1. c. n. 37.

"A. dumosum; ramis basi longe denudatis annotinis elongato-rosulatis, foliis atro"virentibus brevibus planis latis rigidissimis acerosis, scapo folia vix aequante, aspica brevi recta laxiuscule disticha $7-11$-spiculata, rachi flexuosissima, bracteis "atrovirentibus acuminatis albo-marginatis, inferiore aliis paulo breviore.

"Habitat in Asia minori septentrionali (Lady Liston in herb. Hook.).

"Folia $9-12^{\prime \prime}$ longa, basi lineam lata. Spicae $1 \frac{1}{2}-2$-poll. Calyx 3 "' longus. Valde "affine A. plrygio et forsan ejus var., tamen facies diversa, folia atrovirentia, caules basi "denudati, folia et spicae breviora, flores minores." Boiss. 1. c. Non vidi.

32. A. Kotschyi Boiss. diagn. 7. p. 74. DC. prodr. 1. c. p. 628. n. 23. Statice Kotschyi Jaub. et Spach. 1. c. Acanthol. breviscapum Hauskn, pl. syriaco-armen. A. armenum var. Balansae. Hauskn. pl. syr. arm.

A. dense caespitosum, valde glaucum, minute punctatum, dense calcareo squamulatum: ramis abbréviatis foliis reversis tectis, foliis junioribus lanceolatis brevibus rigide acerosis praeter marginem glabris, scapis muriculato-scabris monostachyis, spicis laxiuscule imbricatis subrectis $8-16$-floris elongatis, bracteis subaequilongis calycis tubum pilosum aequantibus, exteriore triangulari-lanceolata margine anguste scariosa, interioribus praeter costam membranaceis acuminato-cuspidatis, limbi calycini concoloris mutici nervis pallidis ad marginem productis, corolla pallide carnea.

Hab. in Tauro Cilicico (Kotschy it. 1836.n. 416!), in alpibus Bulgar-dagh, in valle Karli Boghas versus jugum Ketsiebele alt. 5500' s. m. (Kotsch. it 1853. n. 136!), in Lycaoniae collibus aridis ad planitiem Koniah (Heldreich!), in Anatolia (Tschichatschew! in hb. Fisch.), in Tauri cataonici monte Berytdagh (Hausknecht! sub nomine A. breviscapi); ibidem (Hausknecht! sub nom. A. armeni var. Balansae) v. s. sp.

Species calycibus concoloribus distinctissima, at valde variabilis quoad habitum et spicas pauci-vel plurifloras, plus minusve elongatas, juniores subunilaterales tunc demum distichas. Formae tres praecipue distinguendae:

a. cilicicum foliis $7-8^{\prime \prime \prime}$ longis, bractea exteriore paulo breviore, scapis brevissimis, spica pauciflora. Huc planta Kotschyana et A. breviscapum Hauskn.

3. iconium foliis $9-11^{\prime \prime \prime}$ longis angustioribus, bractea exteriore paulo breviore, scapis folio brevioribus spica usque ad 16 -flora. Specimina Heldreichiana.

$\gamma$. catconicum fol. $12-18^{\prime \prime \prime}$ longis, bractea exteriore paulo longiore calycis tubum superante, scapi folium subsuperantes, spica subflexuosa laxior disticha 8-12flora; planta Hausknechti sub nomine A. armeni var. Balansae. Huc etiam spectare videntur ex parte specimina a Bourgeau in Armenia prope Baibut collecta et sub jo: 235 simul cum A. armeno distributa, a quo differunt calyce vix diaphano concolore, nec hyalino rubrivenio, et ni fallor, corollae colore. 
33. A. armenum Boiss, diagn. ser. 2. n. 4. p. 64.

A. glaucum, impresso punctatum, calcareo-lepidotum, brevirameum, caespitosum; foliis lanceolato-acerosis vetustis nigricantibus patentissimis praeter marginem scaberrimum glabris, scapis folia aequantibus rachique subrecta glaberrimis monostachyis, spicis elongatis $12-15$-spiculatis imbricatis, bracteis lanceolatis subaequalibus aceroso-longe acuminatis albo marginatis glaberrimis, calycis $\left(6^{\prime \prime \prime} 1.\right)$ tubo parce hirto sensim in limbum truncatum nervis rubris adpresse pubescentibus ante marginem evanidis muticum hyalinum longiorem dilatato, petalis roseis.

Hab. in apricis montium Tesch-dagh Armeniae prope Erserum (Huet de Pavillon!), prope Baibut (Bourgeau! ex p.), in provinc. transcaucasicis prope Azkur? (Radde!) v.s. sp.

Folia vix $10^{\prime \prime \prime}$ longa, basi linea parum angustiora. Bracteae $4^{\prime \prime \prime}$ longae subaequales. Spicae $1 \frac{1}{2}-2$-pollicares. Planta baibutensis (excl. specim. ad A. Kotschyi spectantibus) et Raddeana, cujus ultimae unicum vidi specimen incompletum, paululum discrepant rachi minutissime scabra.

34. A. Bulansac Boiss.! in Bal. pl. exs. auni 1856 ! A. armenum $\beta$. Balansae Boiss, diagn. ser. 2. n. 4. p. 64 .

A. subglaucescenti-virens, minute impresso punctatum, vix calcareo-lepidotum, brevirameum, caespitosum; foliis lineari-triquetris elongatis acerosis vetustis fulvescentibus patentibus praeter marginem glabris, scapis folia subaequantibus unibracteatis rachique recta scabriusculis monostachyis, spicis imbricatis, bractea exteriore late marginata ferrugineo picta interioribus breviore, calycis ( $5^{\prime \prime \prime}$ longi) tubo hispidulo subito in limbum breviorem 5-lobum nervis fuscescenti-purpureis subglabris ultra marginem brevissime productis mucronulatum dilatato, petalis carneis.

Habitat in Cappadocia, in monte Aslan-dagh Antitauri ad orientem Caesareae (Balansa!) v. s. sp. comm. ab amic. Boissier.

Notis indicatis abunde diversum videtur ab A. armeno. Folia angustiora longiora extus basi ferruginea, omnino evoluta usque ad 16 "' longa, linea dimidia parum latiora. Bracteae exteriores latiores basi latius virides, intra marginem latiorem hyalinum fusco pictae, nec ut in vero armeno subconcolores; bracteae interiores magis exteriorem superantes et tubum calycis excedentes. Calycis tubus multo brevior, crassior, non sensim, sed subito in limbum ampliatus, limbus ipse magis patens.

35. A. caryophyllaceum Boiss. diagnos. ser 1. n. 7. p. 78, excl, var. $\beta$. DC. prodr. l. c. p. 630. n. 35. exclus. synon. pluribus. Statice caryophyllacea Boiss. in Kotschy alepp. kurd. moss. n. 368 !

A. viride, caespitosum, minutissime impresso punctatum; squamulis calcareis nullis, ramis basi denudatis subelongatis, foliis elongato-lineari-trigonis undique muriculato-scabris (!), scapis folio longioribus minute villosulis monostachyis, rachi recta 
intus hispidula, spicis elongatis laxis multifloris, bractea exteriore breviore, interioribus pubescentibus calycis tubum aequantibus, calycis ( $6^{\prime \prime \prime}$ Iongi) tubo hispidulo aequante limbum ampliatum obsolete 5-lobum nervis purpureis ad marginem productis muticum, petalis calycem vix superantibus.

Hab. in rupestribus montis Gara Kurdistaniae (Kotschy!), in provinciae Müsch districtu Warto ad radices australes montis Bimgöll inter Koweg et pagum Gestemert, alt. 5000' s. m. (Kotschy it. cil. kurd. n'. 315 !) v. s. sp.

Facillime distinctum foliis tota superficie, praesertim subtus, muriculis minutis obtectis. Folia hornotina primaria plana supra basin angustata, apicem versus paulo dilatata subinermia, caetera trigona vel triquetra acerosa quidem, sed minus rigida quam in affinibus nec stricte recta sed arcuato-recurva. Anic. Boissier (diagn. ser 2. n. 4. p. 66) in adnotatione ad Ac caesareum, Ac. phrygium forsan ab A. caryophyllaceo haud differre credit, at foliorum color, superficies, consistentia, scapi et bractearum indumentum omnino diversa.

36. A. Hausknechti m. Ac. caryophyllaceum Hauskn. pl. exs. it. syr. arm. 1865 !

A. glaucescens, impresso punctatum, vix calcareo-squamulosum, brevirameum dense caespitosum; foliis lanceolato-linearibus rigidissime acerosis praeter marginem glabris, scapis firmis rigidis folio subduplo longioribus pluribracteatis puberulis monostachyis, spicis brevibus laxiuscule 3-7-spiculatis, rachis rectae articulis hinc velutino-pubescentibus, bractea exteriore ovata obsolete carinata latiuscule lyalino cincta acuminato-cuspidata, interioribusque vix longioribus praeter carinam albo-hyalinis breviter mucronatis glaberrimis, calycis ( $5^{\prime \prime \prime}$ longi) tubo hispidulo subito in limbum obsolete 10 -lobum rubrinervium muticum ampliato, petalis limbum paulo excedentibus.

Hab. in monte Akerdagh Tauri catronici (Hausknecht!) v. s. sp. comm, ab amic. Boissier.

Ab A. caryophyllaceo omnino distinctum, habitu potius ad Ac. armenum accedens. Rami lignescentes breves flexuosi, foliis anni praeteriti confertis, vetustioribus maxima parte detritis. Rosulae hornotinae breves. Folia basi parum dilatata $7-9^{\prime \prime \prime}$ longa, versus basin $2 / 3-3 / 4$ "'lata, apicem versus subcanaliculata, subtus carinata sensim in cuspidem brevem pungentem acuminata. Bracteae scapi ovato-lanceolatae, basi latiusculae membranaceosubundulato-marginatae, carinatae acuminato-aristatae. Spiculae subunilaterales, inferiores 2 lineis ab invicem remotis. Bractea exterior vix ultra $3^{\prime \prime \prime}$ longa medio coriaceo-herbacea purpurascens, intra marginem hyalinum subrufescenti picta, cuspide canaliculato fusco. Bractea intermedia praeter carinam atropurpuream fere omnino albo-hyalina, intima basi paulo latius membranacea, utraque atropurpureo mucronata. Nervi limbi extus adpresse pubescentes sursum attenuati vix ad apicem loborum majorum producti. 
37. Ac. libanoticum Boiss. DC. prodr. 1. c. p. 630. n. 34. A. caryophyllaceum var. brachystachyum Boiss. diagn. 7. p. 79.

A. subglaucescens, minutissime punctatum; squamis calcareis subnullis, dumulosum, ramis rosulisque subelongatis, foliis vetustis squarroso-patulis, novellis rigidissimis triquetris praeter marginem glabris, scapis folia aequantibus puberulis monostachyis, spicis subconfertis $4-7$-spiculatis, rachi stricta scabra, bracteis aequelongis glabris, exteriore coriacea longe aceroso-acuminata, interioribus obtusis costa producta abrupte cuspidatis calycis $\left(6^{\prime \prime \prime} 1\right.$.) tubum hispidulum aequantibus, limbo dilatato obsolete 5-lobo nervis purpureo-fuseis extus glabris ultra marginem productis mucronulato.

Hab, in Syria in cacuminibus Libani et in regione media Libani ad Cedros et in declivitate orientali circa Ainete (Boissier! Pinard! Aucher Eloy. hb. or. n. 2507 !) v. s. sp.

\section{Series 3. Androsacen.}

Spiculae confertae capitatae rachi abbreviata, raro paulo elongata. Calyces albi vel hyalini $4^{1}{ }_{2}^{\prime \prime \prime}$ longi vel longiores.

Habitant praesertim in Graecia, Asia minore et Syria, rarescentia in Armenia et Persia occidentali, et ad fines boreales et boreali-orientales totius areae, denique in Cabulistano rarissima, omnia fere proxime inter se affinia et vix nisi patria facile distinguenda.

\section{Clavis specierum diagnoslica.}

1. Glaucescentia vel glauca, folia distincte impresso-punctata et calcareolepidota. 2.

viridia rel vix glaucescentia, minutissime vel vix impresso-punctata et vix ac ne vix quidem calcareo-lepidota. 4.

2. Scapus et rachis pubescentes. 3 .

" " $\quad$ glabri, scapi gracillimi elongati 1-raro 2-stachyi, bractea inferior ovato-subrotunda brevissima obtusa .... A. Bodeanum.

3. Folia dense rosulata rigida acerosa diu persistentia vetustiora refracta,

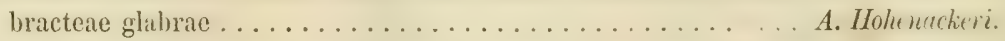

" pauca laxe rosulata carnosula in mucronem contracta mox diffracta, basibus revolutis persistentibus, bracteae velutinae......... A. Hutii.

4. Scapus et rachis glabri, nervi limbi calycini extus glabri. 5 .

" vel rachis pubescens. 9 .

5. Folia basi margine albo-hyalino lato longe producto ciliato cincta, rami elongati, scapi folium superantes, spicae solitariae pauciflorae, bractea exterior longe cuspidata, interiores latissime albido-hyalinae obtusae aristatae calycis tubum late amplec-

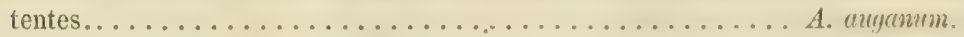


Folia basi breviter anguste fusco membranaceo-dilatata, bracteae interiores atropurpureo pictae. 6 .

fi. rami plus minus elongati. 7 .

" brevissime densissime pulvinato-caespitosi, scapi folio breviores, bracteae subaequales calycis tubum superantes, calycis limbus obsolete 10 -lobus nervis obtuse prominulis........... Wiedemanni.

7. folia margine a basi dense longiuscule ciliolata elongata rigida, scapus folia superans, calycis limbus truncatus............. sahendicum.

" basin versus fere omnino eciliolata, margine minutissime scabra calycis limbus quinquelobus. 8.

8. Rami tenues flexuosi, folia lineari-planiuscula graminea, rosulae hor-

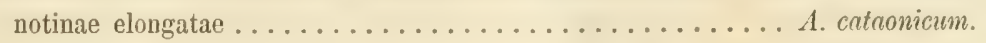

„ crassi rigidi, folia rigide triquetra abbreviata, rosulae hornotinae

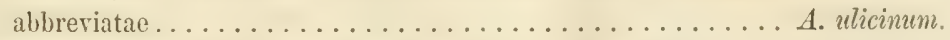

9. Bracteae pubescentes, vel saltem intima ad carinam hispidula. 10.

1) glaberrimae. 13 .

10. Scapi monocephali abbreviati vel brevissimi. 11 .

n conferte di- tristachyi elongati.................. glumaceum.

11. Bracteae interiores acuminato-cuspidatae, folia rigida lin.-lanceolata . A. Echinus.

" $\quad$ obtusae vel bilobae, subito ex apice, vel infra apicem vel inter lobos aristulatae. 12.

12. Folia rigida longe pungenti-mucronata subglabra, bracteae interiores inter lobos aristulatae ....................... lycaonicum. folia subgraminea breviter mucronata pubescentia, bracteae interiores sul) apice aristulatae. ...................... puberulum.

13. Bracteae interiores calycis $\left(6^{1} /_{2}^{\prime \prime \prime}\right.$ longi) tubo breviores, scapus foliis 3-4-plo longior subdistachyus, spicae elongatae........ A. caesareum. " interiores calycis $\left(4^{1} /{ }^{\prime \prime \prime}\right.$ longi) tubum superantes, scapus folia subaequans monostachyus, spicae breves oblongae........ Alatrovicum.

38. A. auganum $\mathrm{m}$.

A. viride, sparse tenuissime punctatum, esquamatum, glabrum; ramis subelongatis, foliis anguste linearibus acerosis strictis a basi longe latiuscule hyalino-marginatis, scapis gracilibus folia superantibus glabris monocephalis, capituli conferti rachi brevissima glabra, bracteis glabris exteriore breviore atroviridi herbacea, interioribus praeter nervum hyalinis obtusis breviter aristato-cuspidatis laxe calycis tubum breviorem amplectentibus, calycis $\left(5^{1 / 2} / 2^{\prime \prime \prime} 1.\right)$ tubo inter nervos hispidulo, limbo hyalino truncato mutico, nervis atropurpureis extus glaberrimis. 
Hab. in alpinis prope Cabul in Afghanistano: Unu-Pass. 11,300' s. m. et Yonutt Ravine 10,800' s. m. (Griffith Journ. 1012!) v. s. sp. in herb. am. Boiss.

Dense caespitosum, ramis confertis intricatis in globum, inferne nudatis. Folia 7-9 lineas longa, undique ciliato-scabra, superficie vero glabra. Bractea exterior vix $2^{\prime \prime \prime}$ excedens anguste albo-marginata acutata et breviter mucronata; intima mediam paulo superans $4^{\prime \prime \prime}$ longa, obovata.

39. A. alatavicum m. A. Hohenackeri $\beta$. subsessile Trautv.! Enum. song. in Bull. mosq. 1866. 2. p. 460. n. 929. Herder! Enumer. Semenow. Bull. mosq. 1868. 1. p. 395. n. 879. $\gamma$. virens Ruprecht! sert. tiansch. p. 69. non Boiss.!

A. viride vel vix glaucescens, impresso-punctatum minutissime calcareo-lepidotum, dense erinaceum; ramis subelongatis foliis persistentibus patentissimis vel reversis horridis, foliis rigide acerosis trigonis, scapis plerumque brevissimis pubescentibus monostachyis, spicis oblongis dense distichis compressis 5-8-spiculatis, rachi puberula, bracteis glabris exteriore crassiuscule cuspidata interioribus calycis tubum superantibus obtusis bifidisve costis vix prominulis breviore, calycis $\left(4^{1} / 2^{\prime \prime \prime}\right.$ longi) tubo basi glaberrimo extus ad faucem inter nervos patulo-hispidulo limbum albo-hyalinum obsolete 5-lobum superante, nervis atropurpureis ad apices loborum productis glabris.

Hab. in cacuminibus alpium Alatau (Schrenck!), in alpibus Alatau transiliensibus in jugo Dürenyn-Assy et in alpibus Tian-schan in valle Sauku, $6000^{\prime} \mathrm{s} . \mathrm{m}$. (Semenow!), in alveo lapidoso ostii torrentis exsiccati in rivulum Dshaman-diban influentis, in alpibus Tianschan australioribus (Osten Sacken!) v. s. sp.

Fruticulosum, rami crassiusculi, folia vetusta fusco-rufescentia, hornotina e basi dilatata castaneo-fusca lucida dense ciliata subtrigona, supra plana, margine tenuissime serrulato-scabra $7-8^{\prime \prime \prime}$ longa, supra basin ${ }^{3 / \prime \prime \prime}$ lata. Scapi plerumque intra bases foliorum occulti, bracteis tecti. Bractea exterior ovata, coriaceo-herbacea fuscescenti-viridis, margine sursum lyalino membranacea, purpureo cuspidata, $2^{\prime \prime \prime}$ parum excedens, dorso modice carinata; interiores a basi acutissime purpureo carinatae, superne praeter carinam albo-hyalinae, intima $3^{\prime \prime \prime}$ longa, intermedia paulo brevior. Calycis tubus $2^{1} / 2$ '" limbus $2^{\prime \prime \prime}$ longus. Corolla rosea parte exserta limbum calycis superans. Planta Schrenckiana a descripta Semenowiaua parum discrepat: deusius foliata, folia longiora saepe pollicaria et usque $15^{\prime \prime \prime}$ longa, praeter basin margine fere omnino laevia, minus rigida, vetusta minus reflexa, impresso-punctata quidem, attamen ne vetustiora quidem calcareo-lepidota (forsan ob locum borealiorem coelumque minus aridum); scapi longiores, saepius pollicares, compressi fere ancipites; spica vero et flos idem, sed interstitia inter nervos tubi fere ad basin usque pilis paucis adspersi.

Insigniorem varietatem collegit L. B. Osten-Sacken, in regionibus australioribus, in statione demissiore exortam e seminibus verosimiliter ex editioribus locis allutis. Haec 
lactius virens, vegetior, ramis elongatis fere laxe foliosis, folia similia quidem illis plantac Schrenckianae, sed jam juniora calcareo-lepidota. Scapi vero bi- tripollicares, minus compressi, minutissime puberuli, di-, tristachyi. Bractearum tamen florisque dimensiones et forma omnino congruae; nisi bractea exterior plerumque lactius picta medio viridis et ante marginem albo-hyalinum laete purpurea.

40. A. Hohenackeri Boiss.! diagn, 7. p. 75. DC. prod. 1. c. p. 628, u. 26. excl. var. $\beta$ ? Statice Hohenackeri Ja ub. et Sp. 11. cc. ann. p. 251. Ill. tab. 92. Led. fl. ross. 3. p. 469. n. 34. cxcl. pl. araratica et alatavica! St. Echinus Habl. taur. p. 163. M. a Bieb. fl. taur.-cauc. 1. p. 251. C. A. Meyer Ind. cauc. p. 47. n. 363. Hohenacker Enum. Talysch. p. 32, non L.! Statice tenuifolia et St. aciphylla Jaub. et Sp. 11. cc. p. 251. et p. 162. Statice horrida Girard ann. sc. nat. ser. 3. จ. 2. p. 331. ex p.

A. glaucescens, impresso-punctatum, calcareo-squamulosum, dense erinacco-caespitosum; ramis subelongatis basi dense refracto-foliosis, foliis rigidis acerosis subulatotriquetris, scapis folio longioribus scabro-puberulis $1-3$-stachyis, spicis $5-8$ floris abbreviatis laxiusculis, rachi hispidula, bracteis glabris, interioribus obtusis exteriorem superantibus calycinumque tubum aequantibus, calycis ( $5^{\prime \prime \prime}$ longi) tubo undique patule hirtulo, limbo mutico nigro-costato, nervis extus adpresse pubescentibus.

Hab. in tractu Suwant jugi Talysch (C. A. Meyer! Hohenacker!), in alpinis jugi Elbrus, in provincia Ghilan (Hablizl! Aucher Eloy. hb. d'Or. n. 5241 ! L. B. Bode! in hb. Fisch.), in subalpinis plagae orientalis Caucasi (MI, a Bieberstein), prope Astrabad? (Karelin! in hb. Fisch.), in aridis montium supra Kelwäs Caucasi orientalis (Seidlitz!), in montosis prope Nehmetabad in provincia Atropatana Persiae boreali-oceidentalis (Bge. et Bienert!) v. v. sp.

Planta valde variabilis secundum varios locos, foliis brevioribus vel longioribus, plerumque $7-9^{\prime \prime \prime}$ longis, latioribus vel angustioribus, intensius glaucis vel fere virentibus, scapis interdum abbreviatis, monostachyis, tum vero folia duplo superantibus tristachyis.

41. A. glumaceum Boiss.! diagn. 7. p. 75. DC. prodr. 1. c. p. 629. 11. 27. Statice glumacea Jaub. et Sp. ann. sc. nat. 1. c. p. 251. Illustr. 1. p. 162, 166. tab. 91 ! excl. syn. Tournef. St. Hohenackeri Led. fl. ross. 1. c. quoad plantam Araraticam ex hb. ht. bot. petr. Limonium orientale Caryophylli folio acutissimo, floribus velut in capitulum congestis, acaulon et calyce albo Tournef. Coroll. p. 25.

A. viride, vix impresse punctatum nec calcareo-squamulatum, ramis basi nudis superne foliis reflexis vestitis, foliis recentioribus patulis linearibus acerosis confertis, scapo foliis $2-3$-plo longiore $1-3$-stachyo rachique pubescente, spicis brevissimis confertis $7-9$-spiculatis, bractea exteriore late ovata herbacea pubescente longius 
cuspidata, interioribus paulo longioribus praeter carinam dorso pubescentem hyalinis glabris, calycis ( $6^{\prime \prime \prime}$ longi) limbo costis parce hispidulis atro-violaceis ad marginem dilatato-prominulis percurso.

Habitat in Armenia (Tournefort) in lapidosis vallis Arguri montis Ararat et inter Ararat magnum et minorem (Parrot! Hehn! Abich!), in Armenia rossica prope rivulum Amanlu in collibus siccis (Frick!) v. s. sp. et cult. in hto. am. Boiss.

Phrasis Tonrnefortii, quam supra allegavi, sola inter omnes nostram plantam, verosimilius a Tournefortio in monte Ararat collectam, quadrat, non vero illa quam citat cl. Spach et quae diserte A. venustum indicat, floribus spicatis, nec capitatis foliisque mollioribus.

42. A. sahendicum Boiss. et Buhse! Aufz. transc. pers. Pft. p. 183.

A. viride, epunctatum, esquamatum, glaberrimum, crinaceo-caespitosum; foliis vetustis patentissimis, rosulis hornotinis brevibus, foliis linearibus basi brevissime fuscomembranaceo marginatis rigide acerosis margine scabris, scapis gracilibus glaberrimis folia superantibus monostachyis, spica laxiuscule 3-7-spiculata abbreviata, rachi anfractuosa glaberrima, bractea exteriore coriacco-herbacea cuspidata, interioribusque glaberrimis fere ex toto membranaceis acute carinatis obtusis breviter aristulatis calycis tubo brevioribus, calycis ( $5^{\prime \prime \prime}$ longi) tubo inter nervos patulo piloso superante limbum albo-hyalinum subtruncatum, nervis atropurpureis latiuscule usque ad marginem productis glabris.

Habitat.in alpe Ssähend Persiae borealis verus orientem ab urbe Tabris (Buhse pl. exs. n. 574! Seidlitz!) v. s. sp.

Valde affine A. glumaceo, sed scapo rachique et bracteis glaberrimis praeter alia facile distinctum. Folia $7-10^{\prime \prime \prime}$ longa, rarius pollicaria, $1 / 2$ "' lata. Scapi vel praeter basin ebracteati, vel unibracteati, in $\mathrm{A}$. glumaceo saepius $2-3$ bracteati. Bracteae spiculae fuscorubrae, exterior $2^{\prime \prime \prime}$ longa, margine anguste membranacea.

\section{A. Bodeanum m.}

A. glaucescens, minute impresso-punctatum, calcareo-squamulosum, glaberrimum, erinaceo-caespitosum; ramis foliis vetustis squarroso-patentibus dense vestitis, foliis lincari-trigonis tbasi vis marginatis rigide acerosis margine scabris, scapis folio 2-3-plo longioribus gracilibus glaberrimis medio unibracteatis ' $1-2$ stachyis, spicis laxiusculis 3-6-spiculatis abbreviatis approximatis, rachi subrecta glaberrima, bractea exteriore membranacea breviter suborbiculari obtusissima mutica, interioribus triplo longioribus glaberrimis membranaceis obtusis bilobisve muticis calycis tubum superantibus, calycis $\left(5^{1} / 2^{\prime \prime \prime} 1\right.$.) tubo medio patentim pubescente vix superante limbum subtruncatum albo-hyalinum, nervis nigris ad marginem usque attenuatis glaberrimis. 
Habit. in Persia transelbrusensi boreali media prope Fullad-mahaleh inter Schahrud et Teheran (I. B. Bode!) v. s. sp. in herb. olim Fischeriano nunc. h. bot. petrop.

Proxime affine A. sahendico, sed abunde diversum colore et superficie foliorum, foliis brevioribus ad summum $8^{1 / 2} / 2$ longis, scapis gracilioribus magis elongatis. Spicae plerumque solitariae quidem, saepe voro et binae; interdum spicula infima solitaria stipitata. Bractea inferior vix $1 \frac{1}{2}$ longa, costa infra apicem desinente: intima $4^{\prime \prime \prime}$ longa, intermedia vix brevior, medio chartaccae margine late fuscescenti-byalinae, apice atropurpureo carinatae, carina supra apicem non producta.

14. A. ulicinum Boiss. DC. prodr. 1. c. p. 627, n. 21. Statice ulicina Willd herb.! ex Roen. et Schult. s. v. 6. p. 798. Spreng. S. v. 1. p. 963. Statice Hystrix Jaub. et Sp. 1l. ce.

A. laete virens, minutissime impresso-punctatum, esquamatum, viscidulum, caespitosum; ramis elongatis crassis rigidis foliis retustis horridis, rosulis hornotinis brevibus paucifoliis, foliis glabris viscidulis infimis brevissimis caeteris brevibus triquetris rigidissime acerosis ima basi brevissime fusco-marginatis eciliolatis, scapis folia aequantibus rachique viscidulis, spica solitaria conferte $3-5$-spiculata, bracteis mucronatis exteriore herbacea viridi triangulari lanceolata, interioribus longioribus carinatis basi herbaceis superne membranaceis atropurpureo-pictis, calycis $\left(5^{1} / 2\right.$ 't' longi) tubo inter costas parce birtello, limbi 5 -lobi nervis atropurpureis glabris late in mucronulum obtusum productis.

Hab. in regione superiore montis Dshebel Schehr Antilibani 7-9000' s. m. (Labillardière! Boissier!), in jugo orientali Mermonis versus Orny 5000's. m. (Kotschy pl. syr. n. 213 !) v. s. sp. Specimen Labillardièrianum in hb. olim Mertens, nunc ht. bot, petrop.

\section{A. cataonicum $\mathrm{m}$.}

A. laete viride, vix minutissime impresso-punctatum, esquamatum, glaberrimum, dense caespitosum; ramis gracilibus flexuosis basibus foliorum vetustiorum foliisque anni praeteriti reflexis vestitis, rosulis sterilibus polyphyllis laxiusculis elongatis, fertilibus brevioribus, foliis basi eciliatis parum dilatatis linearibus plano-subtetragonis scapis folia superantibus glaberrimis uni-vel ebracteatis monostachyis, spica conferte subscorpioidea vel disticho-imbricata $2-5$-spiculata, rachi glaberrima, bractea exteriore herbaceo-coriacea viridi purpureo-picta breviter cuspidata, interioribus duplo longioribus atropurpureis nitidis glaberrimis brevissime acutatis vel ex apice aristulatis, calycis ( $5^{\prime \prime \prime}$ excedentis) tubo basi glabro superne inter nervos hispidulo superante limbum albo-hyalinum obsolete 5-lobum, nervis atropurpureis glabris ad apices loborum late productis.

Habitat in Tauri cataonici alpe Beryt-dagh (Hausknecht! pl. exs. it. syr. arm. sub nom. A. Tournefortii) v. s. sp. ab am. Boissier communicatum. 
Perquam affine A. ulicino, foliorum margine, calycis forma et indumento, attamen habitus omnino alienus ob ramos graciles flexuosos basi longe nudatos, folia laxiora. Folia media subpollicaria, infima multo breviora, basi amplexicauli trinervia, superne tantum margine tenuissime serrulato-scabra, uninervia, nervo utrinque prominulo, subtus rotundato, supra fere acuto, spimula longiuscule terminata. Scani sine spica pollicares rel parum longiores ima basi bractea bicarinata bicuspidata, ceterum membranacca amplexi, ut in plerisque speciebus affinibus, caeterum vel omnino ebracteati vel medio unibracteati. Bractea exterior anguste membranaceo marginata, rarius obtusa, interiores chartaceo-membranaceae basi et margine albido-hyalinae, intermedia plerunque acutata, intima aristulata. Calycis limbus patens. Corolla pulchre rosea fere $8^{\prime \prime \prime}$ longa.

46. A. caesarcum Boiss. Diagn. ser. 2.4. p. 66.

$\Lambda$. viride, impunctatum, esquamatum, erinaceo-caespitosum; ramis foliis vetustis patulis spadiceis horridis parte hornotina elongatis, foliis lineari-trigonis subulatoattenuatis margine scabris, seapis rachique puberulis folio $4-5$-plo longioribus mono-distachyis, spicis subelongatis imbricato-5-9-spiculatis, bracteis glabris exteriore breviore longe attenuato-mucronata, interioribus membranaceis rubellis obtusis costa purpurea in aristam elongatam producta, calycis $\left(6^{1} /{ }^{\prime \prime \prime} \mathrm{I}\right.$.) tubo hirto bracteas superante, limbo breviori erecto patulo nervis parce hispidulis purpureis brevissime ultra marginem productis submucronulato.

Hab. in regione subalpina montis Alidagh prope Caesaream Cappadociae (Balansa!) v. s. sp. ab am. Boissier comm.

A. glumaceo proxime affine, distinctum vero spicis laxioribus, bracteis glabris, interioribus longe aristatis. Rami fere tripollicares. Folia $9-11^{\prime \prime \prime}$ longa. Scapi $2 \frac{1}{2}-3-$ pollicares. Spicae $1-1^{1} / 2$-pollices longae.

47. A. Huetii Boiss. diagn. s. 2. 4. p. 65.

A. glaucescens, minutissime punctatum vix calcareo-lepidotum; ramis paucis basi nudatis procumbentibus, foliis laxe rosulatis recurvo-patulis carnosulis subtrigonis ad apicem usque dense ciliato-scabris in mucronem brevem tenuissimum abrupte contractis, annotinis diffractis basibus dilatatis recurvis persistentibus, scapis folio duplo longioribus dense pubescenti-velutinis distachyis, spicis ovatis distiche 5-9spiculatis, bracteis amplis velutinis exteriore late herbacea attenuato-mucronata, interioribus parum longioribus membranaceis abrupte mucronatis, calycis ( $6^{\prime \prime \prime}$ longi) tubo hispidulo sensim in limbum albo-liyalinum aequalem subdecemlobum ampliato, nervis patulo puberulis purpureis ad marginem usque productis.

Habitat in Armenia supra Maimansur (Huet de Pavillon!) v. s. sp. in hb. am. Boissier. Species singularis cujus ut videtur unicum specimen collectum, distinctissima foliis carnosulis mox difractis. E radice elongata verticali prodeunt caudiculi nudi et rami bre- 
ves procumbentes; folia $6-7^{\prime \prime \prime}$ longa, vix lineam dimidiam lata, laxa recurva. Spicae $A$. glumacei, sed bracteae ampliores, interiores $4^{1} / 2$ "' longae.

48. A. puberulum Boiss. diagn. ser. 2. 4. p. 62.

A. pallide virens, vix punctatum, esquamatum, laxe caespitosum; ramis flexuosis foliis annotinis retrorsis marcescentibus vetustiorumque basibus persistentibus tectis, folis hornotinis laxe rosulatis lineari-triquetris undique patule pubescentibus basi margine tenuissime ciliolato-scabris, scapis brevissimis velutinis, spica breviter ovata fasciculiformi dense 3-7-spiculata folia vix superante, bracteis acnte carinatis, exteriore viridi anguste marginata praeter marginem hispidula pallide breviter mucronata, interioribus longioribus praeter costam virentem pubescentein hyalinis fuscescenti-albis sub apice mucronatis, intima calycis tubum superante, calycis ( $5^{\prime \prime \prime}$ vix excedentis) tubo puberulo in limbum breviorem eroso-sublobatum ampliato, nervis atropurpureis hispidulis usque ad marginem productis vel rarius prominulis.

Hab. in regione alpina montis Aslan-dagh Cappadociae ad orientem montis Argaei (Balansa); in Tauri cataonici alpe Beryt-dagh (Hausknecht! pl. syr. arm. sub nom. A. puberuli! et A. Tournefortii var.!) v. s. sp.

Plantam cappadocicam a cl. Balansa collectam non vidi, et diagnosin confeci secundum specimina Hausknechtiana mihi ab amic. Boissier sub nomine A. puberuli communicata, quae tamen pluribus a descriptione Boissieri 1. c. differunt. Simillimam plantam ab eodem ibidem lectam habeo insuper sub nomine A. Tournefortii var., solummodo diversum foliis laetius viridibus minus pubescentibus et scapis paulo elongatis folia superantibus. Habitus A. Echini, sed folia angustiora minus rigida fere arcuato-curvata, 7-9"' longa, angustissima. Bractea exterior vix $2^{1} /_{2}^{\prime \prime \prime}$, intima $4^{\prime \prime \prime}$ longa. Ab his distinctum A. cataonicum, supra descriptum etiam sub nomine $\Lambda$. Tournefortii distributum, proxime A. ulicino accedens,

49. A. Wiedemanni $\mathrm{m}$.

A. viride, fere epunctatum, esquamatum, glaberrimum, confertissime pulvinato-caespitosum; ramis brevissimis foliis vetustis rufescentibus reversis dense obtectis, foliis hornotinis dense rosulatis lineari-acerosis rigidis basi ciliolatis margine serrulatoscabris subtetragonis, scapis gracillimis glabris folium subaequantibus monostachyis, spicae $1-5$-spiculatae compressae conferte subdistichae rachi glaberrima viscidula, bractea exteriore ovato-lanceolata acute carinata herbacea acuminatocuspidata, interioribus longioribus calycis tubum subsuperantibus oblongis membranaceis breviter attenuato-cuspidatis, calycis (5"' longi) tubo patulo-pilosulo limbum hyalinum patentissinum obsolete 10 -lobum superante, nervis atropurpureis subglabris brevissime supra marginem dilatato-productis.

Hab. in monte Juldri-dagh (ex Fisch.) vel Jyldis-dagh (e sched. herb. h. bot. petrop.) Anatoliae (Wiedemann!) v. s. sp. 
Habitus omnino A. Echini, a quo tamen facillime distinctum scapo rhachique glaberrimis, quae in innumeris speciminibus A. Echini a me examinatis semper velutino-pubescentes. Magis affine A. ulicino sed differt habitu, foliis basi ciliatis, bractearum proportione, bractea exteriore carinata angustiore et longiore, calycis nervis puberulis. Folia $6-8^{\prime \prime \prime}$ longa, angusta, costa utrinque prominula subtetragona apicem versus canaliculata in cuspidem pungentom attenuata. Scapi 1-2-bracteati, bracteis angustis fere omnino membranaceis longe aceroso-cuspidatis. Bractea exterior obscure virens auguste purpurascenti-membranaceo-marginata $2 \%{ }_{2}^{\prime \prime \prime}$ longa. Interiores inter se subaequilongae $3^{\prime \prime \prime}$ parum excedentes, carinatae fere ex toto membranaceae fuscescentes apice ad carinam purpurascentes, atropurpureo cuspidatae. Calycis tubus $3^{\prime \prime \prime}$ longus undique sparse patulo pilosus; nervi limbi hine inde pilis perpaucis adspersi. Corolla amoene rosea parte exserta fere limbum calycinum aequans.

50. A. lycuonicum Boiss. et Heldr. in DC. Prodr. 1. c. p. 627, 11. 22.

A. pallide virens, minutissime punctatum, esquamatum, erinaceo-caespitosum; ramis brevissimis foliis vetustis reversis horridis, foliis rosulae hornotinis erectis strictis acerosis subulato-triquetris glabris, scapis folia superantibus pubescentibus monostachyis, spicis abbreviatis confertis 5-8-spiculatis, rachi velutino-pubescente, bracteis puberulis exteriore late ovata mucronata, interioribus duplo longioribus obtusis bilobisve ex apice vel inter lobos aristulatis, calycis ( $6^{\prime \prime \prime}$ longi) tubo superne patulo-piloso sensim in limbum breriorem obsolete 10-lobum albido-hyalinum ampliato, nervis atropurpureis ad apices loborum productis pilosis.

Habit. inter Bey-schehr et Koniah Lycaniae (Heldreich!) et inter Kiutaja et Arzani Anatoliae (Mitchell).

Vix specie ab A. Echino diversum, tamen bracteis interioribus facile recognoscendum.

51. A. Lehinus L. Sibth! prodr. fl. gr. 1. p. 213 ! (sub Statice) Icon fl. gr. tab. 300. A. androsaceum Boiss, diagn, ser, 1. n. 7. p. 73. DC. prodr. l. c. p.626. n. 19. Statice androsacea Jaub. et Spach ll. cc. Illustr. tab. 89! St. pauciflora Jaub. et Sp. 11. cc. Statice Echinus $\beta$. L. sp. 395. - alii; non MI. a Bieb. Statice foliis caulinis etc. A. v. Royen fl. Leyd. prodr. p. 192? excl. synon. 'Tournef. nisi ad A. acerosum. Limonium creticum juniperi folio Tournef. coroll. 25! Tragacantha tota spinosa etc. Morison, hist. app. sect. 2. tab. 23. fig. 7. Echinus seu alia Tragacantha Prosp. Alpinus de pl. exot. p. 57. Cap. XXVI! Confer in introductione de hac specie prolata.

A. viride, vix minutissime purctatum, esquamatum, erinaceo-caespitosum, puberulum vel glabrum; ramis brevissimis foliis vetustis reversis horridis, foliis rosulae hornotinis patulis strictis acerosis triquetris saepe puberulis brevibus, scapis brevissimis pubescentibus monostachyis, spicis abbreviatis confertis $3-7$-spiculatis, rachi 
velutino-pubescente, bracteis exteriori breviore oblongo-lanceolata basi vel ex toto puberula, interioribus calycis tubum aequantibus vel superantibus ad costam pubescentibus acuminato-cuspidatis, calycis $\left(5^{1 / 2}-6^{\prime \prime \prime}\right.$ longi) tubo hirtello, limbo albohyalino nervis atropurpureis ad marginem vel ultra illum productis mutico vel 5-mucronulato.

Habitat in montibus sphakioticis insulae Cretae (Prosper Alpinus, Tournefort, Sib thorp, Olivier et Bruguière, Sieber!), in montibus excelsis totius Graeciae: Velugo et Parmasso (Spruner!), 'Taygeto (Heldreich!), Malero, 6-7000's. m. (Orphanides!), Olenos (Heldreich!), et Asiae minoris: in Olympo bithyno (Sibthorp, Aucher Eloy. herb. d'Or. n. 2508! Boissier! 'Tschichatschew!), in T'molo (Boissier!), in Tauro cilicico inter fragmina rupium montis Koschan, alt. $8500^{\prime}$ s. m. (Kotschy it. cil. n. 134 $4^{\text {' }} 171$ ! 289! 311 !), perfrequens in jugo Ketsiebele, in monte Kisyl-teppe, Tschidem-goh prope Magara Gülleck alt. $6-8000^{\prime}$ (Kotschy n. $54^{\circ} ! 132^{\circ} ! 254^{a}$ !), in monte Tauro (Kotschy it. 1836 n. 415 !).

Huic speciei certissime servandum nomen antiquum Alpini: Echinus. Species valde polymorpha, sed limites inter formas in innumeris speciminibus a me examinatis certos nullos video, ita ut ne varietates quidem discernere queam. Specimina cretica Sieberiana nomulla tantisper discrepant minutie et densitate foliorum saepius sat dense pubescentium, alia vero ex eodem monte Ida, forsan e locis demissioribus omnino conveniunt cum speciminibus graecis, nec haec differunt ab anatolicis. Me judice A. puberulum, lycaonicum et Echinus unam speciem efformant.

\section{Series 4. Hicrocalycina.}

Spiculae vel confertae, vel remotae, in capitula vel spicas saepius compositas dispositae: Calyces albi, rarissime purpurei $3^{\prime \prime \prime}$, ad summum $4^{\prime \prime \prime}$ longi.

Habitant praecipue in regionibus montanis Persiae austro-occidentalis et Kurdistaniae adjacentis, rara in Cabulistano et in regionibus transcaucasicis. Per A. lepturoides ${ }^{1}$ ) arcte junguntur Caryophyllaceis, per $\Lambda$. subulatum quodammodo habitu appropinquant $A$. lycopodioides.

\section{Clavis specierum diagnostica.}

1. Spiculae remotae in rachi elongata. 2.

n imbricato-confertae in rachi abbreviata. 6 .

2. Scapi elongati. 3.

1) abbreviati. 5 .

3. Bractea exterior interioribus longior vel aequalis, spicae solitariae 1. geminatae coaetaneae, folia rigide lanceolata, scapús firmus rectus. A. lepturoides.

1) Ut melius discrimina inter A. lepturoides et tenuitlorum illuceant, in clavim diagnosticam recepi hoc altimum, in parenthesi inclusum. 
Bractea exterior interioribus brevior, spicae subpaniculatae, terminalis praecocior, folia anguste linearia acerosa, scapus gracilis laxiusculus. 4.

4. (Rosulae abbreviatae folia basi vix dilatata, rachis stricta floribus valde remotis, bractea exterior viridis herbaceo-coriacea, interiores acuminatae aristato-cuspidatae, calyx $4 \frac{1}{2}-5^{\prime \prime \prime}$ longus, limbi nervi glabri........... temiflom.)

Rosulae subelongatae, folia basi hyalino-marginata, rachis anfractuosa, flores inferiores remotiusculi, bractea exterior purpurascens late hyalino-marginata, interiores obtusae muticae, (cal. $4^{\prime \prime \prime}$ ), limbi nervi adpresse pubescentes...... A. flexuosum.

5. valde glaucum, folia lanceolato-linearia, rami brevissimi, bracteae interiores obtusae submuticae, calycis nervi pallidi.....A. aspadanum.

glaucescens, folia anguste linearia, rami subelongati, bracteae interiores acuminatac aristato-cuspidatae, calycis nervi atropurpurei ......................

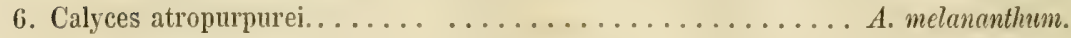

1) albido-hyalini. 7.

7. Scapi mono-rarissime subdistachyi compressi, folia basi vix ciliata superne margine scabra, caeterum glabra, spicae laxe imbricatae. 8 .

"di- pleiostachyi, spicae confertae. 9.

8. glaucescens, rosulae hornotinae abbreviatac, bractea exterior ovalis obtusa mutica dimidio brevior interioribus breve mucronulatis praeter costam albo-hyalinis ......... kurdicum.

virens, rosulae hornotinae subelongatae, bractea exterior acuta submutica parum brevior interioribus, intima medio latius chartacea basi purpureo-plurinervia .............. brachystachyum.

9. Folia tota superficie puberulo-scabra............... genistoides.

" margine tantum scabra. 10.

10. Glancescens, scapi subglabri, bractea exterior late hyalino-marginata, interiores acuminatae aristato-cuspidatae calycis $4^{\prime \prime \prime}$ Jongi tubo hispidulo breviores; folia $1 \frac{1}{2}$-pollicaria . . . . . . . . . . . . . . . . . A. . . .

Viride, scapi pubescentes, bractea exterior coriaceo-herbacea, interiores obtusae vel bilobae muticae calycis $3^{\prime \prime \prime}$ longi tubum glabrum superantes, folia vix ultra semipollicaria. A. subulatum. 
52. A. lepturoides Jaub. et Spach. (sub Statice) ll. cc. tab. 95 ! excl. pl. Hohenackeri; non Boiss. Statice acerosa M. a Bieb.! fl. taur. cauc. 1. p. 252. excl. synon. non Willd. - Ledeb. fl. ross. 3. p. 470. excl. synon. Hohenack. et Boiss.! — et patria: 'Talysch.

A. glaucum, impresso-punctatum, calcareo-squamulosum, caespitosum; ramis brevissimis dense foliosis, foliis vetustis dense retrorsum imbricatis, hornotinis patulis lanceolato-linearibus basi planis 5-nerviis superne triquetris rigide acerosis praeter marginem glabris, scapis folia 3-4-plo superantibus glaberrimis (mono-) subdistachyis, spicis coaetaneis subaequalibus laxe multifloris, rachis valde flexuosae glaberrimae articulis bracteas subaequantibus, bracteis glaberrimis exteriore interiores et tubum calycis vix superante nervo pungente longe acuminato, interioribus scariosis obtusis vel bilobis nervo producto cuspidatis, calycis ( $4^{\prime \prime \prime}$ longi) tubo parce hispidulo limbum hyalinum subtruncatum nervis nigricantibus basi hispidulis ante marginem evanescentibus muticum superante.

Habitat in Iberiae transcaucasicae collibus sterilibus: inter Tiflis et Mzcheti (M. a Bieberstein! Ravergie ex Spach; Steven! Wilhelms!), in Kachetia et Somchetia (Eichwald!) v. s. sp.

Folia margine scaberrima, longiora pollicaria, supra basin lineam lata. Scapi sine inflorescentia 2-4-pollicares purpurascentes, crassiores quam in A. tenuifloro. Spicae fragillimae eximie anfractuosae, spiculae longitudine bractearum ab invicem remotae. Bracteae $3^{\prime \prime \prime}$ longae exterior medio coriaceo-herbacea margine late membranacea. Calycis tubus $3^{\prime \prime \prime}$ longus, limbus vix linea latior omnino expansus.

Haec species ad occidentem ab urbe Tiflis, ut videtur, frequens est vera Statice acerosa 1I. a Bieb., quacum saepe confusum fuit A. tenuiflorum, in regionibus orientalioribus obvium. Hanc etiam sub nomine St. lepturoidis depinxit cl. Spach 1. c.; in descriptione vero, caeterum eandem omnino quadrante, nonnulla A. tenuiflorum indicare videntur, ati scapi $3-5$-stachyi et calycis longitudo usque ad $4{ }_{2}^{1}{ }_{2}^{\prime \prime \prime}$, e speciminibus forsan incompletis Hohenackerianis depromta. E verbis Biebersteinii patet, non A. tenuiflorum sub nomine St. acerosae descriptum fuisse; nam "scapi elongati subramosi" et "scapi . . . in ramos... haud raro subdivisin dicuntur, quum in A. tenuifloro scapi semper pleiostachyi sunt. Equidem in nostra specie, cujus numerosa specimina examinavi, rarius vidi scapos distachyos nunquam tri- pleiostachyos. Jam locus natalis a Biebersteinio indicatus ad solvenda dubia sufficit. Specimen quod in herbario amicissimi Boissier sub nomine A. lepturoidis a Fischero communicatum asservatur, illustrissimum monographum generis in errorem induxisse videtur; constat enim e spica solitaria a caespite soluta et spiculis nonnullis sejunctis in capsula asservatis, characteres $\Lambda$. lepturoidis Boiss. (non Spach) ferentibus, et e caespitibus binis qui, me judice, ad A. lepturoides spectant. Spica et spiculae illae calycis dimensionibus et racheos articulis in latere applanato pubescenti-hirtulis omnio quadrant $\mathrm{A}$. acerosum $(\mathrm{A}$. 
phrygium Boiss.). In herbario olim Fischeriano exstat, inter numerosa specimina A. lepturoidis Spach. specimen, in schedula, manu Stevenii, ut St acerosa designatum, sine loci natalis indicatione, omnino cum spica et spiculis herbarii Boisseriani congruum, cujus caespes adhaerens vero omnino differt, sed cum A. aceroso Willd congruit. Simile specimen ab A. aceroso Willd nullo modo distinguendum exstat in hb. Acad. petrop. inter specimina A. lepturoidis immixtum.

53. A. oliganthum Boiss. diagn. 1. n. 7. p. 77. DC. prodr. 12. p. 629. n. 31.

A. glaucescens, minute punctatum et vix calcareo-squamatum, dumoso-erinaceum; ramis vetustis patule horridis, hornotinis rosulaeformibus, foliis erecto-patulis subulato-triquetris basi late longeque albo-marginatis, scapis glabris folio brevioribus mono-distachyis, spicis laxe 3-5-spiculatis, rachi flexuosa glabra, bractea exteriore ovata multo breviore interioribus subaequilongis tubum calycinum subsuperantibus praeter nervum in cuspidem brevem atropurpureum excurrentem scariosis sordidoalbis, calycis (vix ultra $3 \frac{1}{2}{ }^{\prime \prime \prime}$ longi) tubo parce puberulo, limbo nervis nigricantibus glabris e margine prominulis submucronulato.

Habitat in Persia australi prope Schiras in summae alpis Kuh-Delu cacumine in declivitate occidentali (Th. Kotschy pl. pers. austr. n. 559!) v. s. sp.

54. A. cspadanum $\mathrm{m}$.

A. valde glaucum, albidum, impresso-punctatum, dense calcare-squamatum; ramis abbreviatis dense caespitosum; foliis confertis erecto-patulis lanceolato-linearibus rigide acerosis longe pungenti-cuspidatis planis basi rufescenti $7-9$-costatis breviter anguste marginatis, scapis folio brevioribus $1-3$-stachyis rhachique scabris, spicis laxe 6-12-spiculatis flexuosis, bracteis exteriore breviore praeter carinam virentem albo-hyalinis interioribus obtusissimis bilobisve submuticis, calycis ( $3^{\prime \prime \prime}$ longi) tubo obconico hirsuto sensim in limbum albo-subpellucidum obsolete 5-lobum nervis pallidis ultra marginem productis glabris 5-mucronulatum ampliato.

Habitat in Persia occidentali-media prope Isfahan, Murtschehar in apricis montosis (Bge et Bienert!) et prope Kohrud (Kapherr! in hb. Fischeri) v. v. sp.

Habitu et nervis calycis pallidis A. Kotschyi simile, sed plurimis notis distinctissimum. Humile; squamae calcareae folia fere omnino tegentes et saepe inter se confluentes. Folia $1-1^{1} / 2$-pollicaria, primaria breviora, supra basin lineam lata. Scapi subbibracteati, bracteis fere omnino hyalino-membranaceis, breviter acuminatis. Spicae ad summum bipollicares; spiculae bractearum longitudine ab invicem distantes. Bractea exterior basi et ad carinam viridis, breviter acuminata vel spicularum superiorum acutata tantum, vix ultra $1 \frac{1}{2}$ "' longa; interiores inter se aequales vix $2^{\prime \prime \prime}$ superantes, nervo vix in mucronulum inter lobos producto. Corolla junior videtur albida. 
55. A. flexuosum Boiss. in litt.

A. glancum, impresso-punctatum, dense calcareo-lepidotum, caespitosum; ramis subelongatis foliis vetustis laxius vestitis, foliis e basi dilatata latius hyalino-marginata acerosis supra planis linearibus praeter marginem glabris, scapis elongatis teretibus glabris pleiostachyis, rachi intus velutino-hispida, spicis subracemosis $3-12$-spiculatis laxis, bractea exteriore lata breviter ovata praeter basin et costam rufescentes membranacea glaberrima acuminato-mucronulata, interioribus duplo longioribus praeter costam apice parce hispidulam albo-hyalinis obtusissimis muticis, calycis (4"' longi) tubo hispidulo limbum albo-hyalinum eroso-subtruncatum muticum aequante, nervis atropurpureis extus puberulis ante marginem evanescentibus.

Habitat in Persiae austro-occidentalis provincia Luristan, in alpinis calcareis montium: Kuh-Kiluyeh, Kuh-Sawers, Kuh-Eschker 10000's. m.; in planitie Tschinar $7000^{\prime}$ s. m. nec non in monte Diligan $9000^{\prime}$ s. m., in montibus Nur, Sebsekuh et Kellal (Hausknecht!) v. s. sp.

Planta quoad inflorescentiam variabilis. Folia primaria saepe molliora subcarnosula, vetusta patentissima fusca, hornotina stricta, subtus versus basin convexa, apice acute carinato-triquetra, omnino evoluta pollice parum longiora, supra basin linea dimidia vix latiora. Scapi cum inflorescentia semipedales usque ad 10 -pollicares. Spicae $5-6$ vel plures spicatae vel subracemosae vel apice subpaniculatae, unilaterales vel distichae, rachi recta vel flexuosa, articulis scapi saepe pollicaribus, rhacheos saepe $2^{\prime \prime \prime}$ excedentibus. Bractea exterior linea parum longior, interiores fere $3^{\prime \prime \prime}$ longae. Corolla pulchre rosea calycis limbum ejus longitudine excedens. Interdum scapi parcius ramosi spicis inferioribus longe pedunculatis pauci-, interdum unispiculatis, bracteis interioribus minus obtusis costa media longius in aristulam excurrente (Kuh -Sawers, Diligan $9000^{\prime} \mathrm{s} . \mathrm{m}$.). In nonnullis speciminibus (Kull-Eschker) scapi multo breviores spicam ferunt fere simplicem laxam, racheos flexuosae articulis saepe $3^{\prime \prime \prime}$ longis vel longioribus, simul cum aliis spicis ramosis, ita ut plantam in monte Nur collectam, in qua spicas nonnisi simplices vidi, quia caeteris characteribus omnino cum pleiostachyis congruit, specie non differre credam, etsi interdum in hac nervi limbi calycini ad marginem usque, imo tantisper ultra illum producti sunt. Huc spectant specimina in monte Sawers $8000^{\prime}$ s. m.; in monte Sebsekuh et Kellal collecta.

56. A. brachystachyum Boiss. in litt.

A. virens, minute et sparse impresso-punctatum, parce calcareo-squamulatum, caespitosum; ramis subelongatis foliis vetustis recurvis tectis, foliis infimis multo brevioribus submuticis recurvis caeteris subtriquetris rigide acerosis basi late hyalinomarginatis eciliatis, scapis folium aequantibus vel superantibus subcompressis subglabris, spicis subsolitariis laxiusculis elongatis, rachi hinc scabra, bractea exteriore ovata acuta membranacea glaberrima, interioribus longioribus obtusissimis, media 
praeter nervum angustum albo-hyalina, intima basi purpureo-plurinervia, calycis (4"' longi) tubo parce hirsuto sensim in limbum albo-hyalinum truncatum, nervis ad marginem productis purpureis puberulis muticum ampliato.

Habitat in Kurdistaniae Persiae finitimae monte Dalechani 10,000 s. m. (Hausknecht).

Affine A. flexuoso, sed minus, praesertim bracteis distinguendum. Rosulae hornotinae parum elongatae, folia infima lineari-oblonga mox marcescentia, caetera superne costa subtus prominente quasi bisulcata, supra canaliculata. Scapi vel breviores esquamati, vel longiores medio squama instructi, glabri vel distincte puberuli. Spicae plerumque simplices, rarissime basi ramo brevi $2-3$-spiculato accedente; articuli racheos infimi interdum $3-5^{\prime \prime \prime}$ longi, sequentes vix $2^{\prime \prime \prime}$, summi multo breviores. Bractea inferior basi atropurpureo-virens fere $2^{\prime \prime \prime}$ longa; interiores $3^{\prime \prime \prime}$ parum superantes, intima medio latius chartacea basi striis purpureis pluribus ultra medium excurrentibus inferne confluentibus picta. Corolla videtur pallide carnea, emarcida fere pallide crocea.

\section{A. kurdicum $\mathrm{m}$.}

A. glaucescens, impresso-punctatum, calcareo-squamatum, dense caespitosum; ramis brevissimis dense reliquiis foliorum foliisque vetustis recurvis vestitis, foliis hornotinis abbreviato-rosulatis infimis brevioribus latioribus caeteris strictis patulis acerosis subtrigonis basi hyalino-marginatis vix ciliatis, scapis folio brevioribus ancipiti-compressis pubescentibus monostachyis, spica imbricato-subconferta 310-spiculata, articulis puberulis, bractea exteriore ovali late hyalino-marginata obtusa mutica, interioribus duplo longioribus inter se aequalibus praeter costam in mucronem breviter productam hyalinis oblongis obtusiusculis glaberrimis, calycis (vix $4^{\prime \prime \prime}$ longi) tubo hispidulo limbum albo-hyalinum truncatum nervis atropurpureis basi parce puberulis brevissime ultra marginem productis mucronulatum subsuperante.

Habitat in Kurdistaniae Persiae finitimae montibus calcareis Avroman et Schahu (Hausknecht!) v. s. sp. sub nomine A. melananthi communicatum.

Binis praecedentibus valde affine, ab A. melanantho, cui habitu magis quam illis appropinquat, praeter alia jam calycis colore facile distinctum. Folia in rosulis infima $2-3^{\prime \prime \prime}$ longa, caetera ad summum $7-8^{\prime \prime \prime}$ longa, infra medium $1 / 2$ ' lata, superne margine aculeolato-scabra, longe pungenti-mucronata. Scapi basi bibracteati, bracteis praeter costam longe excurrentem hyalino-membranaceis glabris. Spica disticha, parum flexuosa, articulis infimis interdum usque ad $2^{\prime \prime \prime}$ longis, summis linea brevioribus. Bracteae exteriores spiculae infimae interdum acuminato-cuspidatae; interiores basi virides, medio purpureae, $2^{1} / 2$ "' longae tubum calycis subaequantes. Calycis tubus pallidus. Corolla rosea limbum fere ejus longitudine excedens. 
58. A. melananthum Boiss. Diagn. 1. 7. p. 74. DC. prodr. 1. c. n. 24. Statice melanantha Boiss. in Kotschy pl. Pers. austr.

A. glaucescens, tenuissime punctatum et calcareo-squamatum, caespitosum; ramis abbreviatis dense horridis, foliis infimis abbreviatis caeteris rigide acerosis planotriquetris latiusculis brevibus, scapis rachique puberulis, spica e foliis vix exserta brevissima $6-9$-spiculata, bracteis viscidulis purpureis interioribus hyalino-membranaceis sublucidis obtusis breviter mucronatis exteriorem breviorem triangularem mucronatam superantibus calycis tubo brevioribus, limbi violascenti-purpurei profundius 5-lobi nervis nigris glabris vix mucronulato-prominulis.

Hab. in regione superiore alpis Kuh-Daena prope Schiras Persiae australis (Kotschy 1. c. n. 591) v. s. sp. Caespites densissimi pulvinares, folia $9-10^{\prime \prime \prime}$ longa, fere lineam lata. Spicae semipollicares dense imbricatae. Calyx $4^{\prime \prime \prime}$ longus.

59. A. genistoides Boiss. Diagn. 1. 7. p. 76. DC. prodr. 1. c. n. 28. Statice genistoides Jaub. et Spach ll. cc.

A. glaucescens, impresso-punctatum, calcareo-lepidotum, dumoso-erinaceum; ramis elongatis remotius patule horridis, foliis tota superficie scabro-hispidulis infimis subcarnosis subspathulatis submuticis caeteris triquetris acerosis, scapis folio 2-3-plo longioribus parce puberulis $2-3$-stachyis, racheos articulis hispidulopubescentibus, spicis sessilibus 6-9-spiculatis confertis, bractea exteriore breviore triangulari acuta praeter basin scariosa, interioribus praeter nervum tenuem atropurpureum hyalinis obtusis submuticis calycis tubum aequantibus, calycis ( $4^{\prime \prime \prime}$ longi) costis atropurpureis in tubo patule in limbo truncato mutico adpresse pubescentibus.

Habitat in Mesopotamia vel in Persia (Aucher Eloy. hb. d'or. n. 2511. ex Spach hb. Mus. paris. n. 2024! ex Boiss. 1. c.) v. s. sp. in hb. amic. Boiss.

$\mathrm{Ab}$ omnibus speciebus subsectionis foliorum indumento facile distinctum, etiam ab A. subulato cujus folia sedulo a me examinata practer marginem semper glabra, laevia vidi.

60. A. festucaceum Boiss.! Diagn. 1. 7. p. 76. DC. prodr. 1. c. n. 30. Statice festucacea Jaub, et Spach. Il. cc.

A. glaucescens, vix impresso-punctatum, calcareo-squamulatum, erinaceo-caespitosum; ramis abbreviatis dense foliis deflexis elongatis tectis, foliis hornotinis praeter marginem glabris lineari-triquetris acerosis, scapis subglabris folia multo superantibus 3-7-stachyis, racheos articulis scabro-puberulis, spicis breviter pedunculatis inferioribus distantibus caeteris ad apicem scapi fasciculatis $6-12$-spiculatis subconfertis, bractea exteriore breviore triangulari mucronata basi fuscescenti membranacea caeterum albo-scariosa, interioribus scariosis acuminato-mucronatis, 
calycis ( $4^{\prime \prime \prime}$ longi) tubum subaequantibus, limbi 5-lobi submutici nervis nigricantibus tenuibus basi puberulis.

Habitat in Persiae montibus (Auch. Eloy. hb. d'or. n. 5239 ! et n. 2169. ex Boiss. 1. c.) et in Mesopotamia (Auch. Eloy. hb. d'or. n. 2511.) v. s. sp.

In herbariis haec species cum praecedente confusae videntur; vidi etiam speciminibus floribus destitutis adjectam capsulam cum floribus A. tragacanthini.

61. A. subulatum Boiss. DC. prodr. 12. p. 629. n. 29. A. brachyphyllum Boiss. 1. c. p. 628 . n. 25? Catal. Griff. distr. n. 4166 !

A. virens, denique atratum, fere impunctatum, esquamulatum, dense caespitosum; ramis foliis vetustis dense obtectis abbreviatis, foliis subulato-acerosis brevibus apice abrupte tenuissime spinulosis margine muriculato-scabris, scapis muriculatoscabris folia 3-5-plo superantibus pleiostachyis, spicis sessilibus inferioribus remotis superioribus confertis dense et stricte 5-9-spiculatis, bractea exteriore paulo breviore ovato-triangulari mucronata albo-marginata, interioribus albo-membranaceis truncatis muticis calycis $\left(3^{1 / 2} 2^{\prime \prime \prime}\right.$ longi) tubum glaberrimum subsuperantibus, limbi älbi eroso-truncati mutici nervis atris adpresse pubescentibus.

Habitat in alpinis Afghanistani ad septentrionem ab urbe Kabul (Griffith journ. $\mathrm{n}$. 1583 et 1584; Catal. distr. Griff. n. 4166!) vidi specimen sub nom. A, subulati in hb. am. Boiss., aliaque sine floribus sub nom. A. brachyphylli a h. b. Kewensi communicata in hb. h. b. Petropolitani.

Comparatis speciminibus citatis vix de identitate A. subulati et brachyphylli dubitarem, nec diagnoses citatae utriusque speciei diversitates praebent; specimen hb. Boissieriani A. subulati habet scapum pleiostachyum. Colore nigricante plantae exsiccatae, foliis brevibus $5-6^{\prime \prime \prime}$ longis, floribusque minutis facile recognoscendum.

\section{Sectio VII. Tragacanthina.}

Spiculae uni- raro bi- pluriflorae. Nervi calycis intus glabri. Folia vernalia carnosula saepius mox diffracta, aestivalia spinosa margine laevissima.

Habitant frequentissima in Persia media et orientali, rara in Persia boreali-occidentali, et nonnulla in Beludshistano et Afghanistano. Species plurimae inter se valde affines forsan formae variabiles unius speciei. Spiculis 2-plurifloris distinctae aegre sejungendae ab aliis ob proximam affinitatem, v. c. A. visciduli et Schirasiani, cum tomentello vel talagonico. Melius forsan in subsectiones dividendae e structura calycis, et colore limbi, sequenti modo:

1. Calycis limbus ampliatus 2.

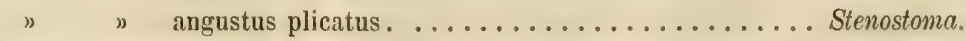

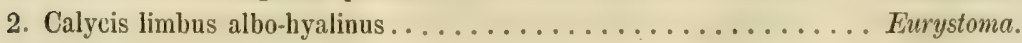

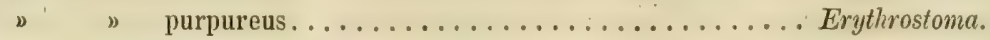


Subsectio 1. Stenostoma.

Calyx limbo plicato angusto tubulosus. Spiculae uniflorae. Calycis tubus fere semper glaberrimus. Spicae plerumque laxissimae.

1. Scapi elongati, spica composita e spicis parvis fasciculatis distantibus, spiculis $2-5$-confertis, calyx $2 \frac{1}{2}{ }^{\prime \prime \prime}$ longus tubo puberulo.... A. polystachyum.

Scapi paniculato-3-pleiostachyi, spicae elongatae laxae. Calyces $3-7^{\prime \prime \prime}$ longi glaberrimi. 2 .

2. Calycis limbus 10-lobus, lobis aequalibus acutis, tubo rubro-punctato $A$. heratense. „5-lobus, 5-fidus vel truncatus. 3.

3. Calycis $\left(5^{\prime \prime \prime} 1\right.$.) limbus truncatus nervis ante marginem evanidis, bractea exterior interiores bilobas calycis triente breviores subaequans A. truncatum.

" limbus distincte 5 -lobus. 4 .

4. Calycis limbus subinfundibularis, lobis acutis vel mucronulatis. 5 .

D angustissime plicato-contractus lobis obtusis. 6 .

5. Calyx $7^{\prime \prime \prime}$ longus, bractea exterior interioribus acutis dimidio brevior, interiores calycis tubo triente breviores ............. longiflorum.

" vix $4^{\prime \prime \prime}$ superans, bractea exterior interiores obtusas calycisque tubum dimidium subaequans.................. Karelini.

6. Calyx $4^{\prime \prime \prime}$ longus, limbi lobi 5 enervii inter nervos retractos ante marginem limbi desinentes, bracteae interiores obtusae exteriore duplo longiores calycis tubum dimidium superantes........ quinquelobum.

" $5^{\prime \prime \prime}$ longus, limbi inter lobos truncati lobi obtusi nervo ante marginem desinente percursi, bracteae subaequales interiores ca-

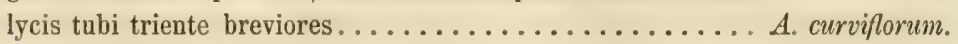

62. A. polystachyum Boiss. DC. prodr. 12. p. 624. n. 7. Catal. Griff. distr. n. 4159.

A. dumosum, glaucurn; ramis paucifoliis elongatis, foliis vernalibus carnosulis multo brevioribus margine scabris mox recurvis et diffractis, aestivalibus longe spinosis laevibus, scapis rigidis firmis tota longitudine remote spicigeris, spicis brevissimis dense $3-5$-spiculatis, bractea exteriore ovata viridi obtusa anguste membranaceomarginata, interioribus duplo longioribus oblongo-linearibus ad carinam scabris obtusis muticis, calycis $\left(2^{1} / 2\right.$ '" longi) tubo ad nervos puberulo, limbo e bracteis brevissime exserto eroso-lobato rubro-striatello.

Habitat in Afghanistano prope Kabul (Griffith! journ. n. 1577) v. s. sp. in hb. Boiss. Caules $2-3$-pollicares. Folia aestivalia $1-1 \frac{1}{2}$-pollicaria. Scapi $1-1 \frac{1}{2}$-pedales spicas $10-25$ inter se $4-6^{\prime \prime \prime}$ distantes $4-4^{\prime \prime \prime}$ longas alternatim gerentes.

63. A. heratense m.

A. dumosum, spinis horridum, glaucum; foliis vernalibus planis abbreviatis margine scabris deciduis, aestivalibus longe spinosis triquetris laevibus, scapis folio brevio- 
ribus fragillimis? monostachyis?, spicis elongatis laxis anfractuosis fragillimis, bractea exteriore brevi ovata mucronulata, interioribus duplo longioribus calycis tubi trientem aequantibus breviter acutatis margine late hyalinis glaberrimis, calycis (5"' longi) tubo glaberrimo rubro-striatello; limbi minutissimi lobis 10 subaequalibus quinis alternis nervo in mucronem prominulo percursis intermediis enerviis lanceolatis acutis.

Habitat in apricis rupestribus prope Herat (Bge. et Bienert!) v. v. sp.

Collegimus autumno pauca specimina floribus jam omnino orbata, spiculasque solutas inter folia ramosque retentas. Fruticulus horridus ramosissimus vix semipede altior, trunco crasso brevi, ramisque intricatis, spinis patentibus inaequalibus $1^{1} / 2^{-p}$ ollicaribus et brevioribus albidis, foliisque vernalibus paucis exaridis tectis. Scapi rudimenta brevia semipollicaria apice squama terminata. Rhacheos articuli, ut videtur, inferiores cum spicula adhuc cohaerentes usque ad 4 "' longi, alii breviores, glaberrimi, teretes; flores summi approximati. Bractea inferior ovata acuta medio herbaceo-membranacea margine late hyalina lineam vix excedens; intima $2^{\prime \prime \prime}$ longa intermedia vix brevior sensim acutatae et in cuspidem brevem productae maxima parte hyalinae Calycis tubus fructifer pentagonus, versus faucem valde angustatus $4^{\prime \prime \prime}$ fere excedens, limbus minutus profunde 10 -tidus, laciniis lanceolatis. Petala limbum calycinum dupla vel tripla longitudine ejus excedentia.

\section{A. truncatum m.}

A. dumosum, spinis horridum, glaucum; foliis vernalibus carnosulis plano-trigonis margine scabris abbreviatis, aestivalibus longe spinosis trigonis calcareo-verrucosis, scapis elongatis pluriarticulatis fragillimis di-? tristachyis, spicis elongatis laxis fragillimis, bractea exteriore breviter ovata acutiuscula interioribus longioribus obtusissimis bilobisve tubi trientem aequantibus glaberrimis, calycis $\left(4-5^{\prime \prime \prime}\right.$ longi) tubo glaberrimo concolore, limbo brevissimo angusto omnino truncato mutico.

Habitat in Persiae mediae occidentalioribus inter Ispahan et Teheran in rupestribus apricis prope Schurab (Bge. et Bienert!), prope Sio-kuh, in Persia media in vicinitate magni deserti salsi versus austrum ab urbe Teheran (Bode! in hb. Fisch.) v. v. sp.

Unicum specimen collegimus speciei calycis structura, ut videtur, bene distinctae. Habitus fruticuli omnino praecedentis. Folia basi membranaceo-auriculato-dilatata; spinae fere bipollicares. Articuli scapi plus quam pollicares, terminati squama fere ex toto hyalina, brevi, breviter acutato-mucronata. Spicae valde laxae articuli $3-4^{\prime \prime \prime}$ longi Bracteae etiam interiores $1 \frac{1}{2 \prime \prime \prime}$ non excedentes. Petala longe exserta rosea. Calyx subcurvatus.

65. A. quinquelobum $\mathrm{m}$.

A. dumosum, spinis horridum, glaucescens; foliis vernalibus carnosulis plano-trigonis recurvis margine scabris emarcidis, aestivalibus subulato-spinosis supra planiusculis laevibus, scapis folium aequantibus vel paulo longioribus gracilibus di-trista- 
chyis, spicis anfractuosis laxissimis 4--12-spiculatis, bractea exteriore dimidio breviore membranacea acutiuscula interioribusque subhyalinis obtusis rubropunctatis calycis (4" longi) tubum glaberrimum dimidium superantibus, limbo nervis retractis marginem haud attingentibus inter nervos breviter obtuse 5-lobo, lobis enerviis.

Habitat in rupibus dolomiticis aridis prope Schahrud provinciae Chorassan occidentalis (Bge. et Bienert!) v. v. sp.

Gracilior quam praecedentes, spinis tenuioribus brevioribus confertis, raro pollice longioribus, basi vix membranaceo-dilatatis. Spica primaria $1 \frac{1}{2}-3$-pollicaris, laterales breviores. Bracteae interiores multo majores quam in praecedentibus et ratione tubi calycis longiores; $2 \frac{1}{2}{ }^{\prime \prime \prime}$ longae. Corolla rosea longe exserta.

66. A. curviflorum $\mathrm{m}$.

A. fruticosum, ramis elongatis longe nudatis, spinis remotis virentibus subulatis gracilibus basi auriculato-membranaceo-dilatatis, folis primariis abbreviatis cornosulis recurvis fugacibus, scapis gracilibus longissimis fragillimis ramoso-pleiostachyis, spicis anfractuosis laxissimis 8-12-spiculatis, bracteis subaequalibus exteriore paulo breviore ovata acuta, interioribus praeter nervum hyalinis obtusis acutis mucronulatisve tubi trientem subaequantibus, calycis ( $5^{\prime \prime \prime}$ longi) tubo curvato glaberrimo, limbo brevissime quinquelobo lobis obtusiusculis lanceolatis nervo percursis inter lobos truncato.

Habitat in rupestribus Persiae mediae occidentalioris prope Kohrud et prope Schur-ab, inter Isfahan et Kum (Bge. et Bienert!).

Valde affine binis praecedentibus et melius forsan cum illis conjungeretur, sed habitus omnino alienus. Fruticulus pedalis vel altior ramis denudatis elongatis; folia spinosa gracilia elongata virentia hinc inde verruculis calcareis adspersa, $1 \frac{1}{2}$-pollicaria vel longiora. Scapi cum inflorescentia plus quam semipedales, spicae inferiores longe pedunculatae remotae breviores, primaria vel terminalis 3-pollicaris vel longior; articuli spicarum arcuati inferiores semipollicares, superiores sensim breviores. Bractea inferior vix duas lineas longa superiores parum longiores. Limbi calycini nervi non retracti, sed in lobos anguste hyalinomarginatos producti. Specimina collecta pauca floribus paucis tantum evolutis; plantae Schurabensis folia validiora bipollicaria vel longiora; spicae breviores, praeter calycis limbum, fere $\mathrm{A}$. truncatum in mentem vocant.

67. A. longiflorum Boiss. Diagn, ser. 2. n. 4. p. 63.

A. dumosum, spinis horridum, glaucescens; foliis vernalibus abbreviatis herbaceis subtrigonis supra canaliculatis glabris emarcidis, serioribus spinosis elongatis basi sensim dilatata vix membranaceo-marginatis laevibus supra planiusculis, scapis folium aequantibus $2-3$-stachyis, spicis laxe $2-4$-spiculatis flexuosis, bractea exteriore ovato-triangulari viridi albo-marginata acuta, interioribus duplo longio- 
ribus dorso herbaceis rubellis late marginatis muticis, calycis $\left(7^{\prime \prime \prime}\right.$ longi) tubo glaberrimo bracteis duplo longiore sensim in limbum vix ampliatum 5-lobum producto, limbi laciniis erectis triangularibus nervo percursis mucronulatis.

Habitat in regno Cabulico circa Choky et Kuelah vulgare (Griffith); in Beludshistano circa Dubend (Stocks!) v. s. sp. comm. a cl. Boissier.

A praecedentibus, quibus arcte affine, calycis limbo paulo ampliore transitum facit ad sequentem speciem et ad subsectionem Eurystoma; habitus omnino A. heratensis.

68. A. Karelini Sczegl. sub Statice in Bull. mosq. 1851. 2. p. 475 . tab. XIII. fig. 4. A. Szovitsii Boiss. et Buhse 1. c. p. 184 (1860).

A. fruticulosum, glaucum, calcareo-squamulatum, laxe foliosum; foliis vernalibus carnosulis planiusculis vel subtriquetris margine scabris recurvis deciduis, aestivalibus spinosis elongatis basi late hyalino-auriculatis laevibus supra planis, scapis folium vix superantibus paniculato-pleiostachyis, spicis elongatis laxis flexuosis $2-12$ spiculatis fragillimis, bractea exteriore ovato-lanceolata acuminata, interioribus obtusis vix longioribus tubum calycinum dimidium aequantibus, calycis ( $4^{\prime \prime \prime}$ longi) limbo anguste plicato 5-fido, lobis ovato-lanceolatis nervosis nervo ad apicem producto acutis vel prominulo mucronulatis.

Habitat in Armenia rossica Persiae contermina in salsuginosis prope Nachitschewan, in valle Alindsha (Buhse!), in collibus aridis circa Nachitschewan (Szovits! Kowalensky!) v. s. sp.

Spinae 10-17"' longae; scapi ipsi subpollicares cum inflorescentia $3 \frac{1}{2}-4$-pollicares. Spicae 3-6, pedunculatae. Spiculae leviter curvatae inter se longitudine bractearum, vel inferiores longius distantes. Bractea exterior crassiuscule cuspidata margine late membranacea, interiores paulo longiores membranaceae nervo viridi valido percursae obtusae, interdum brevissime aristulatae. Calycis tubus raro glaber plerumque puberulus, limbus magis dilatatus quam in praecedentibus, lobis latioribus. Petala rosea longe exserta. Habitu cum A. quinquelobo congruit.

\section{Subsectio 2. Eurystoma.}

Calycis limbus albo-hyalinus expansus infundibularis; spiculae 1-rarius 2-pluriflorae, plerumque fasciculatim confertae, in scapis raro mono- saepins di- tristachyis, interdum cymosae. Habitant in Persia media praesertim in circuitu magni deserti salsi, rariores in Afghanistano et Beludshistano.

Clavis specierum diagnostica.

1. Tomentella, folia fere impunctata, scapi pubescentes, bracteae interiores obtusae vel bilobae muticae, calyx $4^{\prime \prime \prime}$ longus, limbus truncatus, spiculae interdum biflorae. 2.

Glabra, scapi glaberrimi. 4. 
2. Scapi monostachyi, bracteae interiores tubum calycinum superantes, calycis nervi nigri, folia conferte caespitosa glauca, scapi folio breviores . ....................... tomentellum.

Di- pleiostachyi, bracteae interiores tubum aequantes vel breviores, calycis nervi pallidi. 3.

3. Viride, folia conferto-caespitosa, scapi folio breviores, bracteae interiores tubum puberulum aequantes, nervi ad marginem producti, spicae fasciculatae ................. talagonicum.

Glaucum, folia remota, dumosum, scapi folio longiores, bracteae interiores tubo subglabro breviores, nervi ante marginem evanescentes, spicae cymosae................ schahrudicum.

4. Spiculae pleraeque 2-3-florae. 5.

" omnes uniflorae (rarissime una alterave biflora, conf. A. schirasianum et viscidulum). 6 .

5. Dumosum, glaucum, folia crassa rigida, scapi monostachyi, calyx $5^{\prime \prime \prime}$ longus limbo aristulato ................. horridum.

caespitosum, viride, folia tenuiter subulata, scapi di- pleiostachyi, calyx $4^{\prime \prime \prime}$ longus muticus.................. fasciculare.

6. Scapi brevissimi monostachyi, spicae brevissimae pauciflorae, bracteae interiores late obovatae, rachis bracteae et tubus visciduli. 7 .

" plus minusve elongati, spicae pluriflorae. 8.

7. Viride, folia omnia margine glabra confertissima, bracteac interiores calycis tubo glaberrimo breviores acutiusculae ......... viscidulum.

Glaucescens, folia vernalia margine scabra, spinae remotae, bracteae interiores calycis tubum parce hispidulum aequantes obtusissimae mucronatae................... schirasianum.

8. Spicae rachis elongata anfractuosa, spiculae bractearum longitudine vel longius ab invicem remotae.............. aristulatum.

n rachis brevis, spiculae imbricatae, articuli vix bracteam exteriorem aequantes. 9 .

9. Folia basi puberula gracilia elongata, bracteae exterior longe acuminato-cuspidata interiores subaequans............ tragacanthinum.

Folia basi glabra, bracteae interiores exteriorem obtusam vel brevissime obtuse vel hebetato-mucronatam multo superantes. 10 .

10. Folia basi elongato-vaginantia omnia erecto-patula, bracteae interiores acutatae, fruticosum ramis elongatis 
Folia basi vel abrupte breviter membranaceo-auriculata vel fere immarginata, vernalia carnosula recurva decidua, bracteae interiores obtusae vel bilobae. 11.

11. Calyx glaberrimus submuticus, folia basi abrupte membranaceoauriculata, bracteae interiores obtuse bilobae e dorso brevissime mucronulatae vel omnino muticae........... incomptum.

» ad nervos puberulus, bracteae interiores obtusae muticae vel ex apice mucronulatae. 12.

12. Calyx obsolete 5-lobus breviter mucronulatus, spicae confertae, bractea exterior interioribus dimidiis brevior, spinae ve-

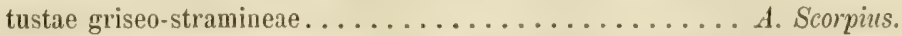

》profunde 5-lobus 5-aristulatus, spicae laxiusculae, bractea exterior interiores dimidias superans, spinae vetustae albidae A. leucacanthum.

69. A. aristulatum $\mathrm{m}$.

A. dumoso-fruticulosum, glabrum, glaucum; ramis elongatis, foliis vernalibus carnosulis recurvis trigonis margine scabris emarcidis, caeteris spinosis laevibus basi glabris patentissimis, scapis folium superantibus pleiostachyis, spicis laxissimis flexuosis, spiculis unifloris fere tota earum longitudine ab invicem distantibus, bractea exteriore herbacea ovata late hyalino-marginata in cuspidem brevem sensim attenuata, interioribus duplo longioribus calycis tubum aequantibus praeter nervum in aristam productum hyalinis, calycis (4"' longi) tubo glabro in limbum albo-hyalinum infundibularem 5-lobum sensim ampliato, lacinis limbi late ovatotriangularibus longe purpureo aristatis.

Hab. versus fines austro-orientales Persiae in apricis montosis prope Kuh-i-bachtun, Sertschah, Serdani, ubi jam Martio florere incipiens collegimus (Bge. et Bienert) v. v. sp.

A subsequentibus facile distinctum spicis laxissimis elongatis. Fruticulus semipedalis vel altior. Rami vetustiores fusco-brunnei, in partibus panlo longioribus reliquiis foliorum emarcidorum vernalium, in brevioribus spinis vetustis albidis remotioribus patentissimis $1-1^{1} / 2$-pollicaribus vel parum longioribus basi anguste membranaceo-marginatis horridi. Folia vernalia recurva mox fragillima apice subito in spinulam tenuissimam contracta. Spicae longe pedunculatae 3-6-spiculatae; articulis jam in spica juniore $2-6^{\prime \prime \prime}$ longis, gracilibus. Spicis laxis accedit ad species subsectionis praecedentis.

70. A. tragacanthimum Boiss. Diagn. ser. 1. 7. p. 81. DC. prodr. 1. c. p. 626. n. 17. Statice tragacanthina Jaub. et Spach ll. cc. St. Spachii Girard. Ann. sc. nat. ser. 3. vol. 1. p. $332 \mathrm{cx}$ parte.

A. dumoso-fruticosum, glaucescens; ramis elongatis, foliis vernalibus carnosulis margine scabris recurvis trigonis, spinis remotiusculis basi auriculato-marginatis 
extus puberulis gracilibus supra planiusculis tenuiter punctatis parce calcareoverrucosis, scapis folium superantibus di-pleiostachyis, rhacheos anfractuosae articulis inferioribus bracteam exteriorem aequantibus, spicis imbricatis abbreviatis, spiculis unifloris, bractea exteriore interiores subaequante coriacea membranaceo-marginata, interioribus scarioso-hyalinis obtusis ex apice vix mucronulatis muticisve tubum aequantibus, calycis ( $5^{\prime \prime \prime}$ longi) tubo glabro limbi hyalini 5-lobi nervis rubris puberulis in aristulam productis.

Habitat in aridis ad lacum Urmiah, Persiae occidentali-borealis (Aucler Eloy! hb. d'or. n. 5239. ex parte), inter Chorum-derreh et Sultanieh ad occidentem ab urbe Teheran (Bge, et Bt.!), prope Teheran (Jenisch! in hb. Fisch.) v. v. sp.

Folia spinescentia graciliora quam in tribus sequentibus, $1-1^{1 / 2}$-pollicaria.

71. A. Scorphits Boiss. 11. cc. n. 16. Statice Scorpius Jaub. et Sp. 11. cc. Statice Spachii Girard l. c. ex parte. Statice ferox Jaub, et Sp. ll. cc. Ac. ferox. Boiss. ll. cc.

A. dumoso-fruticulosum, glancum; ramis subelongatis, foliis vernalibus carnosulis margine scabris recurvis trigonis, spinis confertis basi extus glabris dilatato-hyalino auriculatis supra planis vetustis griseo-stramineis, scapis folio brevioribus 1-3stachyis, spicis confertis racheos articulis brevissimis, spiculis unifloris, bractea exteriore brevissima membranacea obtusa mutica, interioribus scarioso-hyalinis bilobis ex apice mucronulatis vel submuticis tubo brevioribus, calycis ( $4^{\prime \prime \prime}$ longi) tubo glabro ad nervos limbi subtruncati puberulo, nervis ex apice loborum vix prominulis.

Hab. ad sinum Persicum (Aucher Eloy. hb. d'or. n. 5239. ex parte test. Spach), in aridis montium prope Kerman Persiae austro-orientalis (Bge. et Bienert!) v. v. sp.

Statice ferox, cujus specimina authentica non vidi, e diagnosi nulla re a St. Scorpio differt, nisi spicis solitariis, quales vero etiam in speciminibus caeterum scapos 2 - 3 -staclyos ferentibus observavi.

72. A. leucucanthum Boiss. Diagn. ser. 1. 7. p. 81. DC. prodr. 1, c. n. 18. Statice leucacantha Jaub. et Spach. !1. cc.

A. dumoso-fruticosum, glaucum; ramis subelongatis, foliis vernalibus lineari-trigonis margine scabris recurvis, spinis validis subconfertis basi extus glabris vix hyalinomarginatis vetustis cretaceo-albis, scapis folium superantibus di- pleiostachyis, spicis confertis e spiculis unifloris in rachi subflexuosa, bractea exteriore interiores vix dimidias aequante coriacea margine hyalina, interioribus hyalinis bilobis submuticis vel e dorso mucronulatis tubum aequantibus, calycis $\left(4^{1} /{ }_{2}^{\prime \prime \prime}\right.$ longi) tubo parce hispidulo, limbi quinquefidi nervis puberulis rubris in aristulam productis.

Habitat in Persia australiore: ad sinum Persicum (Aucher Eloy. hb. d'or. 11, 5239 ! ex parte), in monte Sofa, prope Isfahan (Bode! in hb. Fisch. Bge. et Bienert!) v. v. sp. 
Folia validiora quam in praecedentibus pollice plerumque longiora interdum plus quam sesquipollicaria.

73. A. incomptum Boiss, et Buhse 1. c. p. 183.

A. dumoso-fruticulosum, glaucescens; ramis subelongatis, folis vernalibus trigonis recurvis carnosulis deciduis margine scabris, spinis remotiusculis supra planis basi auriculato-hyalino-membranaceis glabriusculis, scapis folium superantibus mono-distachyis, rhacheos strictae articulis brevissimis, bractea exteriore breviore' obtusa mutica membranacea, interioribus scarioso-hyalinis bilobis brevissime e dorso mucronatis muticisve tubum aequantibus, calycis ( $5^{\prime \prime \prime}$ longi) superne ad nervos hispiduli limbo obsolete quinquelobo, nervis rubellis extus subglabris marginem vix superantibus.

Hab. in rupestribus pagi Taft, prope urbem Yesd (Bulse!), et prope Kerman-schahi, inter Kerman et Jesd (Bge. et Bienert!) v. v. sp.

Formae sub nominibus A. tragacanthini, Scorpii, leucacanthi, et incompti distinctae, inter se tam affines sunt, ut potius unicam speciem valde polymorpham constituunt. Discrimina nempe omnia characteribus valde variabilibus nituntur. Habitus secundum stationem aridiorem vel fertiliorem variare solet. Spinae mox graciliores, mox firmiores, longiores vel breviores, saepe in eodem specimine e varis annis persistentes. Spicae solitariae binae ternae vel plures in variis scapis ejusdem fruticuli, quare $A$. ferox ab aliis nullo modo distinguendum; $\Lambda$. incomptum saepius vidi distachyum, A. Scorpius 1-2-3-stacliyum. Bractearum forma et longitudo relativa praestantissimos praebent characteres, tamen variant inter certos limites, nam in una eademque spica observantur bracteae interiores obtusae vel bilobae, longius aristulatae, mucronulatae, et omnino muticae. Nec minus pubescentia nervorum limbi calycini variabilis; in $\mathbf{A}$. incompto hi plerumque glaberrimi in caeteris hispiduli, sed et in illo interdum apparent pili nonnulli, et in caeteris pubes vel parcior vel densior, interdum fere nulla. Calycis dimensiones fere in omnibus eaedem, in A. tragacanthino caeteris paulo major; in $\Lambda$. Scorpio et leucacantho paulo minor. Nervi in omnibus purpurascentes, etiam in incompto, quamvis hic paulo pallidiores, semper in mucronem vel aristulam longiorem producti.

74. A. Stocksï Boiss. Diagn. ser. 2. n. 4. p. 63.

A. fruticosum, glaucum, glaberrimum; ramis elongatis remote spinosis; foliis omnibus rigidis erecto-patulis margine laevissimis primariis multo brevioribus caeteris elongato-spinosis tereti-subcompressis subulatis basi elongato-vaginantibus hyalinomarginatis tenuissime ciliolatis, scapis folium subaequantibus $2-3$-stachyis, spicis brevibus laxis $2-4$-spiculatis, rhachi flexuosa, spiculis unifloris, bractea exteriore triangulari acuta herbacea hyalino-marginata, interioribus herbaceo-carinatis late hyalinis duplo longioribus acutis, calycis $\left(5^{\prime \prime \prime}\right.$ longi) inferne glabri superne ad costas 
hirsuti tubo bracteas interiores aequante, limbi patuli quinquelobi nervis rubentibus in mucronulum brevem productis.

Habitat in ditione Beludshistan prope Ispingli (Stocks pl. exs. n. 1091!) v. s. sp. comm. ab am. Boissier.

Ramis elongatis tenuibus, foliisque omnibus spinosis, quamvis vernalibus minoribus, facile a praecedentibus distinguendum. Folia majora $1 \frac{1}{2}-2$-pollicaria. Spicae vix pollicares.

75. A. viscidulum Boiss. Diagn. ser. 1. n. 7. p. 71. DC. prodr. XII. p. 625. n. 10.

A. erinaceo-caespitosum, laete viride, glabrum, minutissime punctatum; ramis abbreviatis, foliis glabris confertissimis subglanduloso-viscidulis infimis brevioribus mucronatis margine glabris caeteris rigide aceroso-spinosis supra planis subtus rotundato-carinatis, scapis brevissimis monostachyis, spicis inter folia subsessilibus capitato-incurvis $4-5$-spiculatis, spiculis unifloris arcte imbricatis, rhachi viscidula brevissima, bracteis viscidulis exteriore brevi mutica obtuse mucronata viridi vix marginata, interioribus subtriplo longioribus chartaceo-membranaceis acutatis muticis tubo brevioribus, calycis $\left(5^{1} / 2\right.$ '" longi) glaberrimi limbo truncato, nervis nigricanti-purpureis vix ultra marginem productis.

Hab. in Persia (Aucher Eloy. herb. d'or. n. 2509!) v. s. sp. in herbario amiciss. Boissier.

Folia omnino evoluta $10^{\prime \prime \prime}$ longa, supra basin vix $1 / 2$ "' lata. Spiculas omnes uniftoras vidi, interdum accedente bractea quarta.

76. A. schirasianum Boiss. 11. cc. p. 72. et p. 625. n. 11. Statice erinacea Boiss. in Kotschy pl, pers. austr. exs. n. 305. non Jaub. et Spach.

A. erinaceo-dumosum, glaucescens, glabrum, subviscidum, tenuiter punctatum; ramis subelongatis, foliis vernalibus brevissimis triangulari-lanceolatis planis mucronatis basi margine scabris, spinis subremotis patulis tereti-subulatis acerosis basi brevissime membranaceo-marginatis, scapis brevissimis monostachyis, spicis inter folia subsessilibus 5-9-spiculatis, spiculis in rhachi viscidula brevissima arcte imbricatis subunifloris, bractea exteriori brevi ovata concava viridi breviter crasse mucronata, interioribus plus duplo longioribus obtusiusculis mucronulatis chartaceo-membranaceis late hyalino-marginatis calycis tubum aequantibus, calycis $\left(5^{\prime \prime \prime}\right.$ longi) tubo superne parce hispidulo, limbi obsolete 5 -lobi nervis rubris vix puberulis ultra marginem in mucronulum productis.

Habitat in rupestribus ad monumentum Nakschi-rustam prope urbem Schiras Persiae australis (Kotschy!) v. s. sp.

Folia $7-9^{\prime \prime \prime}$ longa. 


\section{A. horidum $\mathrm{m}$.}

A. dumosum, dense hystricinum, subglaucescens, glabrum, fere impunctatum, viscidulum; ramis subelongatis, foliis vernalibus breviter lanceolatis margine praeter basin breviter et anguste membranaceam parce ciliolatam glabris, caeteris rigide crasse spinosis patentissimis, scapis folio brevioribus monostachyis, spicis breviter 1-4-spiculatis, spiculis in rachi viscidula confertis subbi- $(1-3)$ spiculatis, $4-6$ bracteatis, bractea exteriore suborbiculari coriaceo-herbacea breviter obtuse mucronata, interiorum extima late obovata medio coriacea margine late hyalina obtusissima sub apice breviter mucronulata, sequentibus sensim angustioribus praeter costam sub apice in mucronem brevissimum productam hyalinis, intima paleaeformi breviore, calycis $\left(5^{3} / 4^{\prime \prime \prime}\right.$ Iongi) glaberrimi limbo obsolete 5-lobo nervis excurreńtibus breviter aristulato.

Hab, in aridis montosis prope Gerde-kuh inter Kerman et Jesd Persiae australis (Bge. et Bienert!) v. v. sp.

Folia vernalia basi saepe $1^{1} / 2$ "' lata, tunc demum refracta, serius decidua, spinae $8-10^{\prime \prime \prime}$ longae rigidissimae diu persistentes, confertae, crassae, supra planiusculae subtus convexae. Scapi graciles $4-6^{\prime \prime \prime}$ longi glabri viscidi, rachisque fragillimi. Spiculae saepius 3 -quam uniflorae. Bractea exterior $1-1^{1} / 2$ "' longa, interdum omnino mutica, anguste hyalino-marginata, sequens $3^{\prime \prime \prime}$ vix excedens, caeterae vix breviores praeter intimam omnino enerviam. Calyces saltem inferiores brevissime stipitati, tubo sensim in limbum infundibularem albo-hyalinum amplihto, nervi limbi basi virentes, superne atropurpurei. Corolla pallida ut videtur brevis, vix calycis limbum excedens. Habitus fere A. schirasiani, sed rigidius, spinae. validiores et spiculae pluriflorae.

78. A. fasciculare Boiss. in DC. prodr. 1. c. p. 626, n. 15. A. tragacanthinum? Griff. collect. catal. Kew. n. 4157 ?

A. glabrum, viride vel subglaucescens, erinaceo-caespitosum confertifolium, tenuiter punctatum, esquamatum, brevirameum; foliis vernalibus margine scabris, spinis supra planis basi dilatato-auriculatis tenuiter subulatis, scapis folia aequantibus glabris di-pleiostachyis, spicis confertis, spiculis in apice scapi subfasciculatis bifloris, bracteis glabris exteriore breviore coriacea aceroso-mucronata, interioribus chartaceo-herbaceis late hyalino-marginatis obtusis ex apice mucronatis tubum calycis (4"' longi) parce hispidulum aequantibus, limbi calycini truncati mutici nervis vix puberulis usque ad marginem productis nigris.

Habitat in regno Cabulico (Griffith! n. 1583. a.) v. s. sp. in herb. amic. Boissier. Folia pleraque pollicaria, angusta.

79. A. tomentellum Boiss. Diagn. ser. 1. n. 7. p. 72. DC. prodr. 1. c. p. 625. n. 12. Statice tomentella Boiss. in Kotschy pl. Pers, austr. n. 670 ! 
A. tomentello-pubescens, glaucescens, dumoso-caespitosum, confertifolium, fere impunctatum, subglandulosum, brevirameum; foliis vernalibus brevissimis triangularilanceolatis margine scabris, spinis validis rigidis patentibus supra planis subtus convexis basi sensim dilatata membranaceo-marginatis, scapis brevissimis pubescentibus monostachyis, spicae brevissimae rhachi glabra viscidula, spiculis uni-rarissime 2-3-floris, bractea exteriore brevissima coricea mucronata, interioribus scariosohyalinis duplo longioribus obovatis obtusissimis muticis calycinum tubum superantibus, calycis (4"' longi) tubo adpresse puberulo, limbi mutici truncati nervis subpuberulis nigris ad marginem usque productis.

Habitat in lapidosis alpis-Kuh-Daëna Persiae anstralis prope Schiras (Kotschy!) v. s. sp.

Folia $9-10^{\prime \prime \prime}$ longa. Scapi usque ad bracteam fere ommino hyalinam patulo-hispidi, abhinc glabri visciduli, ut in sequente, cui valde affine:

S0. A. talagonicum Boiss. in DC. prodr. l. c. p. 625. 11. 14. Kotschy pl. Pers. bor. 11. 514 !

A. pubescens, virens, erinaceo-caespitosum, confertifolium, fere impunctatum parce calcareo-squamulosum; ramis subelongatis, foliis vernalibus brevissimis planis lineari-lanceolatis recurvis margine scabris, spinis elongatis acerosis rigidis patentissimis supra planiusculis subtus convexis, scapis folio vix longioribus 2-pleiostachyis, spicis fasciculatis, spiculis $6-8$ confertis uni-rarissine $2-3$-floris in rachi brevissima viscidula, bractea exteriore ovato-rotundata viridi anguste marginata submutica, interioribus duplo Iongioribus scarioso-hyalinis truncatis muticis calycinum tubum aequantibus, calycis ( $4^{\prime \prime \prime}$ longi) tubo parce hispidulo; limbi vix erososinuati mutici nervis pallidis puberulis ad marginem usque productis.

Hab. in jugi Elbrus Persiae borealis mediae valle Talagon inter pagos Dshoistan et Gettadeh, haud procul ab urbe Teheran (Kotschy) v. s. sp.

Folia longiora graciliora quam in praecedente, horizontaliter patentissima. Scapi indumentum idem.

81. A. schahuedicum m. A. sp.. indet. tomentello aff. Boiss. et Buhse l. c. p. 183.

A. tomentellum, glaucum, fere impunctatum, calcareo-squamulatum, dumoso-fruticosum, remotifolium; ramis. junioribus elongatis subflexuosis, foliis vernalibus carnosis brevibus trigonis margine scabris, spinis validis elongatis supra planis subtus convexis basi brevissime marginatis, scapis folio duplo longioribus pubescentibus 3 -pleiostachyis, spicis cymosis, spiculis in rachi brevissima viscidula glabra confertis $1-3$-floris, bracteis omnibus obtusis muticis, exteriore brevissima coriacea late membranaceo-marginata, interioribus scarioso-hyalinis truncato-bilobis tubo calycino vix brevioribus, calycis (4" longi) tubo subglabro, limbi vix eroso-sinuati subtruncati mutici nervis pallidis ante marginem evanidis. 
Hab. in rupibus aridis montium dolomiticorum prope urbem Schahrud (Bge. et Bienert!), inter Isfahan et Kaschan prope pagum Sof (Buhse!) et prope Kum (Bode! in hb. olim Fisch.) v. v. sp.

A praecedentibus binis quibus proxime affine abunde differre videtur signis in diagnosi expositis, praesertim foliis in ramis junioribus remotis et inflorescentia multifiora, fere cymosa, spicis inferioribus longiuscule pedunculatis $5-8$-spiculatis, et spiculis saepius bitrifloris. Folia longiora, spinae omnino evolutae $1 / 2$-pollicares, crassiores quam in A. talagonico, saepe incurvae.

\section{Subsectio 3. Erythrostoma.}

Calycis limbus roseus vel purpureus expansus infundibularis vel hypocraterimorphus; spiculae uniflorae confertae; scapi saepius brevissimi mono- di-tristachyi.

Habitant in Persia, altera species late vagans in montosis et alpinis totius fere Persiae usque ad regnum Cabulicum, altera in Persiae orientalioris rupibus aridissimis demissioribus.

82. A. roseum Boiss.! Diagn. 1. c. DC. prodr. 1. c. Catalog. Griff. distr. n. 4168! A. rubellum Boiss. in litt.! Statice pungens et erinacea Jaub. et Spach Il. cc. St. Jauberti Girard 1. c. St. juniperina Willd. in Roem. et Schult. s. veg. VI. p. 799 ?

A. viride, fere impunctatum, esquamatum, dense erinaceo-caespitosum, confertifolium, foliis vernalibus brevibus margine scabris mox deciduis paucis, 'caeteris spinosoacerosis supra planis brevibus margine laevibus pubescentibus, vel rarius glabris, spicis subsessilibus $3-5$-spiculatis, spiculis in rachi abbreviata dense pubescente confertis, bractea exteriore breviore lanceolata pungente coriacea margine anguste membranacea, interioribus praeter costam scarioso-membranaceis acutis mucronatis purpurascenti-fuscis tubum calycinum superantibus, calycis $(4-4 \% \underline{1}$ "' longi) tubo glabro, nervis limbi rosei truncati mutici glabris vel pubescentibus.

Habitat in jugo Elbrus Persiae borealis (Hablizl!), ad radicem montis Elanut (Aucher Eloy hb. d'or. n. 5240 ! et n. 2510), in regno Cabulistano (Griffith n. 1591 et catal. Grift. 11. 4168), in alpinis provinciae Chorassan inter Nischapur et Meschhed, provinciae Kuhistan Persiae austro-orientalis inter Isfesar et Derremian 9000' s. m. (Bge. et Bienert!), in montosis prope Teheran (Jenisch! in hb. ol. Fisch.) et in monte Dalachani Kurdistaniae Persiae finitimae alt. 10000 ! (Hausknecht pl. exs. 11. 830 $0^{\text {b }}$ ) v. v. sp.

Species valde variabilis cujus varietates duas distinguit cl. Boiss., errore permutans nomina Spachiana; nam St. pungens habet bracteas velutinas, St. erinacea vero glabras. Formae tamen occurrunt intermediae, interdum cnim bractea exterior, saltem basi pubescit, interiores glabratae sunt. Folia tum dense pubescentia, tum glabra; vix semipollicaria et usque ad $9^{\prime \prime \prime}$ longa; scapi vel omnino nulli, spicaeque sessiles, vel fere folium aequantes, semper ut etiam rhacheos articuli dense pubescentes. Semper vidi spicas solitarias tantum. Calyx rarius omnino glaber, fere semper pili aliquot in uervis limbi adsunt; saepius hi 
dense hirsuti, et pubes interdum etiam in tubum descendit. Species sequens affinis quidem proxime, attamen abunde distincta videtur habitu elongato-fruticuloso, foliis remotis vernalibus crebrioribus fugacibus, spinis multo longioribus validioribus paucis, spicis plerumque $2-3$ in scapo et bractea exteriori interiores aequante, aliter conformata. Planta kurdistana, quam nomine A. rubelli communicavit amiciss. Boissier vix ac ne vix quidem differt a speciminibus Hablizlii e montibus ghilanicis.

\section{A. gulistunum $\mathrm{m}$.}

A. glancescens, impunctatum, esquamatum, dumoso-fruticulosum laxifolium, tenuissime puberulum; foliis vernalibus numerosis fugacibus vaginis hyalinis tantum persistentibus in ramis longius inter spinas denudatis, spinis paucioribus persistentibus elongatis acerosis margine laevissimis, scapis rhachique tomentello-hirsutis folia aequantibus vel brevioribus, spicis fasciculato-geminatis vel ternis, confertim distiche $4-7$ spiculatis, bracteis subaequalibus pubescentibus, exteriore ovatooblonga a basi ultra medium late membranaceo-marginata abhinc longe abrupte Ianceolato-cuspidata, interioribus oblongis acute carinatis margine fusco-membranaceis media breviter mucronulata intima obtusa calycem arcte amplectentibus ejusque tubum superantibus, calycis (5-6"' longi) tubo subglabro, limbi obsolete 5 -lobi mutici purpurascentis et intensius striatelli nervis liirsutis.

Hab. in rupibus aridis demissioribus circa urbem Meschhed in provinciae Chorassan orientalioribus, prope pagum Gulistan, in montibus Tabat-kuh, et ad fines orientales Persiae in jugo Kerat-kuh (Bge. et Bienert!) v. v. sp.

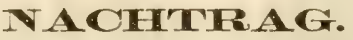

Sach Abschluss des Druckes der vorstehenden Abhandlung erhielt ich von dem Herm Biblinthekar des Kaiserlichen botanischen Gartens von St. Petersburg, von Herder, eine Sendung turkestanischer Pflanzen, die zwei von Herrn Sewerzow gesammelte Arten der Gattung Acantholimon enthielt. Eine vou diesen stimmt genau mit der an demselben Ort - am Dshaman-daban - vom Baron Osten-Sacken gesammelien Pflanze überein, dic ich für eine ausgezeichnete Varietät des $\Lambda$. alatavicum gehalten habe. Sie weicht durch den selır verlingerten, meist dreiährigen Schaft, die zahlreichen Kallsschüppchen auf allen Theilen, die stärker zugespitzten Deckblätter und den grösseren, etwas über $5^{\prime \prime \prime}$ langen 
Kelch, so sehr von der typischen Form ab, dass sie - besonders da keine Uebergaugsformen bekannt sind - wohl als Art sui juris zu betrachten sein möchte (A. Sackeni).

Dagegen zeigt die andere Pflanze eine so auffallend abweichende Bildung von allen andern bekannten Arten der Gattung, dass sie in keine der von mir aufgestellten Sectionen untergebracht werden kann. Ihre weichen, nach oben verbreiterten, nicht stechendeı Blätter, die an der Spitze eine lange, feine, nicht stechende, am Grunde lnieförmig eingeknickte Borste trageu und meist schon während der Bhüthezeit schwinden, unterscheiden sie von allen Arten. Im Blüthenstande ähnelt sie einigermassen dem A. restiaceum und bromifolium, doch sind die Aehrchen fast durchweg einblumig. Das imnerste Deckblatt, nach oben verbreitert und dick lirautartig, ist ganz eigenthümlich und erinnert nur entfernt an die Bildungen bei A. restiaceum und acmostegium, wälrend der Kelchsaum höchstens in A. heratense ein Analogon lat. Sie kömte etwa in folgender Weise der vorstehenden Aufzählung eingereiht werden:

pag. 14, Z. 13 hinzuzufügen zu: foliis acerosis vel spinosis, "rarissime herbaceis innocuis fugacibus $)$.

pag. 14, Z. 20 : nervi calycini intus glabri. $3 "$.

pag. 14, Z. $24: 3^{\text {a }}$. Folia omnia homomorpha margine scabra. $3^{b}$.

pag. 14, zwischen Z. 27 u. 28 einzuschalten:

$3^{\mathrm{b}}$. folia sub apice dilatata herbacea fugacia, apice longe setifera, seta

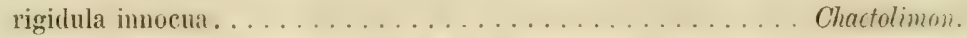

folia acerosa apice pungenti-cuspidata diu persistentia etc. 4.

pag. 24 cinzuschalten :

\section{SECTTO $V^{b}$. Chaetolimon.}

Spiculae sub uniflorae tribracteatae, bractea intima apice herbacea dilatata. Nerri calycini intus glabri. Folia homomorpha, herbacea, margine scabra, sub apice dilatata, apice longe setifera, innocua, fugacia.

A. setifernem n. sp.

Species sectionis unica habitat prope Andersai et in promontoriis Kcharly-tan in vicinitate urbis Chodshent Turkestaniae (Sewerzow!) v. s. sp.

Herba perennis acaulis, radice simplici tenui elongata perpendiculari ad collum parum incrassata. Rosula e foliormu emarcidorum reliquiis fuscis confertis foliis pancis evolutis, ef nomullis nuvellis abbreviati. Folia croluta in petiolum longum gracilem attenuata, spatliulateoblonga fere carnosula, subenervia, (alcareo-punctata, margine minute spimuloso-scabra, alia cum petiolo, sed sine seta, circiter sesquipollicaria, lamina vix ultra 4 -lineari, $1_{\frac{1}{2}}^{\prime \prime \prime}$ lata, alia longiora $2 \frac{1}{2}$ pollicaria, lamina lineari-oblonga fere pollicari, omnia apice setam obliquam vel basi infractam gerentia, $2 \frac{1}{2}$ lineas longam tenuissimam rigidulam, nec tamen pungentem. Folia novella, petiolo nondum evoluto, brevia, vix semipollicaria, caeterum 
conformia. Scapi e rosula plures, basi articulato-fragiles, cum spica octo-pollicares vel pedales et forsan longiores, teretes subglabri calcareo lepidoti, erecti stricti, monostachyi, vel interdum forsan (ex unico specimine) tristachyi, articulis basilaribus $3-4$ sterilibus $1-1_{1 / 2}^{1}$-pollicaribus, squamis scariosis albido-stramineis subenerviis setaceo-acuminatis. Spicac laxissimae 10-18-spiculatae, juniores milaterales rectae, deinde distichae subflexuosae. Articuli rachis inferiores pollicares, sursum breviores, hinc convexi illinc canaliculati, squamulis calcareis crebrioribus scabri. Spiculae uniflorae. Bractea extima ovato-oblonga scariosa straminea, acuta, mutica, subuninervia, nervo apice evanido, spicularum inferiorum $4^{\prime \prime \prime}$ longa, inferne fere duas lineas lata, basi breviter subherbacea amplexicaulis, persistens; interior multo minor hyalina, tenuissime membrauacea inaequilatera, basi breviter dilatata et abrupte setaceo-acuminata, articulo adpressa, persistens. Bractea intima tunc denique cum calyce fructifero articulatim soluta, hunc arcte involvens, coriaceo-herbacea, dorso acute costata, explanata obovata oblonga, acutata, viridis, vix semipollicaris, saepius brevior, marginibus apice subpatulis, interdum subundulatis. Calyx $7^{\prime \prime \prime}$ longus clavato-cylindricus pallidus, tubo minute juberulo, limbo exiguo hyalino facile lacero. laciniis longinscule setaceo-aristatis. Petala amoene rosea calycis tubum circiter tribus lineis excedentia. Stamina et ovarium cum stylis generis. Descriptio facta ad specimina prope Andersai collecta, magis completa. Plantae e montibus Keharly-tau specimen incompletmm paulo ab illa recedit. Folia desunt, nam frustulum caespitis emarcidi adjectum ad aliam speciem pertinet. Scapi pleinstachyi pars snperior paulo rigidior. Spiculae nomnullae biflorae!; in hoc casu bracteola quarta accessoria calycem dimidium fere aequans hyalino-membranacea tenuis, uninervia. Bractea tertia apicem versus paulo magis patulo-dilatata, exsicatione undulata. Caeterum nullum discrimen. 



\section{Index specierum et synonymorum.}

Acantholimon acerosum Boiss.............. 29 acmostegium Boiss, et Buhse.... 3 alatavicum $\mathrm{m} . \ldots . \ldots \ldots \ldots . . .39$ androsaceum Boiss..........51 araxanum $m . \ldots \ldots \ldots \ldots . .28$ aristulatum $\mathrm{m}_{0} . \ldots \ldots \ldots \ldots .699$ armenum Boiss............ 33 aspadanum $\mathrm{m} . \ldots \ldots \ldots \ldots .54$ assyriacum Boiss........... 20 atropatanum $\mathrm{m} . \ldots \ldots \ldots \ldots .24$

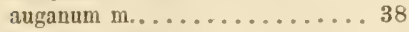
avenaccum $\mathrm{m}, \ldots \ldots \ldots \ldots \ldots . . .18$

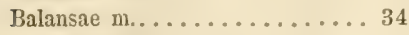
Bodeanum m.............. 43 brachyphyllam Boiss........61 61 brachystachyum Boiss........ 56 bracteatum Boiss............ 5 breviscapum Boiss........... 32 bromifolium Boiss........... 16 cabulicum Boiss........... 7 caesareum Boiss........... 46 Calverti Boiss.............. 26 caryophyllaceum Boiss....... 35 cataonicum m...........45 cephalotes Boiss........... 6 curviflorum m...........666 66 cymosum m............. 1 diapensioides Boiss.......... 12 distachyum Boiss........... 8 Echinus L. Sibth. m......... 51 fasciculare Boiss........... 78 ferox Boiss. ............ 71 festucaceum Boiss.......... 60 flexuosum Boiss............ 55 genistoides Boiss........... 59 glumaceum Boiss............ 41 Griffithianum Boiss.......... 13 gulistanum m............ 83 Hausknechti m........... 36 heratense $m . . . \ldots \ldots \ldots . .63$
Acantholimon Hohenackeri Boiss. .......... 40 Hohenack. Trautv., Herder, Rupr. 39 horridum m. ...........77 Huetii Boiss. ............ 47 incomptum Boiss, et Buhse.... 73 Karelini Sczegl.. . . . . . . . . 68 Kotschyi Boiss. . . . . . . . . . 32 kurdicum m............ 57 latifolium Boiss................. 17 Tatifolium $R u p r . \ldots \ldots \ldots \ldots . . .10$ laxiflorum Boiss. ............ 22 lepturoides Spach.......... 52 Tepturoides Boiss........... 52 leucacanthum Boiss........... 72 libanoticum Boiss. .......... 37 Listoniae Boiss.............. 31 longiflorum Boiss.........67 lycaonicum Boiss. ......... 50 lycopodioides Boiss.......... 11 melananthum Boiss.......... 58 oliganthum Boiss........... 53 Olivieri Boiss. . . . . . . . . . 21 petraeum Boiss............ 23 phrygium Boiss........... 29 Pinardi Boiss. ............. 30 polystachyum Boiss.......... 62 pterostegium m............. 2 puberulum Boiss.............4 48 quinquelobum m..........6 65 restiaceum $m . . . \ldots \ldots \ldots \ldots 15$ roseum Boiss. ........... 82 mubllum Boiss............. 82 Ruprechti m............ 10 sahendicum Boiss. et Buhse..... 42 schahrudicum m. .......... 81 Schirasianum Boiss.........76 scirpoides m.............. 14 Scorpius Boiss. .......... 71 senganense $m_{0} \ldots \ldots \ldots \ldots \ldots . .25$ setiferum m........... pag. 68 
Acantholimon splendidum m........... ${ }_{4} \mid$ Statice bracteata Girard............ 5

Stocksii Boiss............. 74

subulatum Boiss. .........6.61 61

Szovitsii Boiss. et Buthe.....66 68

talagonicum Boiss.......... 80

tataricmm Boiss........... y

tenuiflorum Boiss. . . . . . . . 27

tibeticum Hook. fil. et Th. . . . 11

tomentellum Boiss........... 79

Toumefortii Boiss........... 26

tragacanthinum Boiss........ 70

tragacanthinum Griff.? ......78

truncatum m............64

nlicinum Boiss. ............ 44

venustum Boiss............ 19

viscidulum Boiss.......... 75

Wiedemanni m............. 49

spec. indet. Boiss. et Buhse... . 81

Echinus i. e. Tragacantha altera Prosp. Alp. . 51 Limonium caespitosum fol. aculcatis Buxb. . . 27 creticum juniperi folio Toumef... . 51 orientale caryophylli folio acutissimo floribus velut in capitulum congestis acaulon ct calyce purpurascente................ 26

" oricntale caryophylli folio acutissimo florib. velut in capitulum congestis acaulon et calyce albo... 41 orientale frutescens caryophylli folio in aculeum rigidissimum abeunte 29 orientale lumilus caryopluylli folio angustione non aculeato, flore spicato suave mbente....... 19

Statice accrosa $M$. a Bicb........... 52 acerosa $W \ldots \ldots \ldots \ldots \ldots . \ldots . . .29$ acerosa Hohnck. Led............. 27 aciphylla Jaub. et $S p$. . . . . . . . . 40 androsacea Jaub. et $S p . . . . . . . . .51$ curyophyllacea Boiss............30.35

dianthifolia Jaub. et Sp.......... 19

Echinus L. Sm.............. 51

Echimus M. a Bieb............4 40

Echimus Habl................40 40

erinacea $J$. et $S_{j} \ldots \ldots \ldots \ldots \ldots \ldots . . . . .62$

erinacea Boiss................ 76

ferox $J$. ct $S p . \ldots \ldots \ldots \ldots \ldots . . . . .71$

festucacca J. et $S p \ldots \ldots \ldots \ldots . . . .60$

genistoicles $J$, et Sp............. 59

glumacea $J$. et $S p \ldots . . \ldots \ldots \ldots . . .41$

Histrix J. ef $S p . \ldots \ldots \ldots \ldots \ldots \ldots .44$

Hohenackeri Led................40.41

Hohenackeri $J$. et Sp..........., 40

horrida Girard. .............. 40

Jumberti Girard 82 juniperine W.? ........... 82

Karelini Scregl..............6.68

Kotschyi J. et Sj)............... 32

lepturoinles $J$. et $S p$............ 52

- lercacantha J. et Sp............ 72

lycopoctioides Girard ............ 11

mclanantha Boiss.............. 58

Olivieri $J$. et $S p \ldots \ldots \ldots \ldots \ldots \ldots \ldots . . \ldots 21$

pauciflora J. et $S p \ldots . . \ldots \ldots \ldots . . .51$

pungens $J$. ct Sp............... 82

Scorpius J. ct $S p \ldots \ldots \ldots \ldots . . .71$

Spachii Girard.............. 70. 71

tenuifolia J. et $S_{p} \ldots \ldots \ldots \ldots \ldots \ldots . .40$

tomentella Boiss..............79

Toumefortii J. et Sp............ 26

tragacanthina $J$. et $S p . \ldots \ldots \ldots . . .70$

ulicina $\mid \boldsymbol{V} . \ldots \ldots \ldots \ldots \ldots \ldots \ldots . . .44$

venusta Fenzl. . . . . . . . . . . . 19

Tragacantha tota spinosa et Echinum referens - 


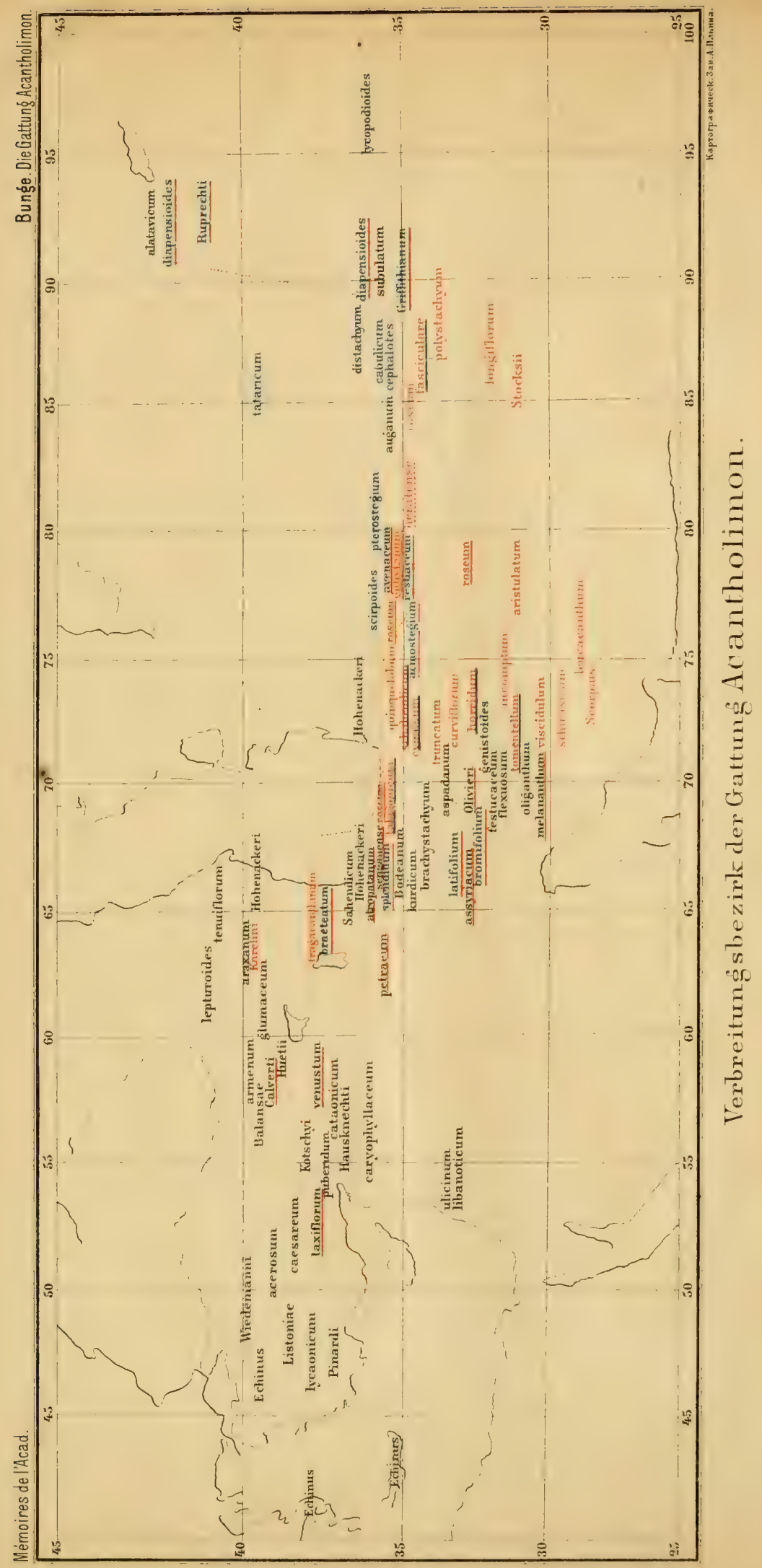




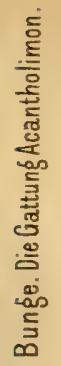

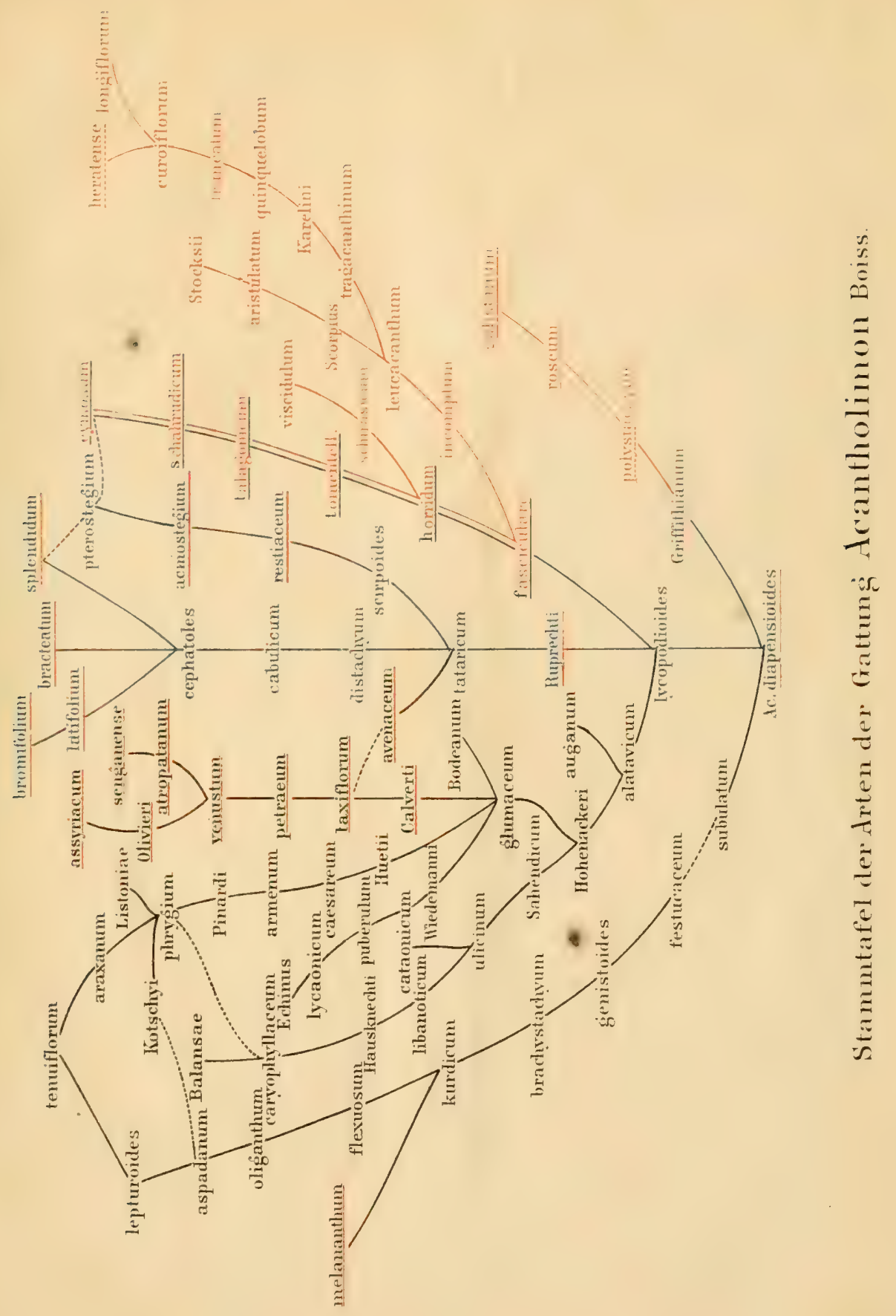

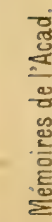



- 

2.

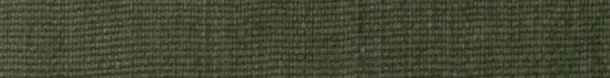

